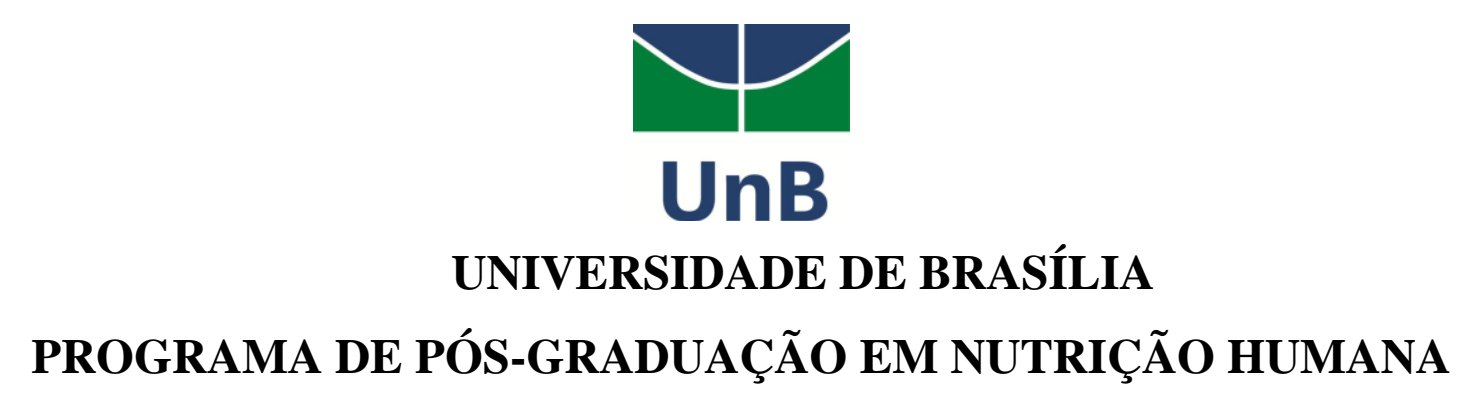

CAMILA DA SILVA REIS

AVALIAÇÃO DA UTILIZAÇÃO DO REPASSE FUNDO A FUNDO PARA ESTRUTURAÇÃO E IMPLEMENTAÇÃO DAS AÇÕES DE ALIMENTAÇÃO E NUTRIÇÃO

BRASÍLIA-DF, 2015 
CAMILA DA SILVA REIS

\section{AVALIAÇÃO DA UTILIZAÇÃO DO REPASSE FUNDO A FUNDO PARA ESTRUTURAÇÃO E IMPLEMENTAÇÃO DAS AÇÕES DE ALIMENTAÇÃO E NUTRIÇÃO}

Dissertação apresentada ao Programa de Pós-Graduação em Nutrição Humana da Universidade de Brasília como requisito para a obtenção do título de Mestre em Nutrição Humana.

Orientador: Prof. ${ }^{\mathrm{a}}$ Dr. ${ }^{\mathrm{a}}$ Leonor Maria Pacheco Santos

BRASÍLIA,

2015 
REIS, Camila.

Universidade de Brasília/Camila Reis;

Orientação Prof. ${ }^{a}$ Dr. ${ }^{a}$ Leonor Maria Pacheco Santos;

Brasília, 2015

$91 \mathrm{f}$

Dissertação de Mestrado apresentada ao Programa de PósGraduação em Nutrição Humana UnB

1. Financiamento da assistência à saúde 2. Alocação de Recursos para a Atenção à Saúde 3. Política Nacional de Alimentação e Nutrição (PNAN) 4. Avaliação de Programas e Projetos de Saúde 


\title{
AVALIAÇÃO DA UTILIZAÇÃO DO REPASSE FUNDO A FUNDO PARA ESTRUTURAÇÃO E IMPLEMENTAÇÃO DAS AÇÕES DE ALIMENTAÇÃO E NUTRIÇÃO
}

\author{
Dissertação apresentada ao Programa de Pós- \\ graduação em Nutrição Humana como requisito para \\ a obtenção do título de Mestre em Nutrição Humana.
}

Prof. ${ }^{\mathrm{a}}$ Dr. ${ }^{\mathrm{a}}$ Leonor Maria Pacheco dos Santos

Faculdade de Ciências da Saúde/ Departamento de Saúde Coletiva Universidade de Brasília

Prof. ${ }^{a}$ Dr. ${ }^{\text {a }}$ Elisabetta Gioconda Iole Giovanna Recine Faculdade de Ciências da Saúde/ Departamento de Nutrição Universidade de Brasília

Prof. ${ }^{a}$ Dr. ${ }^{a}$ Mariana Sodário da Cruz

Faculdade de Ceilândia/ Departamento de Saúde Coletiva

Universidade de Brasília

Dr $^{\mathrm{a}}$ Michele Lessa de Oliveira

Coordenadora-Geral de Alimentação e Nutrição

Ministério da Saúde

\section{BRASÍLIA-DF,}


À minha querida rosa vermelha, vovó Maria, que em vida colocou meus sonhos em suas orações. Serei eternamente grata pelo seu amor incondicional ao falar de mim para Deus. 


\section{AGRADECIMENTOS}

Obrigada Deus, por todas as coisas boas que vivo, pela proteção e amparo diário. Os seus ensinamentos auxiliam as minhas escolhas, oportuniza uma vida de aprendizado e evolução. Sinto-me extremamente abençoada.

Agradeço meus amados pais, Gilma e Geraldo, por acreditarem nos meus sonhos e sempre se protificarem em seguir comigo. Ao meu irmão, Sanzio, pelo companheirismo cheio de boas risadas e minha cunhada, Caroline Royer, pelo carinho.

A amizade é uma dádiva de Deus. Sou grata aos amigos que se fizeram presentes nesta fase cheia de desafios, incentivando, aconselhando, compartilhando conhecimento técnico e abraços. Obrigada, Carolina Chagas, Lívia Antunes, Patrícia Diniz, Yamilla Comes, Diego Paiva, Luciana Xavier, Sumara Oliveira, Mário Valverde, Rafaella Reis, vocês tornaram a caminhada mais tranquila.

Agradeço à minha orientadora, Leonor Pacheco, pela liberdade e confiança na elaboração do meu trabalho. Admiro sua postura ética, coerente e direta, pois, faz-me lembrar de uma frase de Paulo Freire que gosto muito: "Ensinar não é transferir conhecimento, mas criar a possibilidade para a sua própria produção ou a sua construção". Muito obrigada!

À equipe da pesquisa nacional, Sandra Maria Chaves, Maria Luiza de Sena, Marlus Henrique Queiroz, Maria Fabiana Damásio, Antônio José Costa Cardoso, Naíza Nayla Bandeira de Sá, Mayara Ferreira Santos, esta dissertação foi possível pelo empenho de vocês. Acredito que o trabalho em equipe é fundamental para o alcance dos objetivos. Obrigada.

A Coordenação Geral de Alimentação e Nutrição do Ministério da Saúde CGAN/MS e Organização Pan-Americana da Saúde - OPAS pelo incentivo e financiamento da pesquisa nacional que originou este estudo. E a Finatec que contribuiu para a apresentação de um dos resultados do estudo em congresso científico. 
“Comece fazendo o que é necessário, depois o que é possível, e de repente você estará fazendo o impossível."

São Francisco de Assis 


\section{RESUMO}

A Política Nacional de Alimentação e Nutrição (PNAN) foi aprovada pelo Conselho Nacional de Saúde, por meio da Portaria do Ministério da Saúde $n^{\circ} 710$, de 10 de junho de 1999 e atualizada em 2011. A PNAN é reconhecida como importante instrumento norteador das ações de Alimentação e Nutrição no Sistema Único de Saúde (SUS). Para a operacionalização, o fortalecimento, a concretização e a implementação das diretrizes, esta política recebe um recurso específico conhecido como Fundo de Alimentação e Nutrição (FAN) seguindo as normativas de alocação de recursos do SUS, no âmbito da municipalização da saúde, caracterizado pela transferência fundo a fundo regular e automática de recursos financeiros para aumentar a autonomia das unidades federativas. O objetivo deste trabalho é avaliar a utilização do repasse fundo a fundo para estruturação e implementação das ações de alimentação e nutrição no âmbito estadual e municipal com base na Política Nacional de Alimentação e Nutrição - PNAN. Este estudo utilizou dados oriundos da pesquisa nacional intitulada Avaliação da modalidade de repasse anual fundo a fundo para estruturação e implementação das ações de alimentação e nutrição no SUS de 2006 a

2013, adotando a tríade metodológica estrutura - processo - resultado. Foram utilizados os dados dos grupos focais e dos questionários autoaplicáveis destinados aos Responsáveis Técnicos de Alimentação e Nutrição - RTAN, totalizando uma amostra de 83 gestores de diferentes esferas de atuação. Realizou-se uma análise quali-quantitativa.

Os resultados foram divididos em dois artigos. O artigo 1 apresentou a análise das normas que regulamentam o recurso e pode-se observar que as portarias são um importante instrumento para a implementação e execução das ações de Alimentação e Nutrição no Brasil e esclarece sobre como se deve utilizar o recurso. Concluiu-se, a partir da análise de utilização do FAN, que a consolidação da PNAN está em grande medida vinculada às finalidades do fundo, uma vez que a existência do recurso potencializa a execução de diversas ações de Alimentação e Nutrição, por meio de competências atribuídas à União, Estados, Municípios e ao Distrito Federal. O artigo 2 apresentou os resultados da avaliação da utilização do recurso e constatou que o incentivo de custeio é muito importante para o fortalecimento da área de Alimentação e Nutrição (A\&N), conferindo maior visibilidade para a área e contribuindo para a execução de parte das ações previstas nas diretrizes da PNAN. Foram identificadas limitações como falta de recursos humanos e falta de continuidade das atividades. Pode-se observar também a execução de muitos projetos e programas do Governo Federal, como 
aqueles previstos no Pacto pela Saúde e os relacionados com atividades da Atenção Básica a Saúde.

Sendo assim, sugere-se que o incentivo de custeio permaneça e mecanismos de avaliação sejam utilizados para contribuir com sua utilização de maneira efetiva.

Palavras-chaves: Financiamento da assistência à saúde; Alocação de Recursos para a Atenção à Saúde; Política Nacional de Alimentação e Nutrição (PNAN); Avaliação de Programas e Projetos de Saúde. 


\begin{abstract}
The National Food and Nutrition Policy (PNAN) was approved by the National Council of Health, through the Ministry of Health's order $n^{\circ} 710$, of June 1999 and updated in 2011. The PNAN is recognized as an important guiding tool for the Food and Nutrition policies in the Unified Health System (SUS). For effectuation, strengthening, achievement and implementation of this policy guideline, it receives a specific resource known as Fund of Food and Nutrition (FAN) following SUS resources allocation standards, within the health municipalization, characterized by the regular and automatic fund to fund transfer to increase the autonomy of the states and federal district. The aim of this study is to evaluate the use of the fund to fund transfer in order to structuring and implementation of food actions and nutrition under State and Municipal levels based on National Food and Nutrition PolicyPNAN. This study used data from the national survey entitled Evaluation of annual allocation modality fund to fund for organization and implementation of food actions and nutrition in the SUS since 2006 to 2013, adopting the methodological triad structureprocess-result. We used the data from the focus groups and from the self-applicable questionnaires for the Responsible Technical of Food and Nutrition (RTAN), totaling a sample of 83 different spheres of action managers. Quali-quantitative analysis was performed.

The results were divided into two articles. Article 1 analyzed the rules that control the resources and it can be observed that the ministerial orders are an important instrument for the implementation and execution of food and nutrition action in Brazil and explains how to use the resource. It is concluded from the FAN analysis that the PNAN consolidation is partly linked to the purposes of the fund, once the existence of the resource enhances the performance of several actions of food and nutrition, through the powers conferred on the Union, States, County and the Federal District. Article 2 evaluated the use of the resource and found that the incentive of funding is very important for the strengthening of the area of Food and Nutrition $(A \& N)$, giving it greater visibility and contributing to the execution of part of the actions expected for in PNAN guidelines. Lack of human resources and lack of continuity of the activities were identified as this work limitations. You can also see the execution of many Federal Government projects and programs, such as the Pact for health and those related to Basic Health Care Activities.
\end{abstract}


Therefore, it is suggested that the incentive of funding should be maintained and evaluation mechanisms should be incorporated to contribute to a more effective use of the fund.

Keywords: Financing of health care; Allocation of resources to Health Care; National Food and Nutrition Policy (PNAN); Evaluation of Health Programs and Projects. 


\section{LISTA DE QUADROS}

\section{RESULTADOS}

\subsection{ARTIGO 2}

QUADRO 1. IMPORTÂNCIA, OPORTUNIDADES E LIMITES DO REPASSE DE RECURSOS PARA ESTRUTURAÇÃO E IMPLEMENTAÇÃO DAS AÇÕES DE ALIMENTAÇÃO E NUTRIÇÃO (FAN), SEGUNDO RESPONSÁVEIS TÉCNICOS DE ALIMENTAÇÃO E NUTRIÇÃO POR ESFERA DE ATUAÇÃO.

BRASIL 2012 63

QUADRO 2:PERCENTUAL DE AÇÕES/ ATIVIDADES DE ALIMENTAÇÃO E NUTRIÇÃO QUE FORAM REFERIDAS COMO FINANCIADAS E EXECUTADAS COM RECURSOS DO REPASSE PARA ESTRUTURAÇÃO E IMPLEMENTAÇÃO DAS AÇÕES DE ALIMENTAÇÃO E NUTRIÇÃO (FAN), 


\section{LISTA DE FIGURAS}

\section{RESULTADOS}

\subsection{ARTIGO 1}

FiguRA 1. DESCRIÇÃO DAS FINALIDADES DOS RECURSOS DESTINADOS AO FUNDO DE ALIMENTAÇÃO E NuTRIÇÃo (FAN), NO PERÍODO DE 2006 A 2013

FIGURA 2. EVOLUÇÃO DOS VALORES DOS RECURSOS TRANSFERIDOS DO FUNDO DE

ALIMENTAÇÃO E NUTRIÇÃo (FAN), NO PERÍODO DE 2006 A 2013.

FIGURA 3. NÚMERO DOS MUNICÍPIOS CONTEMPLADOS COM O FUNDO DE ALIMENTAÇÃO E NUTRIÇÃO (FAN), NO PERÍODO DE 2007 A 2013

\subsection{ARTIGO 2}

FiguRA 1. DisTRIBUIÇÃO DO PERCENTUAL (\%) DO RECURSO FINANCEIRO DO FAN PARA A ESTRUTURAÇÃO E IMPLEMENTAÇÃO DAS AÇÕES DE ALIMENTAÇÃO E NUTRIÇÃO EXECUTADOS PELOS RESPONSÁVEIS TÉCNICOS, BRASIL 2012. 63

FIGURA 2. PERCENTUAL DAS AÇÕES ESTADUAIS REFERENTES À EXECUÇÃO E RELEVÂNCIA PARA ESTRUTURAÇÃO/ IMPLEMENTAÇÃO DAS AÇÕES, BRASIL 2012. 67

FIGURA 3 PERCENTUAL DAS AÇÕES MUNICIPAIS REFERENTES À EXECUÇÃO E RELEVÂNCIA PARA ESTRUTURAÇÃO/ IMPLEMENTAÇÃO DAS AÇÕES. BRASIL 2012 


\section{LISTA DE ABREVIATURAS}

\begin{tabular}{ll} 
Abreviatura & Significado \\
AB & Atenção Básica \\
A \& N & Alimentação e Nutrição \\
CONASEMS & Conselho Nacional de Secretarias Municipais de Saúde \\
CONASS & Conselho Nacional dos Secrtários de Saúde \\
DCNT & Doenças Crônicas Não Transmissíveis \\
ESF & Estratégia Saúde da Família \\
FAN & Fundo de Alimentação e Nutrição \\
FNS & Fundo Nacional de Saúde \\
ICCN & Incentivo de Combate as Carências Nutricionais \\
NASF & Núcleo de Apoio à Saúde da Família \\
NOB & Norma Operacional Básica \\
PAB & Piso da Atenção Básica \\
PACS & Programa de Agentes Comunitários \\
PCCN & Programa de Combate as Carências Nutricionais \\
PNAB & Política Nacional de Atenção Básica \\
PNAN & Política Nacional de Alimentação e Nutrição \\
POF & Pesquisa de Orçamentos Familiares \\
PSF & Programa de Saúde da Família \\
RTAN & Responsável Técnico de Alimentação e Nutrição \\
SUS & Termo de Consentimento Livre e Esclarecido \\
TCLE & Unico de Saúde \\
\hline &
\end{tabular}




\section{SUMÁRIO}

1. INTRODUÇÃO ..........................................................................................................................................................24

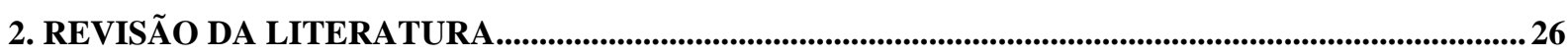

2.1 ALIMENTAÇÃ̃O E NUTRIÇÃO E O SISTEMA ÚNICO DE SAÚDE - SUS.........................................26

2.2 PROCESSO DE FINANCIAMENTO DAS AÇÕES DE ALIMENTAÇÃO E NUTRIÇÃO...................27

2.3 IMPORTÂNCIA DA SISTEMATIZAÇÃO DE UM PROCESSO CONTÍNUO DE AVALIAÇÃO. ... 31

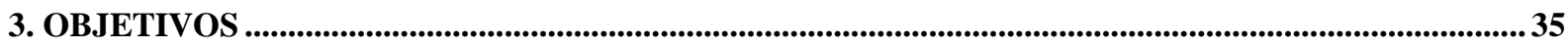

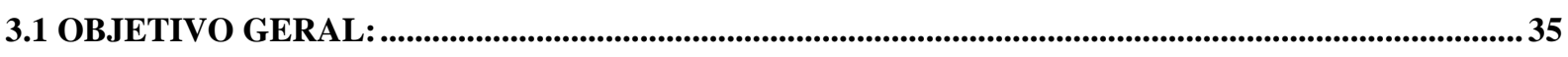

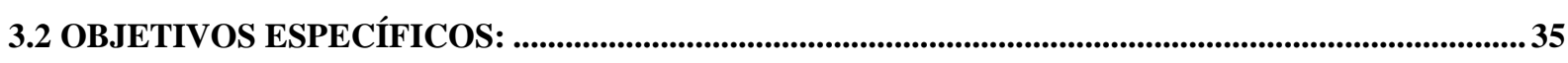

4. METODOLOGIA ……..................................................................................................................36

4.1 DELINEAMENTO DA PESQUISA ..............................................................................................................36

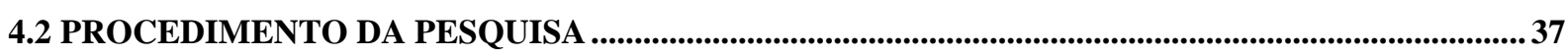

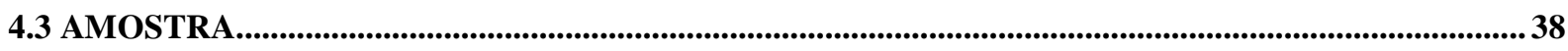

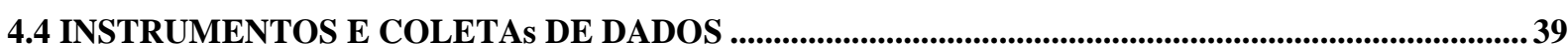

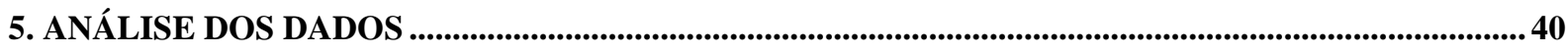

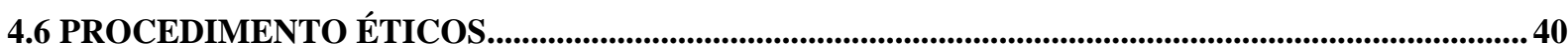

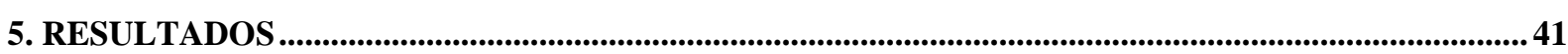

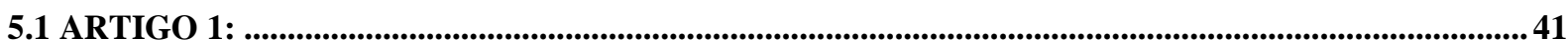

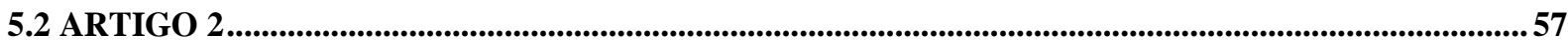

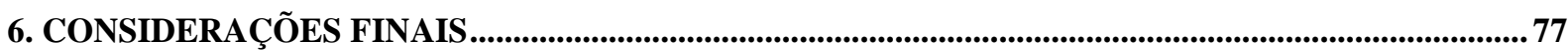

7. REFERÊNCIAS BIBLIOGRÁFICAS.........................................................................................................79

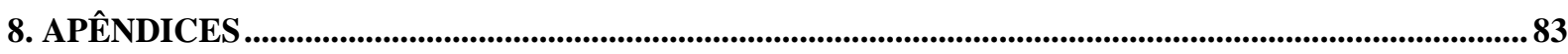

8.1. APÊNDICE 1. MATRIZ - CATEGORIAS DE ANÁLISE PARA AS DIMENSÕES ESTRUTURA, PROCESSO E RESUlTAdOS - QUESTÕES ORIENTADORAS PARA A COLETA DE DADOS. PESQUISA NACIONAL DE AVALIAÇÃO DO REPASSE FUNDO A FUNDO PARA INCENTIVAR AS AÇÕES DE ALIMENTAÇÃO E NUTRIÇÃO, BRASIL 2006 A 2011 ......................................................83

8.2. APÊNDICE 2. QUESTIONÁRIOS AUTOAPLICÁVÉIS PARA RESPONSÁVEIS TÉCNICOS DE ALIMENTAÇÃO E NUTRIÇÃO - NÍVEL ESTADUAL E MUNICIPAL ..................................................85

8.3 APÊNDICE 3 - ROTEIROS DOS GRUPOS FOCAIS: MUNICÍPIOS DO INTERIOR, CAPITAL E

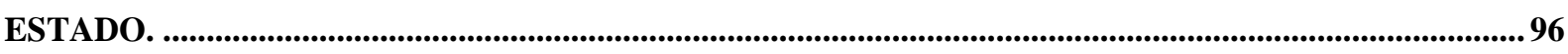

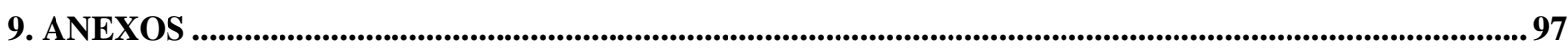

9.1 ANEXO 1. TERMO DE CONSENTIMENTO LIVRE E ESCLARECIDO - TCLE ................................97 


\section{APRESENTAÇÃO}

Esta dissertação é parte de uma pesquisa nacional intitulada: Avaliação da modalidade de repasse anual fundo a fundo para estruturação e implementação das ações de alimentação e nutrição no SUS de 2006 a 2013, que tem por objetivo avaliar o repasse fundo a fundo para estruturação e implementação das ações de alimentação e nutrição no Sistema Único de Saúde - SUS em estados e municípios. Por meio do financiamento da Coordenação - Geral de Alimentação de Nutrição do Ministério da Saúde - CGAN/MS e Organização Pan-Americana da Saúde - OPAS, os pesquisadores da Universidade de Brasília - UnB, Universidade Federal da Bahia - UFBA e da Fundação Oswaldo Cruz - FIOCRUZ realizaram um estudo de caráter avaliativo, fundamentado no modelo sistêmico de estruturaprocesso - resultado e metodologia quali-quantitativa. Para operacionalização dos conceitos foi elaborada uma matriz que sistematizou um conjunto de questões que serviram de base para definir os dados e informações de interesse, contribuindo para a construção dos instrumentos de pesquisa e para a identificação das fontes de informação. Foram construídos três instrumentos de pesquisa para obtenção do máximo de informações sobre o repasse específico destinado à área de Alimentação e Nutrição - A\&N. Os instrumentos foram: questionário auto aplicado, roteiro do grupo focal e entrevista in loco com gestores responsáveis pelas ações de $A \& N$, e informantes chaves que estavam diretamente envolvidos com o recurso, separados na esfera estadual e municipal.

O questionário auto aplicado e o grupo focal foram aplicados no XII Encontro Nacional de Rede de Alimentação e Nutrição do SUS, realizado na cidade de Brasília-DF em maio de 2013. Foram realizados três grupos focais com representantes conforme sua esfera de atuação: estados, capitais e municípios do interior. Os dados obtidos por estes dois instrumentos foram utilizados neste trabalho.

Surgiram algumas inquietações que nortearam o presente estudo: As normas que regulamentam o recurso são claras? São adequadas ao contexto? Quais as principais atividades que são executadas com a utilização do recurso? As ações estão de acordo com a Política Nacional de Alimentação e Nutrição? Quais as potencialidades e fragilidades que favorecem/impedem a execução do recurso?

Para facilitar o entendimento e com o objetivo de responder as perguntas citadas, esta dissertação foi estruturada nas seguintes seções: introdução, revisão da literatura, objetivos, metodologia, resultados, discussão e considerações finais. Inicialmente, será feita a 
contextualização do estudo por meio da introdução. Posteriormente, serão abordados o panorama da nutrição, o financiamento das ações por meio de recurso específico, a avaliação dos recursos e a metodologia do trabalho. Os resultados e a discussão serão apresentados em forma de dois artigos. As considerações finais apresentaram a conclusão dos dados obtidos e a avaliação quanto ao cumprimento dos objetivos propostos. Na parte final, encontram-se as referências bibliográficas, os apêndices e o anexo. 


\section{INTRODUÇÃO}

A Saúde faz parte do tripé que compõe a Seguridade Social presente na Constituição Federal de 1988. A Carta Magna brasileira a consagrou como direito de todos e dever do Estado, artigo 196, o que representou um grande avanço para a área (CARVALHO, 2011). Para Mendes e colaboradores (2011), privilegiar a política de saúde significa observar os desafios para a promoção e proteção da saúde da população brasileira como direito, que vem sendo consolidado desde a regulamentação do Sistema Único de Saúde - SUS pela Lei Orgânica 8080/90 e a Lei 8142/90.

Nóbrega e colaboradores (2010) destacam que, com o surgimento do SUS, foi necessário definir estratégias que normatizassem e operacionalizassem as relações entre as esferas de governo, as competências e as responsabilidades dos gestores, com vistas a fortalecer o processo de descentralização por meio de critérios de transferência de recursos federais para estados e municípios.

O financiamento dos serviços e ações de saúde, por meio da transferência de recursos públicos para as Unidades Federadas e os Municípios, tem o objetivo de promover a efetiva descentralização, contemplando a atenção à saúde nos três níveis de complexidade; garantir a priorização da atenção básica e incentivar os governos locais a ampliar o percentual de recursos destinados, oferecendo o atendimento básico e executando os programas específicos definidos pelo governo federal (VAZQUEZ, 2011).

A Norma Operacional Básica - NOB nº 01/93 do SUS normatiza esta lógica de descentralização dos recursos para municípios e estados. Já a NOB 96 instituiu o Piso Assistencial Básico, denominado posteriormente como Piso da Atenção Básica (PAB), que com base no critério populacional e no valor per capita nacional, financia ações estratégicas de serviços básicos de atenção à saúde, entre eles o Programa de Saúde da Família (PSF) e o Programa de Agentes Comunitários (PACS) (MENDES, 2011; BRASIL, 2011).

As transferências intergovernamentais no âmbito do SUS apresentam caráter regular e automático, fundo a fundo, em conta única e específica, com os recursos federais sendo organizados para serem repassados em formas de blocos de financiamentos, totalizando seis blocos. Os recursos dos blocos devem ser utilizados em ações específicas do próprio bloco, como Saúde da Família; Agentes Comunitários de Saúde; Saúde Bucal e outros que venham a ser instituídos por meio de ato normativo específico; Núcleo de Apoio à Saúde da Família (NASF); Inclusão do microscopista na atenção primária; Implantação da Política Nacional de 
Atenção Integral à Saúde do Homem e; Programa de Saúde na Escola (PSE), que estão entre as estratégias financiadas pelo bloco da Atenção Básica (BRASIL, 2011).

Argumenta-se que o financiamento é primordial para a operacionalização das políticas públicas, favorecendo a gestão descentralizada e a implementação de estratégias de organização pelos estados e municípios (REDENUTRI, 2015). No entanto, Marques (2002) destaca que a modalidade de transferência direta de recursos fundo a fundo, por exemplo, para a atenção básica, pode prejudicar a autonomia local, na medida em que o recebimento do recurso específico acaba concentrando ações somente neste nível de atuação, não considerando as necessidades de saúde da população, as dimensões epidemiológica, demográfica, socioeconômica, espacial e de capacidade de oferta de ações e de serviços de saúde, prejudicando a alocação equânime do recurso.

As ações de Alimentação e Nutrição (A\&N) estão intrínsecas no SUS, fazem parte das ações da Atenção Básica, e a Política Nacional de Alimentação e Nutrição - PNAN, a partir de 2007, também começou a receber um recurso específico para estruturação e implementação das ações de A\&N, popularmente conhecido como Fundo de Alimentação e Nutrição - FAN.

Além da importância do financiamento para execução das ações de $A \& N$, é imprescindível realizar o monitoramento e a avaliação da aplicação do recurso para verificar se o objetivo do repasse esta sendo contemplado. Com a avaliação é possível identificar as limitações e as potencialidades para enfrentar os desafios da utilização do recurso. Observa-se escassos estudos sobre avaliação referente à temática na literatura.

Este estudo tem o objetivo de avaliar a utilização do repasse fundo a fundo para estruturação e implementação das ações de A\&N no âmbito estadual e municipal, com o a finalidade de contribuir para o delineamento de ações estratégicas e eficazes no que é proposto. 


\section{REVISÃO DA LITERATURA}

\subsection{ALIMENTAÇÃO E NUTRIÇÃO E O SISTEMA ÚNICO DE SAÚDE - SUS}

No Brasil, ao longo dos anos o debate em torno da questão da saúde atraiu a atenção de pesquisadores, militantes e da população como um todo que não dispunha de uma assistência à saúde. Seguindo a mesma lógica, as discussões sobre a alimentação e nutrição também começaram a avançar e era possível observar a intervenção estatal desde a década de 30. Segundo Vasconcelos (2011), a intervenção estatal acontecia "[...] por meio de ações e programas de assistência alimentar e nutricional voltados aos trabalhadores vinculados à previdência social, às gestantes, nutrizes e crianças menores de cinco anos de idade e aos escolares".

As ações de alimentação e nutrição, no Brasil, surgiram como políticas públicas no governo do presidente Vargas, materializando-se com a instituição da "ração essencial mínima" presente no Decreto-lei $\mathrm{n}^{\circ}$ 399, de 30 de abril de 1938 e posteriormente, com a criação do Serviço de Alimentação da Previdência Social - SAPS, em 1940 (BARROS, 2003; VASCONCELOS, 2011).

É consenso na literatura a relação direta entre a alimentação e nutrição, e a saúde. Ora devido seu contexto histórico com cenário epidemiológico caracterizado, no período de 1930-1980, pelas doenças relacionadas às carências nutricionais (desnutrição proteicocalórica, hipovitaminose A, pelagra, anemia ferropriva, bócio etc.), e mais tarde pelas relacionadas ao excesso nutricional (obesidade, diabetes, dislipidemias, hipertensão, certos tipos de câncer, etc.) (VASCONCELOS, 2011). Ora pela importância de desenvolver estratégias para a promoção de saúde e prevenção de doenças, por meio de ações voltadas aos hábitos alimentares mais saudáveis, com vistas a tornar os gastos no setor saúde mais eficientes e menos onerosos.

No que concerne ao aspecto epidemiológico brasileiro, assim como em outros países em desenvolvimento, a transição nutricional é uma realidade preocupante. Segundo a Pesquisa de Orçamentos Familiares (POF) de 2008-2009, a obesidade afeta 12,5\% dos homens e, aproximadamente, $17 \%$ das mulheres adultas no país. Os resultados da POF demonstraram que as prevalências de excesso de peso e obesidade aumentam em todos os estratos de renda (IBGE, 2010). O estudo de Santos (2013) corrobora com os achados da pesquisa, demonstrando que a obesidade entre as mulheres pobres está aumentando progressivamente. 
Apesar desse panorama caracterizado, principalmente, pelo excesso no consumo de alimentos ricos em açúcares e gorduras associados à predominância das Doenças Crônicas não Transmissíveis - DCNT, ainda é possível observar a presença da fome, das carências nutricionais e da desnutrição (COUTINHO et al., 2008).

A promoção de práticas alimentares saudáveis, a prevenção e controle dos agravos nutricionais foram tornando centro de importantes debates. No arcabouço legal, a alimentação aparece na Lei Orgânica da saúde como determinante e condicionante de saúde. A alimentação e nutrição assumiram um importante papel entre os determinantes sociais da saúde e se consolidou como direito social por meio da Emenda Constitucional $\mathrm{n}^{\circ}$ 64, aprovada em 2010. Com o passar dos anos novas estratégias com foco na temática e considerando o contexto epidemiológico foram instituídas e incorporadas às políticas de saúde (JAIME et al., 2011).

Com a organização dos serviços de Atenção Básica à saúde, que objetiva promover a saúde, prevenir e o tratar doenças, considerando o sujeito em sua singularidade, integralidade e inserção sociocultural, a alimentação e nutrição, enquanto requisito básico para promoção e proteção a saúde, foi ganhando espaço institucional neste contexto (JAIME et al., 2011).

\subsection{PROCESSO DE FINANCIAMENTO DAS AÇÕES DE ALIMENTAÇÃO E NUTRIÇÃO.}

$\mathrm{Na}$ Constituição de 1988 e legislações infraconstitucionais subsequentes (Lei $\mathrm{n}^{\circ}$ 8.080 de 19 de setembro de 1990, Lei $\mathrm{n}^{\circ} 8.142$ de 28 de dezembro de 1990, normas e portarias regulamentadoras) a descentralização na área da saúde já apresentava um delineamento com contornos mais definitivos, contrapondo a tendência "estadualista" desenhada pelos sistemas anteriores à reforma sanitária (UGA, 2003).

A institucionalização do SUS, a partir dos anos 90, com enfoque nos seus princípios, principalmente, referente à descentralização e municipalização, foi um ganho na consolidação da agenda progressista construída na década de 80. No entanto, é imprescindível ressaltar que ainda existem problemas estruturais que impõe enormes desafios para a concretização do SUS (LEVCOVITZ et al., 2001).

O caráter descentralizado do sistema tem na questão dos repasses financeiros um dos seus maiores entraves, uma vez que para a execução de ações em um país da dimensão territorial como o Brasil, com marcantes desigualdades entre as regiões, territórios e, dentro 
dos estados e municípios, são necessários recursos suficientes que garantam uma boa cobertura dos serviços de saúde (UGA, 2003).

Com vistas ao fortalecimento de ações e programas de saúde no país, e redução das iniquidades na alocação dos recursos públicos, o SUS adotou mecanismos de transferências para aumentar a autonomia das unidades federativas nos gastos em saúde (LEVCOVITZ et al., 2001), com o financiamento compartilhado entre as três esferas do governo (BRASIL, 2011). A Lei no 8142/90 elucida no seu conteúdo como os repasses do Fundo Nacional de Saúde (FNS) deverão ser alocados e, ainda, elenca os requisitos para recebimento fundo a fundo. Assim, os municípios, os estados e o Distrito Federal deverão contar com: um Fundo de Saúde; um Conselho de Saúde, com composição paritária; plano de saúde; relatórios de gestão; contrapartida de recursos para a saúde no respectivo orçamento e; uma Comissão de elaboração do Plano de Carreira, Cargos e Salários (PCCS), previsto o prazo de dois anos para sua implantação (BRASIL, 1990).

No Brasil, Baptista (2007) identificou que várias portarias da saúde são editadas por ano, superior a mil, e o financiamento está entre os principais temas propostos. A definição de transferência e gestão dos recursos para estados, municípios e Distrito Federal, bem como, a habilitação e incentivo com recursos específicos para programas, campanhas, ações verticais e estratégicas em saúde, também são subtemas constante nos documentos normativos.

Evidenciou-se, na pesquisa citada anteriormente, que a transferência de recursos ocupa um lugar privilegiado no eixo de financiamento, uma vez que é central na implementação das políticas e execução das ações (BAPTISTA, 2007).

As NOB's são instrumentos de regulação do processo de descentralização, normatizando as transferências de serviços, de responsabilidades e introduzindo os instrumentos de gestão. As NOB 01/1991 e a 01/1992 não contemplaram as condições e as formas para viabilizar os repasses regulares e automáticos dos recursos do SUS, este foi possível somente com a NOB 01/1993. Esta última além de criar a transferência regular e automática referenciava os critérios de alocação, a partir da série histórica de gastos no estado e município (BRASIL, 2011).

A NOB 01/1996 rompe com a lógica de alocação dos recursos centrada no pagamento por produção de serviço e na história dos gastos. A norma elucida novos critérios de alocação com base no número populacional e no valor per capita nacional e; aponta mudanças no modelo de atenção, pautando o financiamento em procedimentos ambulatoriais básicos de responsabilidade municipal (MENDES, 2011). 
Outra inovação da NOB 01/1996 foi à instituição do Piso da Assistência Básica, posteriormente transformado em Piso da Atenção Básica (PAB), incentivo para o financiamento do Programa de Saúde da Família (PSF) e do Programa de Agentes Comunitários de Saúde (Pacs) (MENDES, 2011; BRASIL, 2011).

Com a instituição do PAB pode-se inferir que ocorreu o fortalecimento do novo modelo de organização dos serviços à saúde, com enfoque na Atenção Básica à saúde (SAMPAIO, 2011). A Portaria $\mathrm{n}^{\mathrm{o}}$ 2.488, de 21 de outubro de 2011 aprovou a "Política Nacional de Atenção Básica - PNAB, estabelecendo a revisão de diretrizes e normas para a organização da atenção básica, para a Estratégia Saúde da Família (ESF) e o Programa de Agentes Comunitários de Saúde (PACS)". A PNAB destaca o alto grau de descentralização da Atenção Básica, ocorrendo mais próximo do usuário, garantindo maior acessibilidade e outros princípios norteadores como universalidade, o vínculo, a continuidade do cuidado, da integralidade da atenção, da responsabilização, da humanização, da equidade e da participação social (BRASIL, 2012).

A viabilização de ações de Atenção Básica à saúde é feita por meio de recursos financeiros que compõe o Bloco de Financiamento de Atenção Básica (Bloco AB) e parte do Bloco de Financiamento de Investimento (BRASIL, 2012).

Segundo informações do Conselho Nacional de Secretarias Municipais de Saúde CONASEMS, no ano de 2013, o bloco AB com seus dois componentes, Piso da Atenção Básica Fixo - PAB Fixo e Piso da Atenção Básica Variável - PAB Variável, destina recursos para execução de 35 ações/serviços com um gasto estimado de mais de 12 bilhões de reais. Entre as ações estão presentes: Saúde da Família, Agentes Comunitários da Saúde, Núcleos de Apoio à Saúde da Família- NASF, Programa Saúde na Escola - PSE, entre outros.

Ainda referente à destinação de recursos específicos o levantamento do CONASEMS (2015) refere que existem 195 incentivos de custeio e ressalta que:

\footnotetext{
As transferências federais atualmente praticadas por meio dos repasses por blocos de financiamento, não contemplam diferentes necessidades socioeconômicas e sanitárias. Tais repasses são feitos com base em 230 portarias ministeriais e os valores são precificados de acordo com o que é pactuado e com isso cria-se um valor per capta.
}

O CONASEMS reforça que para a viabilidade da política e do sistema, de acordo com o princípio da equidade, os mecanismos de repasse de verbas com caráter redistributivo são preponderantes e devem ser suficientes. $\mathrm{O}$ documento elaborado apresentou propostas de condições de rateio dos recursos federais para o SUS com base na necessidade de saúde da população; desempenho nas metas de saúde e; organização do serviço com a capacidade de 
resposta da rede (CONASEMS, 2015). Do ponto de vista do Conselho Nacional de Secretários de Saúde - CONASS, o desafio para o financiamento do SUS pode ser observado na ótica de insuficiência dos recursos e a qualidade da alocação do gasto (CONASS, 2007).

A alocação descentralizada de recursos para financiamento das políticas sociais, além de favorecer o desenvolvimento de ações mais próximas das necessidades locais, contribui também para maior controle social sobre a aplicação dos recursos. No entanto, não há consenso, mesmo com o reconhecido avanço da transferência direta de recursos fundo a fundo, por exemplo, para a atenção básica. Autores como Marques (2002) esclarece que esta forma de repasse pode prejudicar a alocação equânime do recurso, não favorecendo a autonomia local, na medida em que o recebimento do recurso específico acaba concentrando ações somente naquele nível de atuação, não considerando as necessidades de saúde da população, as dimensões epidemiológica, demográfica, socioeconômica, espacial e de capacidade de oferta de ações e de serviços de saúde.

No contexto da A \& N, é possível verificar há existência de fontes de recursos para ações de A\&N na Atenção Básica, por exemplo, uma vez que os cuidados relativos à temática são parte da atenção integral à saúde que deve ser garantida pelo SUS a todos os brasileiros (REDENUTRI, 2015).

Em plena consonância com os princípios doutrinários e organizativos do SUS, em 1999, foi aprovada a Política Nacional de Alimentação e Nutrição (PNAN) que direciona esforços na construção de uma agenda integrada, com o propósito de melhorar as condições de alimentação, nutrição e saúde da população, bem como, promover práticas alimentares adequadas e saudáveis; vigilância alimentar e nutricional e; prevenção e cuidado integral dos agravos relacionados à $\mathrm{A} \& \mathrm{~N}$ (PNAN, 2012).

O incentivo de custeio destinado às ações da PNAN é sucedâneo ao incentivo do Programa de Combate às Carências Nutricionais (PCCN). Este também foi instituído pelo Ministério da Saúde e objetivava o fortalecimento e consolidação das ações de combate às carências nutricionais específicas, assistindo crianças na faixa etária de seis a 23 meses de idade devido à maior vulnerabilidade à desnutrição enérgico-proteica e às deficiências de ferro e vitamina A (BRASIL, 2001).

Pode-se inferir que o fim do PCCN e a modificação do incentivo devem-se ao contexto epidemiológico, apesar da presença da desnutrição e da carência de micronutrientes essenciais em menor escala, e a necessidade da adoção de uma política com um propósito mais amplo. 
A PNAN é parte integrante da Política Nacional de Saúde e do SUS e, desde 2006, para sua operacionalização e estruturação das ações de A\&N pelas Secretarias Estaduais e Municipais de Saúde, foram realizados repasses financeiros do FNS para os fundos locais de saúde, definidos inicialmente pela Portaria $n^{\circ} 1.357$, de 23 de Junho de 2006, que tinha a finalidade de "normatizar a utilização do saldo restante dos recursos financeiros referentes ao Incentivo de Combate as Carências Nutricionais (ICCN) nos municípios qualificados" (BRASIL, 2006).

Em 2007 foi promulgada a Portaria $n^{\circ} 3.181$, as ações de A\&N, a partir de então, passaram a contar com uma linha própria de financiamento, com recurso repassado para uma conta específica denominada Fundo de Alimentação e Nutrição - FAN. O FAN tem como objetivo "incentivar a estruturação e a implementação das ações de Alimentação e Nutrição no âmbito das Secretarias Estaduais e Municipais de Saúde, com base na Política Nacional de Alimentação e Nutrição" (BRASIL, 2007).

O FAN foi ampliado por meio da Portaria $n^{0} 2.324 / 2009$, anteriormente eram contemplados somente municípios a partir de 200 mil habitantes. De acordo com a Portaria $\mathrm{n}^{\circ}$ 2.685, de 16 de novembro de 2011, todos os estados recebem o FAN; na esfera municipal são contemplados apenas aqueles que possuem mais de 150 mil habitantes e o valor repassado é proporcional ao porte populacional (BRASIL, 2011).

Além do financiamento para execução das ações que objetivam a promoção da saúde, bem como, o enfrentamento da dupla carga de doenças que ainda é um enorme desafio no âmbito das políticas públicas (COUTINHO et al., 2008), a avaliação da utilização dos recursos voltados para a implementação de ações $A \& N$ se faz necessário, pois também contribui para o alcance do propósito da PNAN.

\subsection{IMPORTÂNCIA DA SISTEMATIZAÇÃO DE UM PROCESSO CONTÍNUO DE AVALIAÇÃO.}

Segundo Minayo (2010) a avaliação caracteriza-se como um processo sistemático de fazer perguntas sobre o mérito e relevância de determinado assunto, proposta ou programa. A boa avaliação tem o objetivo de reduzir incertezas, melhorar a efetividade das ações e proporcionar a tomada de decisões relevantes. A avaliação de programas, políticas, e do contexto que elas estão inseridas, contribui para determinar se são necessárias mudanças na sua execução (BROWNSON, 2003). Cardozo (2009) destaca que por meio da avaliação os 
governos podem gerir e ajustar estrategicamente suas políticas e programas para alcançar seus objetivos e metas.

Corroborando com a discussão, Fagundes e colaboradores (2009) elucidam que por meio dos processos de avaliação “[...] é possível identificar e incentivar os programas que funcionam com mais efetividade, eficiência e eficácia, bem como orientar aqueles com fraco desempenho, no sentido do seu aperfeiçoamento, da correção de erros e da superação de obstáculos".

O conceito de avaliação dos programas públicos surgiu logo após a Segunda Guerra Mundial, com a busca do Estado em encontrar meios que tornassem a utilização dos recursos eficazes. A avaliação referente à saúde, com ênfase nas ações sanitárias, foi impulsionada no decorrer dos anos 70, com o período de implantação dos grandes programas baseados no seguro médico (CONTANDRIOPOULOS, 1997).

Nos últimos anos grande número de países tem apresentando um interesse na avaliação e melhoria da qualidade de atenção dos serviços de saúde, no entanto, a institucionalização da cultura avaliativa esta em processo de desenvolvimento. A avaliação, mesmo incipiente, apresenta grandes avanços em países como os EUA ou Reino Unido, com algumas experiências importantes no Canadá, França e Espanha, e nos subdesenvolvidos na América Latina em geral, em meados dos anos 80 (CARDOZO, 2009).

No Brasil, o Ministério da Saúde elaborou um documento para enfatizar o caráter político da avaliação, buscando delinear a trajetória da construção avaliativa para as políticas e programas de saúde no âmbito da Atenção Básica (CAMPOS, 2010). O documento define avaliação em saúde como:

[...] um processo crítico-reflexivo sobre práticas e processos desenvolvidos no âmbito dos serviços de saúde. É um processo contínuo e sistemático cuja temporalidade é definida em função do âmbito em que ela se estabelece. A avaliação não é exclusivamente um procedimento de natureza técnica, embora essa dimensão esteja presente, devendo ser entendida como processo de negociação entre atores sociais. Deve constituir-se, portanto, em um processo de negociação e pactuação entre sujeitos que partilham co-responsabilidades (BRASIL, 2005).

O processo de avaliação em saúde no Brasil vem sendo pouco incorporado às práticas e muitos o considera com uma característica mais prescritiva, burocrática e punitiva ao invés de subsidiário do planejamento e da gestão. É importante reconhecer o caráter formativo, pedagógico e orientador da avaliação, bem como, o papel do gestor federal como ser indutor da institucionalização da avaliação nas três esferas de governo (BRASIL, 2005). 
Avedis Donabedian estabeleceu um modelo para avaliar e comparar a qualidade dos cuidados de saúde, baseado em três dimensões (Estrutura, Processo e Resultado). A relação entre os métodos de processo e resultados, a sistematização dos critérios geraram importantes reflexões sobre as responsabilidades na melhoria da qualidade no serviço. Os indicadores de estrutura estão relacionados aos materiais e atributos organizacionais relativamente estáveis, recursos humanos e financeiros disponíveis nos locais onde os cuidados são prestados. $\mathrm{O}$ componente processo compreende atitudes que os médicos e prestadores são capazes de fazer para os pacientes, a interação com as atividades, habilidades e competências técnicas para execução. No que diz respeito aos resultados, estão relacionados aos encaminhamentos para os diferentes níveis de saúde e a satisfação do paciente pelo atendimento recebido (DONABEDIAN, 1966; TORRES, 2011).

Seguindo o modelo teórico de Donabedian, Contandriopoulos e colaboradores (1997) descrevem cada dimensão desta metodologia, argumentando que estrutura é condizente com os recursos, instrumentos e estrutura física empregados com a finalidade de se atingir os resultados esperados. No que diz respeito ao processo, este é caracterizado como a adequação dos serviços para obtenção dos resultados, ou seja, os procedimentos realizados para se chegar ao objetivo. O resultado está relacionado com o julgamento sobre o que foi planejado e o que foi atingido, verificando as mudanças atribuídas à intervenção. As três dimensões constituem um continuum no processo da avaliação, e estão intrinsecamente relacionadas. A estrutura somente cumpre suas finalidades se os processos forem adequados e o contrário é verdadeiro; os processos não podem sozinho, ultrapassar as limitações estruturais. E a concretude dos objetivos finais pelas três dimensões depende do alcance dos resultados.

Seguindo a proposta metodológica da tríade original, Santos (2007), reinterpretou e adequou os conceitos da avaliação da qualidade do cuidado médico a luz da temática de A\&N e desenvolveu um modelo teórico-metodológico para avaliar políticas de segurança alimentar e nutricional para auxiliar no reconhecimento das contribuições das ações implantadas.

No contexto dos programas sociais, a área de alimentação e nutrição ressente de uma prática avaliativa continuada. Segundo Henrique e colaboradores (2007), a implementação de programas de $A \& N$ não tem sido acompanhado, de forma sistemática, por um processo avaliativo e soma-se a este fato a necessidade de aprimorar os critérios e metodologias utilizadas.

Dessa forma, reconhecendo a importância de se criar uma prática avaliativa nas instituições com o objetivo de direcionar uma maior qualidade no uso dos recursos públicos, o 
objetivo do presente trabalho é avaliar a utilização do recurso fundo a fundo para estruturação e implementação das ações de alimentação e nutrição, no âmbito Estadual e Municipal. 


\section{OBJETIVOS}

\subsection{OBJETIVO GERAL:}

Avaliar a utilização do repasse fundo a fundo para estruturação e implementação das ações de Alimentação e Nutrição no âmbito Estadual e Municipal.

\subsection{OBJETIVOS ESPECÍFICOS:}

Analisar as portarias editadas pelo Ministério da Saúde, no período de 2006 a 2013, que se destinaram a regulamentar a organização do Fundo de Alimentação e Nutrição.

Identificar a execução das ações de alimentação e nutrição no âmbito de Secretarias Estaduais e Municipais de Saúde que foram financiadas pelo repasse, destacando os avanços e as limitações e/ ou fragilidades para sua execução.

Verificar a correspondência das ações/atividades, executadas com os recursos do FAN, com as diretrizes da PNAN. 


\section{METODOLOGIA}

\subsection{DELINEAMENTO DA PESQUISA}

O desenho deste trabalho foi realizado de acordo com a pesquisa nacional denominada "Avaliação da modalidade de repasse anual fundo a fundo para estruturação e implementação das ações de alimentação e nutrição no SUS de 2006 a 2013”. Sendo assim, caracteriza-se como um estudo descritivo, quali-quantitativo, embasado no modelo tridimensional de estrutura-processo - resultado.

A metodologia utilizada no estudo original foi uma adaptação da abordagem sistêmica estrutura - processo - resultado que originalmente foi indicada para avaliar o cuidado médico e vem sendo adaptada para a avaliação de políticas e programas públicos. Santos (2013, ainda não publicado) propôs um modelo utilizando esta abordagem para avaliação do FAN e seus resultados serão descritos abaixo. Também foi elaborada uma matriz (Apêndice 1) para auxiliar na investigação, identificação das variáveis e no direcionamento da construção dos instrumentos utilizados.

Para avaliação do FAN o conceito de estrutura esta relacionado aos objetivos do repasse, analisando os aspectos normativos e as ferramentas físicas. Assim, contemplam esta dimensão informações como: o histórico do repasse anual fundo a fundo para A\&N no estado e no município; estrutura normativa; responsabilidades decisórias e gerenciais; Responsável Técnico de A\&N formalmente indicado; recursos humanos qualificados e disponíveis; planejamento da aplicação financeira; proposta orçamentária; planejamento das ações, projetos e programas; adequação das ações; critérios de seleção de municípios apoiados pela SES e aderência do programado às diretrizes da PNAN.

$\mathrm{Na}$ dimensão processo analisou-se como as intervenções foram desenvolvidas tendo por referência o estabelecido na estrutura. As informações relacionadas ao planejamento e seleção das atividades, a implementação das ações previstas, o acompanhamento e a avaliação da execução das ações/atividades desenvolvidas por meio da utilização do recurso, o conhecimento dos objetivos e marcos legais do recurso e da PNAN pelos gestores, são contemplados nesta dimensão.

O último componente da abordagem é o resultado. Esta dimensão confere finalidade a estrutura e processo, compreendendo o alcance dos objetivos gerais. Para contemplar o resultado, foram verificadas a tipologia e quantidade de ações, projetos e programas executados, o acompanhamento da execução técnica e financeira das ações, projetos e 
programas por parte dos gestores e o diferencial na estruturação e implementação de ações de A\&N após recebimento do recurso. Interessam sobretudo: (1) Vigilância alimentar e nutricional (SISVAN nos serviços de saúde, Inquéritos, Chamadas Nutricionais); (2) Promoção da Saúde e da Alimentação Adequada e Saudável (Guias Alimentares, Educação Alimentar e Nutricional, Estratégias Amamenta e Alimenta Brasil, Controle e regulação de alimentos, Academia da Saúde, Saúde na Escola); (3) Prevenção e controle de agravos nutricionais (suplementação com vitamina A e ferro, deficiência de iodo, beribéri, excesso de peso e obesidade, desnutrição, necessidades alimentares especiais); (4) SISVAN Bolsa Família.

Fagundes (2009) discorre sobre a importância de mais de um método para apreender todas as dimensões da avaliação. Assim, no delineamento metodológico deste trabalho, além da análise das dimensões proposto por Santos (2013), também foi utilizada a análise qualitativa, por meio de leituras sucessivas para estabelecer conexões lógicas com o modelo da abordagem tridimensional e inferir o nível de sucesso ou fracasso da utilização do recurso com base nas percepções dos responsáveis técnicos da área de A\&N. Para Turato (2005), a avaliação qualitativa não tem o objetivo de descrever os fenômenos em si, mas sim a significação que o fenômeno ganha para quem os vivencia e as representações que os participantes têm desta experiência.

Segundo Minayo (2010), o método qualitativo é caracterizado pela sistematização do conhecimento, dos fenômenos analisados até a compreensão da lógica interna do grupo. Os mediadores dos grupos focais deste estudo, por meio de um roteiro, promoveram a participação de todos e estimulavam o aprofundamento das discussões de maneira a chegar ao esgotamento das percepções dos participantes sobre a temática.

\subsection{PROCEDIMENTO DA PESQUISA}

Primeiramente, para contemplar a análise da dimensão estrutura foi realizado um levantamento normativo orientado pela Lei Complementar 95/1998, que define como devem ser grafados os atos de regulamentação expedidos pelos órgãos do Poder Executivo. Foram analisadas as oito portarias que regulamentam o recurso, no período de 2006 a 2013. Foram pprivilegiados alguns elementos que compõe as normas, como: epígrafe (natureza, número e data); ementa (descrição sucinta do seu conteúdo); preâmbulo (justificativa); corpo da norma (texto relacionado à matéria); fecho (medidas necessárias à implementação, disposições transitórias, cláusula de vigência e cláusula de revogação); assinatura e anexos. Os 
procedimentos de análise foram a identificação dos núcleos de conteúdo e comparação, quantificação, quando pertinente, e interpretação. Estes foram analisados a partir da LC $\mathrm{n}^{\circ}$ 95/1998 e LC 107/2001. É importante ressaltar que a análise das normas favorece o entendimento sobre a forma como deve ser gasto o recurso.

À análise documental iniciou-se com uma busca das legislações publicadas a partir do ano de 2006 e, também de artigos e textos relacionados à transferência de recursos específicos. Publicações relacionadas à temática foram buscadas nas bases de dados eletrônicas Scientific Electronic Library Online Brasil (SciELO), Sistema de Legislação em Saúde (Saude-legis, Ministério da Saúde, Brasil), sendo utilizados os descritores: "Alimentação e Nutrição" e "Financiamento do SUS".

As dimensões processo e resultados foram contempladas por meio dos instrumentos construídos a partir da matriz. Esta sistematizou categorias de análise para as três dimensões contribuindo para construção de questões orientadoras para a coleta de dados.

O modelo da matriz contemplou categorias como: "Histórico do repasse anual fundo a fundo no estado", "Estrutura Normativa para a gestão do programa", "Força de trabalho para a gestão do programa" e "Planejamento da aplicação financeira dos recursos do FAN". As categorias de análise presentes orientaram a construção dos instrumentos da pesquisa.

\subsection{AMOSTRA}

A amostra deste estudo é não probabilística, numa amostragem por conveniência, composta por responsáveis técnicos de $\mathrm{A} \& \mathrm{~N}$ de diferentes esferas governamentais que recebem o recurso orçamentário e estavam presentes no XII Encontro Nacional de Rede de Alimentação e Nutrição do SUS, realizado maio 2013 na cidade de Brasília.

Cabe elucidar que a partir da Portaria no 2.324 de 2009 todos os estados e municípios com mais de 150 mil habitantes, recebem recurso de custeio. Em 2006, o repasse financeiro contemplou 26 municípios (as capitais) e atualmente são 178 localidades incluindo do interior, capitais e estados. Assim, a amostra total de responsáveis técnicos foi correspondente ao número de unidades federativas que são contempladas pelo recurso.

A ausência no encontro e o fato de não ser o responsável técnico de alimentação e nutrição - RTAN que trabalhava diretamente com o recurso foram fatores de exclusão para a participação do estudo. Assim, a amostra final foi composta por 83 representantes, dentre eles 61 e 22 RTAN municipais (16 de capitais e 45 do interior) e estaduais, respectivamente. Optou-se por não coletar informações dos 95 faltantes para evitar viés de informação, devido 
tempo entre a primeira coleta e a segunda, e também por ser um período posterior às eleições municipais de 2012, caracterizado por mudanças estruturais e de transição.

\subsection{INSTRUMENTOS E COLETAS DE DADOS}

O estudo original para a coleta de dados primários elaborou questionários auto aplicáveis para os gestores RTAN, roteiros para grupos focais com RTAN's separados conforme sua esfera de atuação e por fim, roteiros de entrevistas semi estruturadas preparados para aplicação no estudo de caso em nove unidades da federação, para os seguintes informantes-chave: (a) responsável técnico da área de alimentação e nutrição; (b) seu supervisor imediato; (c) gestor da área de planejamento e finanças; (d) representante do controle social.

Para este estudo foram utilizados dados de dois dos três instrumentos construídos na pesquisa original. Os dados foram coletados por meio de questionários específicos para gestores estaduais e municipais (APÊNDICE 2), contendo questões objetivas e discursivas, com a finalidade de investigar a utilização do recurso de acordo com as atribuições previstas para estados e municípios junto ao FAN, as ações realizadas e o conhecimento dos objetivos e dos marcos legais do FAN e da PNAN.

Os questionários apresentavam 28 questões (discursivas e objetivas) e um quadro com sentenças relacionadas ao FAN. Nesta última parte, os respondentes foram orientados a classificar se as sentenças foram realizadas (totalmente, parcialmente ou não realizada) e a relevância (muito relevante, parcialmente relevante e não relevante) da ação/atividade para estruturação/implantação da PNAN.

Outro instrumento de coleta de dados utilizado foi o roteiro (APÊNDICE 3) norteador do grupo focal, em média cada roteiro apresentava duas questões. Estas tinham como objetivo estimular os responsáveis a expor sobre: o repasse anual fundo a fundo para ações de alimentação e nutrição, a aplicação dos recursos e as principais ações desenvolvidas. Os RTAN's foram agrupados: estados, capitais e municípios do interior. Os grupos eram compostos em média por dez participantes, além do mediador e um relator.

Todos os participantes, tanto os respondentes dos questionários quanto os dos grupos focais foram esclarecidos sobre a pesquisa e convidados pelos pesquisadores a assinarem Termo de Consentimento Livre e Esclarecido - TCLE (APÊNDICE 4). 


\section{ANÁLISE DOS DADOS}

A abordagem teórica do estudo com a dinâmica de investigação que associa as três dimensões - estrutura, processo e resultado - e a compreensão que os diferentes atores constroem sobre a implementação e execução das ações financiadas pelo recurso, demandou uma análise que integrava as informações quantitativas com os depoimentos que aprofundavam questões semelhantes. Assim, relacionando as informações provenientes das questões objetivas dos questionários com as falas dos grupos focais.

Os dados quantitativos foram registrados em planilha eletrônica (Excel®) e as análises estatísticas descritivas foram realizadas no pacote estatístico SPSS versão 21.

Para análise dos grupos focais, inicialmente realizou-se a transcrição das gravações e, posteriormente, o conteúdo foi organizado dentro dos aspectos que eles contemplavam (estrutura - processo - resultado) de maneira a se adequar ao objetivo. Para as questões discursivas do questionário a análise também se baseou nesta técnica qualitativa.

Os dados qualitativos foram ordenados e categorizados nas três dimensões citadas anteriormente, favorecendo assim que a técnica de análise de conteúdo parta de uma leitura do primeiro plano de depoimentos para atingir um nível mais profundo das discussões (MINAYO, 2010).

\subsection{PROCEDIMENTO ÉTICO}

O estudo foi aprovado pelo Comitê de Ética em Pesquisa da Faculdade Ciências da Saúde da Universidade de Brasília, sob o número do Parecer 273.515/ 2013. 


\section{RESULTADOS}

\subsection{ARTIGO 1:}

O artigo 1 intitulado "Análise das normas legais do Financiamento das Ações de Alimentação e Nutrição no âmbito do SUS de 2006 a 2013" será submetido Revista Ciência \& Saúde Coletiva.

Título: Análise das normas legais do Financiamento das Ações de Alimentação e Nutrição no âmbito do SUS de 2006 a 2013.

\section{Resumo}

Desde os anos 90, no processo de implantação do Sistema Único de Saúde, houve a adoção de mecanismos diferenciados para transferência de recursos fundo a fundo, vinculados às ações e programas de saúde. A Política Nacional de Alimentação e Nutrição passou a contar com uma linha própria para financiamento descentralizado a partir de 2006, com o objetivo de incentivar a estruturação e a implementação de ações de Alimentação e Nutrição (A\&N), sendo instituída pela Portaria $n^{\circ} 1.357$ de junho de 2006. Em 2007, os recursos destinados para as ações de $\mathrm{A} \& \mathrm{~N}$ foram depositados numa conta específica do Fundo estadual ou municipal de saúde denominada Fundo Alimentação Nutrição, com repasse para localidades com mais de 200.000 habitantes. Dois anos mais tarde, por força da Portaria $\mathrm{n}^{\mathbf{o}}$ 2.324, de 6 de outubro de 2009 e das Portarias anuais subsequentes, o FAN foi expandido para alcançar os municípios que possuem mais de 150.000 habitantes. Até o momento não foram registrados na literatura específica análises sobre esta iniciativa. Assim, este artigo objetivou analisar as portarias editadas no período de 2006 a 2013 que se destinaram a regulamentar a organização do repasse, efetuado pelo Ministério da Saúde. A análise da forma foi orientada pela Lei Complementar (LC) 95/1998 que dispõe sobre a elaboração, a redação, a alteração e a consolidação das leis, bem como com a LC 107/2001, que altera da LC 95/1998. Após a análise, foi possível observar que ocorreram mudanças nas portarias do FAN que são editadas a cada ano. Essas mudanças aconteceram desde o objeto e finalidade da portaria até as justificativas para implantação, visto que a cada ano foram consideradas novas ações, programas e políticas na área da saúde ligadas diretamente às ações de $\mathrm{A} \& \mathrm{~N}$, como a Política Nacional de Atenção Básica, a Vigilância Alimentar e Nutricional, entre outras. Observou-se também um aumento de $283 \%$ no número de municípios contemplados com o 
FAN, e um incremento de $131 \%$ no orçamento, no período entre 2006 a 2013. Assim, as portarias editadas pelo Ministério da Saúde sofreram importantes mudanças que objetivaram proporcionar o melhor uso do Fundo de Alimentação e Nutrição, buscando otimizar a utilização, esclarecer a especificação no conteúdo textual, superando as constantes dúvidas e as diferentes interpretações quanto a utilização do incentivo financeiro de custeio

Palavras-chave: Avaliação em Saúde; Recursos em Saúde; Planejamento em Saúde.

\section{INTRODUÇÃO}

Durante o processo de implantação do Sistema Único de Saúde (SUS) de forma descentralizada e municipalizada, houve a adoção de mecanismos diferenciados para transferência de recursos fundo a fundo, vinculados às ações e programas de saúde no Brasil (LEVCOVITZ et al., 2001). Esta estratégia caracteriza a ação indutora e reguladora da esfera federal e foi entendida como essencial para aumentar a autonomia local nos gastos em saúde. A área de Alimentação e Nutrição (A\&N) também passou a contar com uma linha específica de financiamento, descentralizado a partir de 2006, para implementar ações contempladas na Política Nacional de Alimentação e Nutrição (PNAN).

A PNAN, aprovada em 1999 e atualizada em 2011, se constitui no compromisso do Ministério da Saúde com a promoção de práticas alimentares saudáveis e, a prevenção e controle dos agravos nutricionais relacionados à insegurança alimentar e nutricional (tanto referentes à escassez, quanto ao excesso). Esta política compõe o conjunto de ações que contribuem para a concretização do direito humano à alimentação (JAIME et al., 2011).

Assim, a partir de 2006, com a finalidade de estruturar as ações de Alimentação e Nutrição por parte das Secretarias Estaduais e Municipais de Saúde, foram iniciados os repasses financeiros do Fundo Nacional de Saúde (FNS), programa orçamentário "Programa Alimentação Saudável", para os fundos estaduais e municipais de saúde, definidos inicialmente pela Portaria $n^{\circ} 1.357$, de 23 de junho de 2006 (BRASIL, 2006).

O objetivo desta iniciativa, conhecido como Fundo de Alimentação e Nutrição (FAN) é incentivar a estruturação e favorecer a pactuação dos princípios e diretrizes presentes na PNAN. A Portaria previu, inicialmente, repasses para todas as Unidades da Federação (UF) e suas capitais, e, após modificações, para outros municípios brasileiros, considerando o porte populacional. 
As portarias ministeriais são mecanismos do Poder Executivo de normalização de políticas, e buscam, principalmente, definir instruções para a implementação das leis, decretos e regulamentos aprovados. Na área da Saúde estas estratégias se destacam pela quantidade em que é emitida a cada ano, bem como pela função indutiva para implementação das políticas do setor (BAPTISTA, 2007). No campo da A\&N, especificamente sobre a definição de execução do Fundo de Alimentação e Nutrição, foram produzidas oito portarias ministeriais, entre 2006 e 2013.

Uma análise dessa natureza também auxilia no entendimento de como a descentralização do financiamento no SUS tem se estabelecido. Argumenta-se que a descentralização dos recursos para financiamento de políticas sociais, de forma automática, seria uma estratégia que, além de favorecer o desenvolvimento de ações mais próximas das necessidades locais, promoveria também maior controle social sobre a aplicação dos recursos e com isso, somaria para a redução de práticas clientelistas. Em que pese o reconhecimento de avanços na direção indicada, alguns autores que se debruçaram sobre a implementação de transferências direta de recursos fundo a fundo, por exemplo, para a atenção básica, questionam se este mecanismo não estaria, ao contrário do pretendido, reduzindo a autonomia local e se conformando em obstáculo à formulação de uma política de saúde voltada às necessidades locais (MARQUES e MENDES, 2002).

Apesar dessa dinâmica em torno do FAN, até o momento não foram registrados na literatura específica avaliações sobre esta iniciativa. A análise do Fundo de Alimentação e Nutrição a partir de suas normativas pode ajudar a compreender melhor o papel que esse instrumento exerce no setor, e se, de fato, tem contribuído ou não para a estruturação das ações de alimentação e nutrição nos estados, municípios e no Distrito Federal.

Expectativas e questões são postas, portanto, ao financiamento descentralizado do SUS, iniciado ainda nos anos 90.

Este estudo objetivou analisar as Portarias Ministeriais da Saúde editadas no período de 2006 a 2013 que se destinaram a regulamentar a organização do Fundo de Alimentação e Nutrição.

\section{METODOLOGIA}

Desenhou-se como estratégia de pesquisa, a identificação e análise das portarias do Ministério da Saúde editadas no período de 2006 a 2013, que se destinaram a implementação das ações de Alimentação e Nutrição no âmbito das Secretarias Estaduais e Municipais de Saúde. 


\section{Identificação das Portarias}

A identificação dos documentos foi realizada com a busca no Sistema de Legislação da Saúde (SAÚDE LEGIS), um site do Ministério da Saúde, que permite a consulta de normas editadas, como portarias, normas técnicas, instruções normativas, resoluções, súmulas e ordens de serviços do poder executivo.

Para a busca no sistema foram utilizadas as palavras-chave "Alimentação e Nutrição", "Financiamentos SUS". Após a busca e identificação das portarias foi realizada análise dos referidos documentos.

\section{Análise das Portarias}

Como etapa inicial do processo, as portarias foram organizadas a partir da sua estrutura: epígrafe (natureza, número e data); ementa (descrição sucinta do seu conteúdo); preâmbulo (justificativa); corpo da norma (texto relacionado à matéria); fecho (medidas necessárias à implementação, disposições transitórias, cláusula de vigência e cláusula de revogação); assinatura; e anexos.

A análise da forma foi orientada pela Lei Complementar (LC) 95/1998 que dispõe sobre a elaboração, a redação, a alteração e a consolidação das leis, conforme determina o parágrafo único do art. 59 da Constituição Federal, e estabelece normas para a consolidação dos atos normativos, inclusive as portarias ministeriais. Utilizou-se também a LC 107/2001, que altera da LC 95/1998.

Quanto à análise do conteúdo das normas, foram feitas leituras sucessivas, identificação de núcleos de conteúdo, comparação, quantificação quando pertinente. A análise do conteúdo textual teve por objetivo resgatar os núcleos de significados, muitas vezes não expressos no corpo da norma, à luz do contexto histórico e institucional, no cenário do desenvolvimento e da dinâmica das políticas públicas relacionadas ao setor saúde que foram implementadas nesses anos de execução do FAN.

\section{RESULTADOS E DISCUSSÃO}

\section{Análise da epígrafe}

Foram identificadas oito portarias ministeriais sobre o FAN entre 2006 a 2013: Portaria GM/MS 1.357, de 23 de junho de 2006; Portaria GM/MS 3.181, de 12 de dezembro de 2007; Portaria GM/MS 1.424, de 10 de julho de 2008; Portaria GM/MS 2.324, de 6 de 
outubro de 2009; Portaria GM/MS 1.630, de 24 de junho de 2010; Portaria GM/MS 2.685, de 17 de novembro de 2011; Portaria GM/MS 2.349, de 10 de outubro de 2012; e a Portaria GM/MS 1.738, de 19 de agosto de 2013. As portarias analisadas apresentam numerações altas (a menor, $\mathrm{n}^{\circ} 1.357$, de junho de 2006, e a maior, $\mathrm{n}^{\circ} 3.181$, de dezembro de 2007), indicativas do quantitativo (superior a três mil por ano) de normas que foram publicadas a cada ano na primeira década do século XXI pelo Ministério da Saúde, mas principalmente do "papel de destaque", do "forte poder de indução que este instrumento assumiu na definição da política setorial" e por definirem instruções para execução de leis, decretos e regulamentos editados e previamente aprovados (BAPTISTA, 2007).

Quanto à periodicidade, além da observação de que têm sido anuais, pode-se analisar estes intervalos em termos mensais. Observou-se que variou de sete (entre dezembro de 2007 e julho de 2008) a 17 meses (entre junho de 2010 e novembro de 2011), tendo sido algumas destas portarias publicadas no final do ano (exemplo: dezembro de 2007 e novembro de 2011), o que pode dificultar a execução financeira por estados e municípios dos recursos repassados e, desta forma, o cumprimento de sua finalidade.

Essas edições de portarias revelam, também, uma busca do Ministério da Saúde para a atualização de suas normas, frente às ações e programas de saúde que foram implementadas no período e que estão relacionados direta ou indiretamente com a área de Alimentação e Nutrição. Pode-se citar a Política Nacional da Atenção Básica, a Política Nacional de Promoção da Saúde, o Programa Saúde na Escola, o Núcleo de Apoio a Saúde da Família, o Sistema Nacional de Vigilância Alimentar e Nutricional, e atualização da Política Nacional de Alimentação e Nutrição (BRASIL, 2013).

\section{Análise da ementa}

A respeito do objeto das portarias, observou-se que a primeira tratava da utilização do saldo residuais dos recursos repassados referente ao Incentivo de Combate a Carências Nutricionais (ICCN); a segunda versava sobre os recursos financeiros para o Programa Alimentação Saudável, e a partir da terceira portaria, editada em 2008, até a sétima, o objeto é tratado como o repasse anual fundo a fundo, correspondendo ao Fundo de Alimentação e Nutrição. A última portaria explicita como objeto, o incentivo de custeio para estruturação e implementação, de ações de alimentação e nutrição, pelas Secretarias Estaduais e Municipais de Saúde, com base na Política Nacional de Alimentação e Nutrição. O FAN é incentivo exclusivamente de custeio, por isso, é vedada sua utilização para aquisição de materiais para 
tratamento de doenças ou reabilitação de pacientes, aquisição de alimentos, suplementos alimentares, fórmulas alimentares, de vitaminas ou minerais, por exemplo, (REDENUTRI, 2015).

Em termos de abrangência verificou-se que a finalidade inicial das normativas foi estruturar as ações de Alimentação e Nutrição nos estados e capitais, sendo alterada no ano seguinte para municípios com mais de 200.000 habitantes, e finalmente estabelecida a partir da terceira portaria a finalidade de implementação das ações de Alimentação e Nutrição, no âmbito das Secretarias Estaduais e Municipais de Saúde das capitais e municípios com mais de 150.000 habitantes. Destaca-se que em todas as portarias, a PNAN aparece como eixo norteador e base para todas as ações, ou seja, não houve rompimento entre o delineamento das normativas e o arcabouço estruturante da iniciativa. É importante ressaltar ainda que, em 2011, a PNAN foi atualizada, e que as duas últimas portarias (2012 e 2013) baseiam-se na última versão da política.

\section{Análise do Preâmbulo}

$\mathrm{Na}$ análise do preâmbulo, foram observadas como justificativas para a edição da primeira portaria: o saldo financeiro nos municípios outrora qualificados para o recebimento de recursos de Incentivo de Combate a Carências Nutricionais; a reunião da Comissão Intergestores Tripartite (CIT); a Política Nacional de Alimentação e Nutrição; a Portaria Interministerial $n^{\circ} 2.509$, de 18 de novembro de 2004 que trata das ações de saúde relativas às condicionalidades do Programa Bolsa Família; e a necessidade de implementar as ações de Alimentação e Nutrição no âmbito da Atenção Básica à saúde voltadas à promoção da alimentação saudável.

A partir da segunda portaria, no ano de 2007, também foram acrescentadas como justificativas: a Política de Atenção Básica; o Programa Nacional de Prevenção e Controle dos Distúrbios por Deficiência de Iodo (DDI) - Pró-Iodo -; as ações de Vigilância Alimentar e Nutricional; o Programa Nacional de Suplementação de Vitamina A; o Programa Nacional de Suplementação de Ferro; e a Promoção da Alimentação Saudável nas Escolas.

Em 2008, foram adicionadas ao preâmbulo a Portaria no 154/GM, de 24 de janeiro de 2008, que cria os Núcleo de Apoio à Saúde da Família (NASF), bem como a Portaria ${ }^{\circ}$ 325/GM, de 21 de fevereiro de 2008, que estabelece prioridades, objetivos e metas do Pacto pela Vida para 2008 e a Política Nacional de Promoção da Saúde. A presença da norma que faz alusão ao NASF mostra como a criação deste núcleo e a inserção do nutricionista nas 
equipes podem fortalecer e, proporcionar o matriciamento das ações de Alimentação e Nutrição no contexto das equipes de Atenção Básica (JAIME, 2011).

A sétima e oitava portarias referenciam a Portaria $n^{\circ} 4.279 / \mathrm{GM} / \mathrm{MS}$, de 30 de dezembro de 2010, que estabelece diretrizes para a organização da Rede de Atenção à Saúde no âmbito do SUS. A norma de 2013 também traz no seu preâmbulo a Portaria $\mathrm{n}^{\circ}$ 424/GM/MS, de 19 de março de 2013, que redefine as diretrizes para a organização da prevenção e do tratamento do sobrepeso e obesidade como linha de cuidado prioritária da Rede de Atenção à Saúde das Pessoas com Doenças Crônicas (DCNT).

As DCNT's constituem um eixo temático que gera preocupação e norteia importantes discussões no âmbito da saúde pública. A população mundial tem experimentado mudanças epidemiológicas, demográficas e nutricionais importantes nas últimas décadas, caracterizadas por uma alteração na estrutura etária e consequente envelhecimento populacional, com maior prevalência de doenças crônicas não transmissíveis, maior causa de morbimortalidade em todo o mundo, as quais estão relacionadas com o perfil de consumo alimentar (CONSEA, 2010; COUTINHO et al., 2008).

Percebeu-se que a cada nova edição da portaria referente ao FAN, novos objetos foram considerados como justificativa para a implementação da portaria, isso mostra uma atualização do setor $\mathrm{A} \& \mathrm{~N}$ frente às novas demandas, ações e programas do Ministério da Saúde, bem como do contexto epidemiológico. As justificativas presentes nos preâmbulos, em sua maioria, estão relacionadas com a atenção básica, revelando a estreita relação das ações de $A \& N$ com as ações de promoção e proteção da saúde e prevenção de agravos.

No estudo de Mendes (2009), os sistemas de atenção à saúde baseados na atenção primária à saúde se organizam por meio das demandas da população, o que os tornam mais adequados por impactarem de maneira significativa na saúde da população, sendo mais efetivos para o enfrentamento da situação epidemiológica de maior prevalência das condições crônicas; além disso, não oneram o orçamento porque apresentam menores custos e reduzem procedimentos mais caros; são equitativos e enfatizam a promoção da saúde e a prevenção de comorbidades, garantindo assim melhor qualidade de vida para o usuário (MENDES, 2009).

O trabalho de Jaime e colaboradores corrobora com este aspecto, ao afirmar que a Atenção Básica é um importante espaço para desenvolvimento de ações no âmbito individual e coletivo voltados à promoção da saúde e prevenção de doenças, como a obesidade (JAIME et al., 2011). 


\section{Análise do Corpo}

Na comparação e análise textual das normas, foram observadas algumas modificações, todas as portarias os requisitos legais para o recebimento do Fundo de Alimentação e Nutrição devem obedecer ao disposto no art. $4^{\circ}$ da Lei $n^{\circ} 8.142$, de 28 de dezembro de 1990, ou seja, os municípios deveriam comprovar o funcionamento do Fundo de Saúde, Conselho de Saúde, Plano de Saúde, relatórios de gestão, contrapartida de recursos para a saúde no respectivo orçamento e Plano de Carreira, Cargos e Salários (PCCS).

Esses requisitos são elementos estruturantes do SUS, e no caso do FAN, passam a ser fundamentais para que o repasse aconteça, bem como para avaliação e monitoramento das ações, por meio dos Conselhos de Saúde, dos Planos e dos Relatórios de Gestão.

De forma geral, analisando o corpo da norma, percebeu-se que na primeira portaria as finalidades destinadas a utilização do recurso englobavam várias ações do campo da saúde, como: Equipes de Saúde da Família (ESF); redução da desnutrição;promoção da alimentação adequada e saudável (PAS); incentivo ao consumo de alimentos regionais brasileiros; Sistema de Vigilância Alimentar e Nutricional (SISVAN); Programas Nacionais de Suplementação de Ferro e Vitamina A; além do apoio a estudos, pesquisas e elaboração de informes e relatórios sobre a situação da alimentação e nutrição.

A partir da segunda portaria, em 2007, as finalidades ficaram mais focadas em algumas diretrizes da PNAN, como: promoção de práticas alimentares e estilos de vida saudáveis; monitoramento da situação alimentar e nutricional; prevenção e controle dos distúrbios e doenças nutricionais e; o desenvolvimento e capacitação de recursos humanos em saúde e nutrição, conforme a figura 1.

Os dados obtidos referentes à finalidade mostraram que as portarias sofreram modificações de maneira a enfrentar os grandes desafios atuais. Jaime e colaboradores (2011), em seu estudo, vão ao encontro do exposto ao elucidar que “[...] a expansão da Estratégia de Saúde da Família, a harmonização com o modelo tradicional de Atenção Básica, a qualificação das ações para garantia da equidade às populações em vulnerabilidade social, a qualificação dos profissionais, a organização do sistema de saúde em redes de atenção, e o financiamento [...]” são importantes desafios a serem enfrentados pela Atenção Básica. 


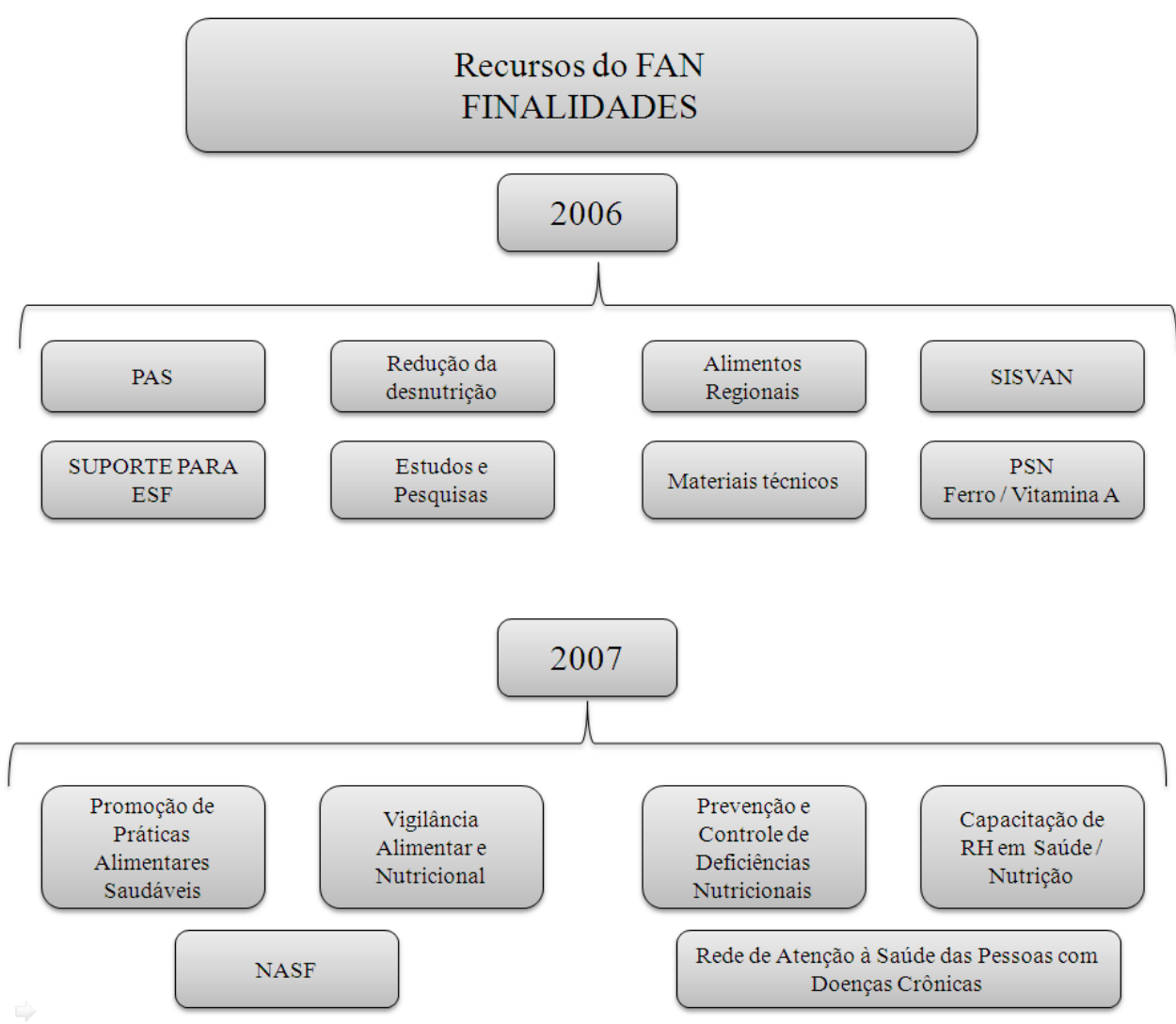

Figura 1. Descrição das finalidades dos recursos destinados ao Fundo de Alimentação e Nutrição (FAN), no período de 2006 a 2013.

É no conteúdo textual das normas que se apresentam as competências das três esferas governamentais a serem executadas por meio do FAN, com exceção da norma de 2013. Segundo o Departamento de Atenção Básica, as alterações propostas nesta portaria, que a torna diferente das anteriores, têm como objetivo facilitar o entendimento quanto à utilização do incentivo financeiro de custeio e sanar as constantes dúvidas (BRASIL, 2013).

Foram observadas as competências, das três esferas, poderiam ser colocadas em quatro grupos: capacitação de recursos humanos (CRH), gestão e cooperação $(\mathrm{GC})$, vigilância alimentar e nutricional (VAN) e promoção da alimentação saudável/ prevenção e controle de doenças crônicas e nutricionais (PAS/PRE).

$\mathrm{Na}$ análise das competências em âmbito federal, verificou-se que as sete competências estavam relacionadas com o grupo de gestão e cooperação, são elas: estabelecer diretrizes para as ações a serem desenvolvidas com base na PNAN; estimular e apoiar as Secretarias Estaduais e Municipais de Saúde para a implantação, implementação e a avaliação do desempenho e impacto das ações de A\&N; bem como criar mecanismos que vinculem a transferência de recursos às instâncias estaduais e municipais. A pactuação entre as três 
esferas, respeitando os preceitos e instâncias praticados no SUS favorece que as ações assumidas e incorporadas pelos gestores, sejam consolidadas em todo território nacional (PNAN, 2012). O conteúdo da produção normativa relativa às competências na esfera federal mostra o direcionamento para o fortalecimento e regulação das políticas que são executadas por meio de repasses financeiros com o objetivo de desenvolvimento único de ações de Alimentação e Nutrição.

Observou-se ainda como competência do Ministério da Saúde, participar da negociação das metas a serem pactuadas com os Estados na efetivação do Pacto pela Saúde; promover mecanismos de consolidação do SISVAN; acompanhar e monitorar a situação dos Estados, Distrito Federal e Municípios quanto ao nível de implantação e operacionalização das ações de Alimentação e Nutrição; acompanhar, por intermédio do Departamento Nacional de Auditoria do SUS (DENASUS), a conformidade da aplicação dos recursos transferidos; estabelecer parcerias com outras instâncias, órgãos e instituições, governamentais e não governamentais; bem como avaliar o desempenho e o impacto das ações em nível nacional.

Em âmbito estadual, foram observadas 19 competências, seis estão relacionadas à capacitação de recursos humanos; oito, abordam aspectos de gestão e cooperação com os municípios; três relacionam-se à promoção da alimentação saudável/prevenção e controle de doenças crônicas e nutricionais; e duas competências versam sobre a vigilância alimentar e nutricional. O maior número de competências relacionadas ao papel orientador do estado com os municípios pode-se inferir como um aspecto que favorece a descentralização administrativa, ampliando o alcance estatal.

As competências das Secretarias Municipais de Saúde são similares às estaduais, mas observou-se que essas estão mais focadas na capacitação de recursos e na promoção da alimentação saudável/prevenção e controle de distúrbios crônicos e nutricionais, ou seja, na execução das ações dos programas e das estratégias de saúde. Entretanto, existem competências também de gestão e vigilância alimentar e nutricional.

\section{Análise do fecho}

Como observado, as portarias relativas ao FAN orientam quanto à utilização dos recursos. Castro e Machado (2010) realizaram análise da condução federal da política de Atenção Primária à saúde e constataram que, no final dos anos 90, a indução de políticas e programas federais ocorreu, principalmente, por meio de mecanismos de financiamento (CASTRO e MACHADO, 2010). 
$\mathrm{Na}$ primeira portaria isso acontece de forma mais geral, versando que os recursos poderiam ser utilizados para a execução de ações cuja finalidade estejam relacionadas aos objetivos da portaria. Em 2007, a portaria faz algumas restrições sobre a utilização dos recursos e proíbe a utilização do FAN para a finalidade de proporcionar tratamento de doenças ou reabilitação de pacientes, inclusive, no caso de aquisição de suplementos alimentares, ou de vitaminas e minerais para estes fins. A partir de 2009, a portaria estabelece que a aquisição de material permanente deve estar relacionada com a estruturação das ações de alimentação e nutrição, não podendo, estes materiais, serem utilizados para outras finalidades.

Verificou-se também que para a utilização desses recursos, a portaria apontou alguns métodos de avaliação e monitoramento. A portaria publicada entre 2006 e 2007 determinou que as ações fossem avaliadas e monitoradas com base nas metas definidas nos Planos Estaduais ou Municipais de Alimentação e Nutrição, elaborado a cada ano. A partir da terceira portaria, em 2008, essas avaliações foram orientadas pelas Portarias 3.085/2006, 3.332/2006 e 3.176/2008, que, respectivamente, regulamentam o Sistema de Planejamento do SUS e aprova orientações gerais acerca dos instrumentos básicos.

Sobre a forma como os recursos do FAN seriam transferidos, observou-se que na primeira portaria esse assunto não foi muito bem esclarecido. Porém em 2007, a portaria estabelece que os recursos fossem depositados em uma conta específica do Fundo Estadual ou Municipal de Saúde e que seria proibida a movimentação financeira para outras contas e ações que não fossem recomendadas pela portaria. Já a partir de 2008, a norma define que os recursos seriam parte integrante do bloco de financiamento de gestão do SUS.

Observou-se também que desde a primeira norma, houve mudanças em relação à fonte dos recursos disponíveis para o FAN. Na primeira portaria, os recursos eram provenientes dos programas: monitoramento da situação nutricional da população brasileira, promoção de hábitos de vida e de alimentação saudáveis para a prevenção das obesidades crônicas. $\mathrm{Na}$ segunda portaria, em 2007, foram adicionados recursos de mais dois programas: apoio a estudos e pesquisas sobre alimentação, com enfoque na recuperação nutricional e alimentação saudável, e apoio à gestão descentralizada da Atenção Básica nos municípios. E somente a partir de terceira portaria, em 2008, os recursos tiveram uma única fonte: do programa de alimentação e nutrição, do orçamento do Ministério da Saúde.

Concernente às alterações da fonte de recursos disponíveis para o FAN, é importante destacar que estas podem ter sido definidas em consonância com o Plano Plurianual, que tem como objetivo organizar e viabilizar a ação pública com vistas a cumprir os fundamentos e 
objetivos da República, incluindo as despesas para o exercício financeiro subsequente, orientando para a execução futura dos recursos (BRASIL, 1988).

\section{Análise dos anexos}

$\mathrm{Na}$ análise dos anexos, observando o orçamento destinado ao Fundo de Alimentação e Nutrição, verificou-se um aumento de $131 \%$ no valor financeiro repassado aos estados e municípios, passando de 4,2 milhões para pouco mais de 9,7 milhões de reais, entre 2006 a 2013 (figura 2). Apesar desse incremento na gestão financeira, quando se analisa a distribuição geográfica do valor total destinado ao FAN por regiões, percebe-se que essa distribuição não é homogênea. Dos 9,7 milhões do FAN, em 2013, é possível observar, pela distribuição dos recursos, que a maior parte está concentrada nos municípios pertencentes à região sudeste (49\%), seguida pela região nordeste (20\%).

Quanto à distribuição dos valores repassados, na primeira portaria ficou estabelecido que o valor do repasse fosse proporcional ao porte populacional dos estados, com o recurso variando de 60 a 120 mil reais, medida mantida nos anos subsequentes. Para os municípios, esse recurso inicialmente variou de 40 a 100 mil reais, mas a partir da segunda portaria houve uma alteração do valor do recurso, sendo de 20 a 100 mil reais.

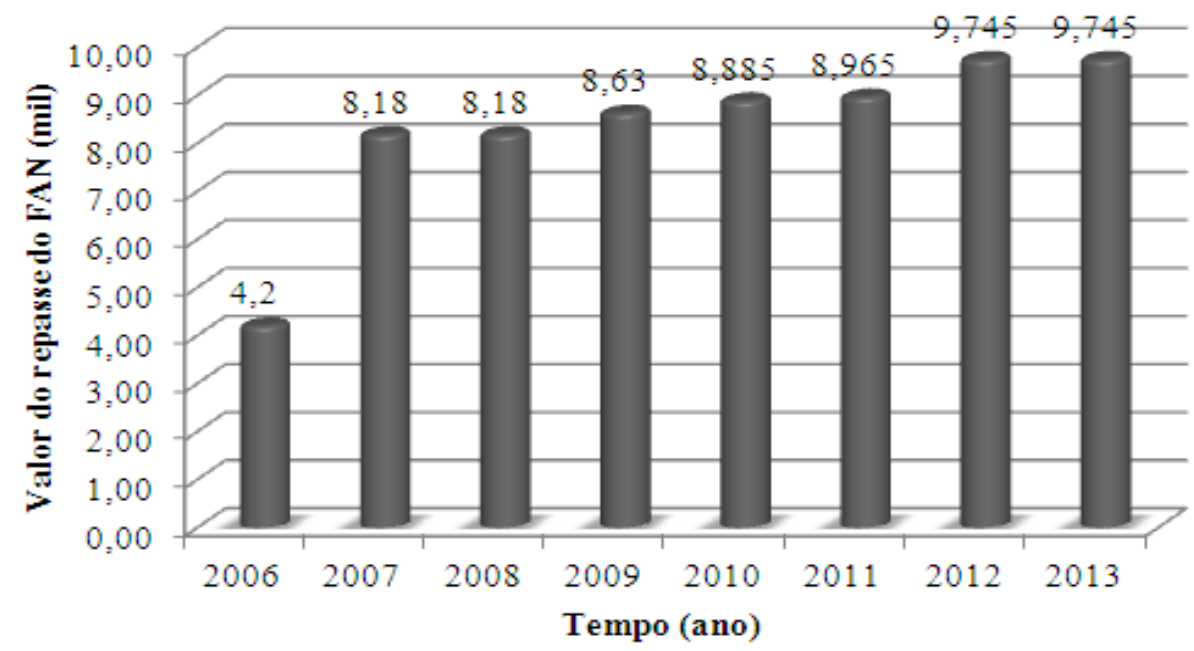

Figura 2. Evolução dos valores dos recursos transferidos do Fundo de Alimentação e Nutrição (FAN), no período de 2006 a 2013.

Quanto ao número de municípios contemplados com o FAN, também foi possível observar um aumento de 218\%, passando de 26 municípios (as capitais) em 2006 para 178 em 2013. O aumento de municípios contemplados com o repasse amplia a capilaridade das políticas que convergem para o alcance da Segurança Alimentar e Nutricional, por meio da 
execução das diretrizes previstas na PNAN. Esta, segundo Recine e Vasconcellos (2011), estimular ações intersetoriais, promove práticas alimentares saudáveis, previne e controla distúrbios nutricionais.

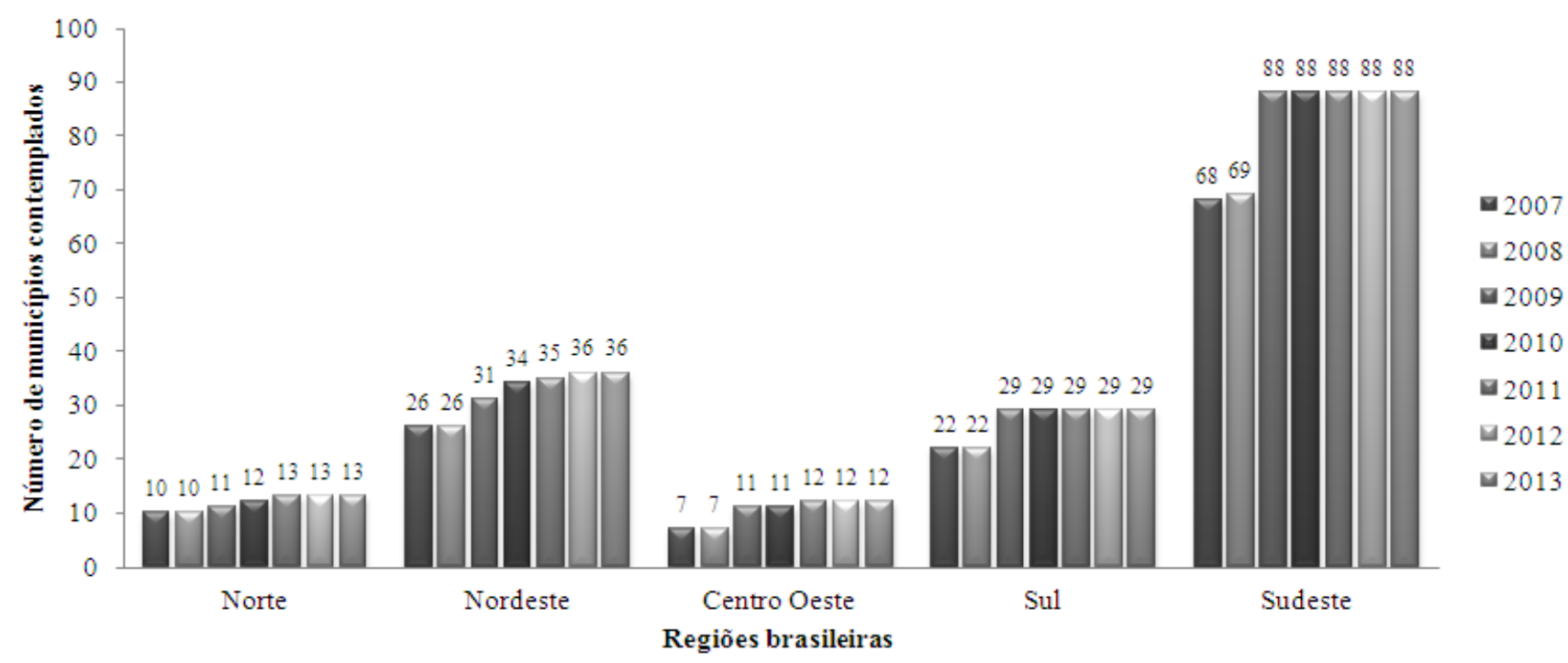

Figura 3. Número dos municípios contemplados com o Fundo de Alimentação e Nutrição (FAN), no período de 2007 a 2013.

\section{CONCLUSÃO}

As portarias relacionadas ao Fundo de Alimentação e Nutrição sofreram modificações com vistas a se adequarem aos novos desafios enfrentados no campo da alimentação e nutrição no Sistema Único de Saúde (SUS).

Conclui-se, da análise das portarias que definem o FAN que muitas diretrizes presentes na PNAN estão em sua maior parte vinculadas às finalidades do fundo, uma vez que a existência do recurso contribui para a execução de diversas ações de Alimentação e Nutrição, por meio de competências atribuídas à União, Estados, Municípios e ao Distrito Federal.

Assim, frente às novas demandas, ações e programas do Ministério da Saúde, desde a sua criação, as portarias apresentaram diversas mudanças que objetivaram proporcionar o melhor uso do Fundo de Alimentação e Nutrição, otimização do recurso e especificação no conteúdo textual, superando as constantes dúvidas e as diferentes interpretações quanto a utilização do incentivo financeiro de custeio. Desta forma, o marco normativo do repasse em estudo pode ser entendido como uma ação indutora de boas práticas, ao tempo em que 
potencializa maior espaço e diálogo das ações de alimentação e nutrição com as demais ações de interesse para o SUS.

\section{REFERÊNCIAS}

BAPTISTA, T.W. F. Análise das portarias ministeriais da saúde e reflexões sobre a conduta nacional da política de saúde. Cad Saúde Pública, v.23, n.3, mar. 2007; p. 615-26.

BRASIL. Congresso Nacional. Lei Complementar 95, de 26 de fevereiro de 1998. Dispõe sobre a elaboração, a redação, a alteração e a consolidação das leis, conforme determina o parágrafo único do art. 59 da Constituição Federal, e estabelece normas para a consolidação dos atos normativos que menciona. Brasília, 1998.

. Congresso Nacional. Lei Complementar 107, de 26 de abril de 2001. Altera a Lei Complementar $\mathrm{n}^{\circ}$ 95, de 26 de fevereiro de 1998. Brasília, 2001.

. Ministério da Saúde. Portaria $n^{\circ} 1.357$, de 23 de junho de 2006. Define e estrutura as ações de Alimentação e Nutrição por parte das Secretarias Estaduais e Municipais de Saúde das capitais com base na Política Nacional de Alimentação e Nutrição e normatiza a utilização do saldo restante dos recursos financeiros referentes ao Incentivo de Combate a Carências Nutricionais nos municípios qualificados. DOU $N^{o} 120$, página 44, 26 de junho de 2006.

. Ministério da Saúde. Portaria $\mathrm{n}^{\circ}$ 3.181, de 12 de dezembro de 2007. Define recursos financeiros do Programa Alimentação Saudável para incentivar a estruturação e a implementação das ações de Alimentação e Nutrição no âmbito das Secretarias Estaduais e Municipais de Saúde, com base na Política Nacional de Alimentação e Nutrição. DOU $N^{o}$ 239, página 86, 13 de dezembro de 2007.

. Ministério da Saúde. Portaria no 1.424, de 10 de julho de 2008. Estabelece o repasse anual fundo a fundo para a estruturação e implementação das ações de Alimentação e Nutrição no âmbito das Secretarias Estaduais e Municipais de Saúde com base na Política Nacional de Alimentação e Nutrição. DOU N $N^{o}$ 132, página 45, 11 de julho de 2008.

. Ministério da Saúde. Portaria $n^{\circ} 2.324$, de 6 de outubro de 2009. Estabelece o repasse anual fundo a fundo para a estruturação e implementação das ações de Alimentação e Nutrição no âmbito das Secretarias Estaduais e Municipais de Saúde com base na Política Nacional de Alimentação e Nutrição. DOU N ${ }^{o}$ 192, página 40, 7 de outubro de 2009.

. Ministério da Saúde. Portaria $n^{\circ} 1.630$, de 24 de junho de 2010. Estabelece o repasse anual fundo a fundo para a estruturação e implementação das ações de Alimentação e Nutrição no âmbito das Secretarias Estaduais e das Municipais de Saúde com base na Política Nacional de Alimentação e Nutrição. DOU N $N^{o}$ 120, página 71, 25 de junho de 2010.

. Ministério da Saúde. Portaria no 2.685, de 16 de novembro de 2011. Estabelece o repasse anual fundo a fundo para a estruturação e implementação das ações de Alimentação e Nutrição no âmbito das Secretarias Estaduais e Municipais de Saúde com base na Política Nacional de Alimentação e Nutrição. DOU N $N^{o}$ 220, página 85, 17 de novembro de 2011. 
. Ministério da Saúde. Portaria no 2.349, de 10 de outubro de 2012. Estabelece o repasse anual fundo a fundo para a estruturação e implementação das ações de Alimentação e Nutrição no âmbito das Secretarias Estaduais e Municipais de Saúde com base na Política Nacional de Alimentação e Nutrição. DOU $N^{\circ}$ 198, página 47, 11 de outubro de 2012a.

. Ministério da Saúde. Portaria $\mathrm{n}^{\mathrm{o}} 1.738$, de 19 de agosto de 2013. Estabelece incentivo de custeio para estruturação e implementação de ações de alimentação e nutrição pelas Secretarias Estaduais e Municipais de Saúde com base na Política Nacional de Alimentação e Nutrição. DOU $N^{o} 160$, página 22, 20 de agosto de 2013a.

- Ministério da Saúde. Secretaria de Atenção à Saúde. Departamento de Atenção Básica. Política Nacional de Alimentação e Nutrição. Secretaria de Atenção Básica à Saúde. - Brasília: Ministério da Saúde, $2012 b$.

Ministério do Desenvolvimento Social. Secretaria Nacional de Segurança Alimentar e Nutricional. Departamento de Estruturação e Integração dos Sistemas Públicos Agroalimentares. Educação Alimentar e Nutricional: o direito humano à alimentação adequada e o fortalecimento de vínculos familiares nos serviços socioassistenciais. Cadernos teóricos. Brasília, DF: MDS, $2013 b$.

Constituição (1988). Constituição [da] República Federativa do Brasil. Brasília: Senado Federal, 1988.

CASTRO, A. L. B.; MACHADO, C. V. A política de atenção primária à saúde no Brasil: notas sobre a regulação e o financiamento federal. Cad. Saúde Pública, Rio de Janeiro, v.26, n.4, 2010; p. 693-705.

CONSELHO NACIONAL DE SEGURANÇA ALIMENTAR E NUTRICIONAL (CONSEA). A segurança alimentar e nutricional e o direito humano à alimentação adequada no Brasil realização- indicadores e monitoramento - da Constituição de 1988 aos dias atuais. Brasília (DF): CONSEA; 2010; Disponível em: <http://www2.planalto.gov.br/consea/biblioteca/publicacoes/a-seguranca-alimentar-enutricional-e-o-direito-humano-a-alimentacao-adequada-no-brasil>. Acesso em: 20 jun. 2014.

COUTINHO, J. G.; GENTIL, P.; BERTOLIN, M. N. T. A desnutrição e obesidade no Brasil: o enfrentamento com base na agenda única da nutrição. Cad. Saúde Pública, v.24, 2008; p. 332-340.

JAIME, P. C.et al. Ações de alimentação e nutrição na atenção básica: a experiência de organização no Governo Brasileiro. Rev. Nutr., v.24, n.6, 2011; p. 809-824.

LEVCOVITZ, E.; LIMA, L.D. de; MACHADO, C.V. Política de saúde nos anos 90: relações intergovernamentais e o papel das Normas Operacionais Básicas. Ciênc. Saúde Coletiva, v.6, n.2, 2001; p. 269-291.

MARQUES, R. M; MENDES, A. A política de incentivos do Ministério da Saúde para a atenção básica: uma ameaça à autonomia dos gestores municipais e ao princípio da integralidade? Cad. Saúde Pública, v.18, suppl. 2002; p. S163-S171. 
MENDES, E.V. Agora mais do que nunca: uma revisão bibliográfica sobre a atenção primária à saúde. Belo Horizonte [s.n]; $2009 . \quad$ Disponível em: <http://new.paho.org/bra/apsredes>. Acesso em: 20 jun.2014.

RECINE, E.; VASCONCELLOS, A. B. Políticas nacionais e o campo da Alimentação e Nutrição em Saúde Coletiva: cenário atual. Ciênc Saúde Coletiva, Rio de Janeiro, v.16, n.1, 2011; p. 73-79. 


\subsection{ARTIGO 2}

O artigo 2 intitulado "Avaliação da utilização do repasse financeiro para estruturação e implementação das ações de Alimentação e Nutrição no âmbito Estadual e Municipal” será submetido Physis: Revista de Saúde Coletiva

Título: Avaliação da utilização do repasse financeiro para estruturação e implementação das ações de Alimentação e Nutrição no âmbito Estadual e Municipal.

\section{Resumo}

A Política Nacional de Alimentação e Nutrição (PNAN) foi aprovada pelo Conselho Nacional de Saúde, por meio da Portaria do Ministério da Saúde $n^{\circ} 710$, de 10 de junho de 1999 e atualizada em 2011. A PNAN é reconhecida como importante instrumento norteador das ações de Alimentação e Nutrição no Sistema Único de Saúde (SUS). Para a operacionalização, o fortalecimento, a concretização e a implementação das diretrizes a política recebe um recurso específico conhecido como Fundo de Alimentação e Nutrição (FAN) seguindo as normativas de alocação de recursos do SUS, no âmbito da municipalização da saúde, caracterizado pela transferência fundo a fundo regular e automática de recursos financeiros. O objetivo deste trabalho é avaliar a utilização do repasse fundo a fundo para estruturação e implementação das ações de alimentação e nutrição no âmbito Estadual e Municipal com base na Política Nacional de Alimentação e Nutrição - PNAN. Este estudo utilizou dados oriundos da pesquisa nacional intitulada: Avaliação da modalidade de repasse anual fundo a fundo para estruturação e implementação das ações de alimentação e nutrição no SUS de 2006 a 2013, adotando a tríade metodológica estrutura processo - resultado. Foram utilizados os dados dos grupos focais e dos questionários auto aplicados destinados aos Responsáveis Técnicos de Alimentação e Nutrição (RTAN). Realizou-se análise quali-quantitativa. Os resultados mostraram que o recurso é muito importante para o fortalecimento da área de Alimentação e Nutrição $(A \& N)$, conferindo maior visibilidade para a área e contribuindo para a execução de parte das ações previstas nas diretrizes da PNAN. Foram identificadas limitações como falta de recursos humanos e falta de continuidade das atividades. Pode-se observar também a execução de muitos projetos e programas do Governo Federal, como aqueles relacionados ao Programa Nacional de Suplementação do Ferro, Vitamina A, acompanhamento nutricional dos titulares do Bolsa 
Família, os previstos no Pacto pela Saúde, bem como os relacionados com atividades da Atenção Básica à Saúde.

Palavras-chave: Financiamento da assistência à saúde; Alocação de Recursos para a Atenção à Saúde; Política Nacional de Alimentação e Nutrição (PNAN); Avaliação de Programas e Projetos de Saúde.

\section{INTRODUÇÃO}

Com o passar dos anos e a preocupação do Estado brasileiro em definir a contribuição do setor saúde na promoção do estado nutricional adequado, observou um cenário favorável para construção de uma política com o objetivo de cooperar com a segurança alimentar e nutricional no país, e fortalecer a realização do direito universal à saúde e a alimentação (ROCHET, 2011).

A Política Nacional de Alimentação e nutrição (PNAN), do Ministério da Saúde, foi resultado deste cenário. Publicada por meio da Portaria $n^{\circ} 710$, de 10 de junho de 1999, apresentava como propósito: “[...] a garantia da qualidade dos alimentos colocados para consumo no País, a promoção de práticas alimentares saudáveis e a prevenção e o controle dos distúrbios nutricionais, bem como o estímulo às ações intersetoriais que propiciem o acesso universal aos alimentos [...]” (BRASIL, 2003).

No ano de 2009, a PNAN completou dez anos de publicação e frente a sua importância como referencial inovador da agenda política de alimentação e nutrição, como princípio norteador no planejamento das ações, como o elo potencial entre o Sistema único de Saúde (SUS) e o Sistema Nacional de Segurança Alimentar e Nutricional (SISAN), e tendo em vista seu propósito, iniciou o processo de atualização em 2010, com a publicação da Portaria $n^{\circ}$ 2.715, de 17 de novembro de 2011(BRASIL, 2011; RECINE, VASCONCELOS, 2011).

Recine e Vasconcelos (2011) destacam no seu trabalho que o fortalecimento e a institucionalização das ações de alimentação e nutrição no âmbito do SUS, recuperando as diretrizes da PNAN, são importantes e reforçam que o financiamento adequado favorece a concretização e a implementação das diretrizes da política.

Em 2006, considerando a necessidade de implementar as ações de alimentação e nutrição no âmbito da Atenção Básica à saúde voltadas à promoção da alimentação saudável, e também a existência de saldo financeiro nos municípios anteriormente qualificados para o 
recebimento de recursos de Incentivo de Combate a Carências Nutricionais (ICCN), foi publicada a Portaria $\mathrm{n}^{\circ} 1.357$, a qual deu início ao repasse do recurso destinado a incentivar a estruturação e a implementação das ações de Alimentação e Nutrição no âmbito das Secretarias Estaduais e Municipais de Saúde com base na Política Nacional de Alimentação e Nutrição. O recurso foi denominado Fundo de Alimentação e Nutrição - FAN (BRASIL, 2006).

O FAN é um recurso específico com vistas a financiar ações e programas de Alimentação e Nutrição (A\&N) no SUS. O repasse segue as normativas de alocação de recursos do SUS, no âmbito da municipalização da saúde, caracterizado pela transferência fundo a fundo regular e automática de recursos financeiros para aumentar a autonomia das unidades federativas, e fortalecer ações locais de responsabilidade do gestor municipal.

A partir de 2009 o incentivo de custeio para implementação das ações de alimentação e nutrição (FAN) começou a contemplar municípios com mais de 150 mil habitantes; antes eram somente os municípios com mais de 200 mil habitantes. Conforme contemplado na PNAN de 2011, "para o alcance da melhoria das condições de alimentação e nutrição da população, faz-se necessário garantir estratégias de financiamento tripartite para implementação das diretrizes da PNAN" (BRASIL, 2012). Sendo assim, a gestão de um recurso específico contribui para desenvolver mecanismos para a pactuação entre as três esferas para co-financiamento das ações (CARVALHO, 2011).

Para a consolidação das ações de alimentação e nutrição, além do financiamento, também se faz necessário o planejamento envolvendo a tomada de decisões políticas, criação de marcos legais e distribuição de responsabilidades. $O$ planejamento favorece $o$ monitoramento e a avaliação das ações. A prática avaliativa de projetos, programas e políticas de saúde, apesar de ser considerada importante para a melhoria na qualidade dos serviços de saúde, ainda não foi incorporado como prática sistemática e cotidiana (CAMPOS, 2010)

A avaliação referente à saúde, ações sanitárias, foi impulsionada no decorrer dos anos 70, com o período de implantação dos grandes programas baseados no seguro médico. Neste contexto, autores como Contandriopoulos (1997) elucidou sobre um modelo que consiste em realizar uma avaliação com base em três dimensões, sendo elas: os recursos empregados e sua organização (estrutura), os serviços ou os bens produzidos (processo), e os resultados obtidos, com critérios e normas.

No contexto dos programas sociais, a área de alimentação e nutrição ressente de uma prática avaliativa continuada. Segundo Henrique e colaboradores (2007), a implementação de programas de $A \& N$ não tem sido acompanhado, de forma sistemática, por um processo 
avaliativo e soma-se a este fato a necessidade de aprimorar os critérios e metodologias utilizadas.

Este estudo utilizou dados oriundos da Pesquisa "Avaliação da modalidade de repasse anual fundo a fundo para estruturação e implementação das ações de alimentação e nutrição no SUS de 2006 a 2013”, uma parceria entre a Universidade de Brasília, a Universidade Federal da Bahia e a Fundação Oswaldo Cruz (FIOCRUZ), financiado pela Coordenação Geral de Alimentação de Nutrição do Ministério da Saúde - CGAN/MS e Organização PanAmericana da Saúde - OPAS. Tem o objetivo de avaliar a utilização do repasse financeiro fundo a fundo para estruturação e implementação das ações de alimentação e nutrição no âmbito Estadual e Municipal com base na Política Nacional de Alimentação e Nutrição, destacando os avanços e as limitações e/ou fragilidades para sua execução.

\section{METODOLOGIA}

Trata-se de um estudo descritivo, de abordagem quali-quantitativa e enfoque muldimensional baseado na tríade estrutura-processo-resultado adaptado para ser empregado no contexto da avaliação de políticas em saúde (SANTOS, 2011).

O estudo original avaliou o repasse fundo a fundo para estruturação e implementação das ações de alimentação e nutrição em uma amostra de estados e municípios. Para isso, desenvolveu um modelo teórico-metodológico (estrutura, processo e resulta) tendo como pano de fundo o recurso específico, FAN.

A "estrutura" é condizente com os recursos humanos e financeiros, instrumentos e estrutura física, empregados com a finalidade de se atingir os resultados esperados (CONTRADIPOULOS, 1997). A dimensão "Processo" refere-se ao procedimento para atingir os objetivos propostos, verificará o acompanhamento da execução técnica e financeira por parte dos gestores; o conhecimento dos objetivos e marco legal do FAN e da PNAN pelos gestores; implementação do monitoramento e avaliação. "Resultados" estão relacionados à estruturação e implementação de ações de A\&N após recebimento do anual do FAN. Referese à tipologia e quantidade de ações executadas, o acompanhamento da execução técnica e financeira das ações, a implementação do monitoramento e avaliação das ações, projetos e programas; e na população-alvo.

Foi elaborada uma matriz apresentando um conjunto de questões que serviram de base para definir os dados e informações de interesse, contribuindo para a construção dos 
instrumentos de pesquisa (questionário auto aplicado, roteiro para o grupo focal e para entrevista com informantes chaves in loco).

Os questionários auto aplicados, específicos para gestores estaduais e municipais, continham questões objetivas e discursivas e um quadro com sentenças relacionadas às ações executadas por meio do FAN. Nesta última parte, os respondentes foram orientados a classificar se as sentenças foram realizadas (totalmente, parcialmente ou não realizada) e a relevância da ação/atividade para estruturação/implantação da PNAN (muito relevante/parcialmente relevante/não relevante). $\mathrm{O}$ roteiro dos grupos focais apresentava em média duas questões, o das entrevistas realizadas in loco apresentavam em média 14 questões. A metodologia foi desenvolvida para auxiliar no reconhecimento das ações implementadas e executadas pelo repasse do FAN.

O presente estudo baseou-se nas informações coletadas pelos questionários auto aplicados e nas dos grupos focais. Os questionários auto aplicados foram respondidos pelos responsáveis técnicos da área de alimentação e nutrição (RTAN) dos estados e dos municípios que trabalhavam diretamente com o recurso. Com relação ao grupo focal, os RTAN's foram agrupados conforme sua esfera de atuação: estados, capitais e municípios do interior. Os grupos focais eram formados por cerca de 10 participantes.

Os dados foram coletados durante o XII Encontro Nacional de Rede de Alimentação e Nutrição do SUS, maio 2013, em Brasília-DF, após aprovação pelo Comitê de Ética em Pesquisa da Faculdade Ciências da Saúde da Universidade de Brasília, sob o número do Parecer 273.515/ 2013.

As questões abordadas e as respostas obtidas pela aplicação dos questionários foram digitadas no software StatisticalPackage for Social Science (SPSS) ${ }^{\circledR}$, para a realização da análise descritiva. As questões dos municípios do interior e das capitais foram analisadas em conjunto por serem referentes às responsabilidades municipais como um todo, não apresentando distinção quando referenciadas na PNAN.

As gravações realizadas nos grupos focais foram transcritas e seu conteúdo organizado dentro dos aspectos que eles contemplavam (estrutura, processo e resultado) de maneira a se adequar ao objetivo deste estudo, destacando as possibilidades e as limitações para a utilização do recurso conforme as diretrizes PNAN. 


\section{RESULTADOS}

Participaram da coleta de dados 83 entrevistados, sendo 61 RTAN municipais e 22 estaduais. Os respondentes municipais eram gestores de capitais (16 entrevistados) e cidades do interior (45 entrevistados) de diferentes estados e regiões do país. Foram realizados os três grupos focais previstos, compostos por RTANs estaduais, das capitais e dos municípios do interior.

As informações e os dados foram sistematizados contemplando a tríade: estrutura, processo e resultado. A dimensão "estrutura", para esta análise, focou nos recursos humanos, as responsabilidades decisórias e gerenciais; tempo de atuação como gestor de alimentação e nutrição, RTAN formalmente indicado.

Considerando o tempo de atuação na gestão como RTAN, observou-se que $86,4 \%$ dos gestores estaduais, $62,5 \%$ dos gestores de capitais e 75,6\% do interior estavam na gerência há mais de um ano, com mediana de tempo de seis, cinco e quatro anos, respectivamente. A respeito da indicação formal para ocupação do cargo, a maioria dos RTAN (60\%) informou ter sido formalmente indicado para ocupação do cargo.

Com relação ao processo de repasse financeiro, a quase totalidade $(98,3 \%)$ dos RTAN's das três esferas referiram que o recurso é repassado de maneira regular. Mais de $60 \%$ destes gestores avaliaram que esta modalidade de repasse para apoio as ações de alimentação e nutrição é muito boa. No entanto, ao observar o percentual (aproximado) do orçamento executado no ano de 2012, verificou um baixo desempenho na utilização do recurso, com uma menor execução dos municípios do interior, conforme mostra a figura 1 . 


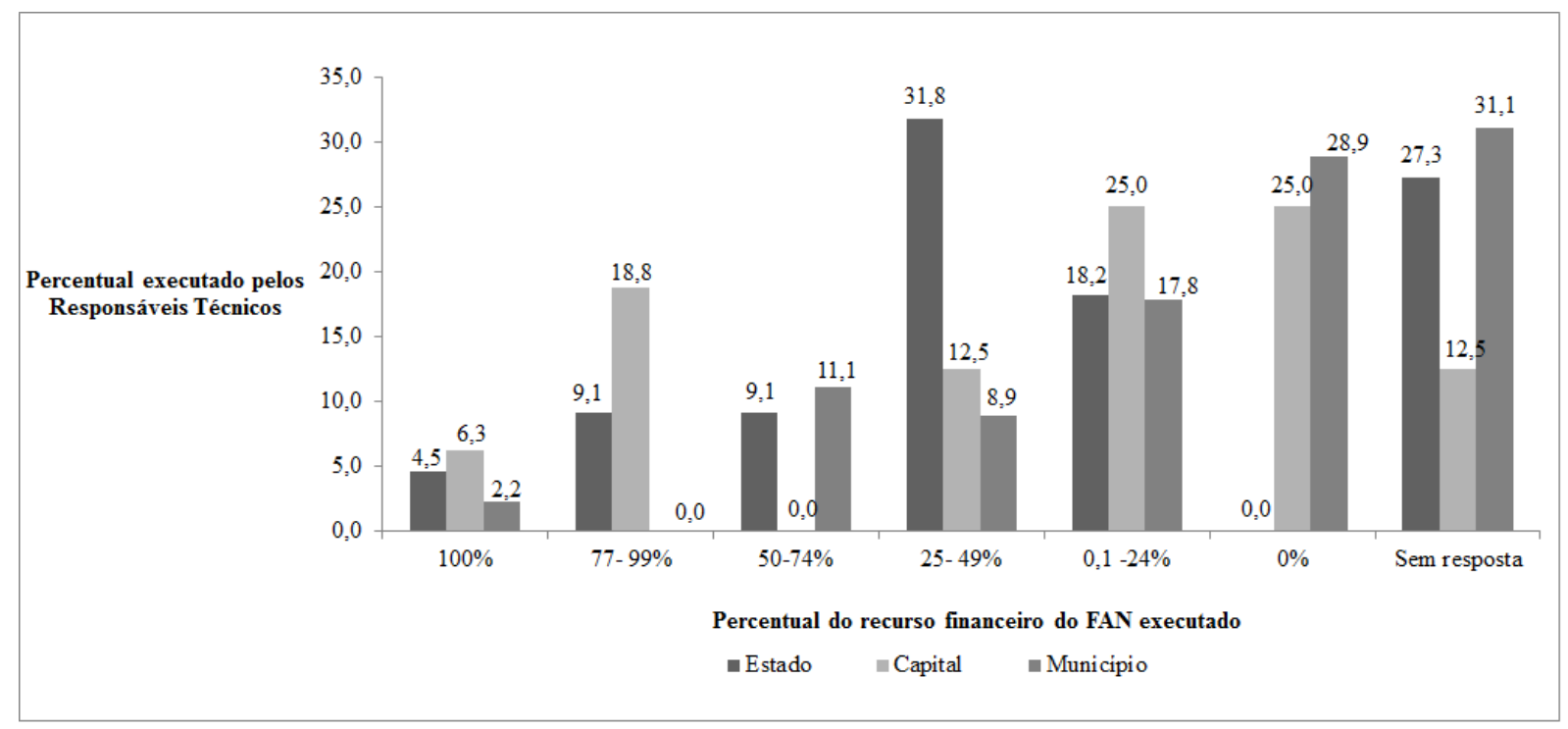

Figura 1 Distribuição do percentual (\%) do recurso financeiro do FAN para estruturação e implementação das ações de Alimentação e Nutrição (FAN) executados pelos Responsáveis Técnicos, Brasil 2012.

$\mathrm{O}$ quadro 1 destaca a importância e as oportunidades que o recurso financeiro promove para as ações de alimentação e nutrição, como também seus limites.

Quadro 1. Importância, oportunidades e limites do repasse de recursos para estruturação e implementação das ações de Alimentação e Nutrição (FAN), segundo Responsáveis Técnicos de Alimentação e Nutrição por esfera de atuação. Brasil 2012

\begin{tabular}{|l|l|l|l|}
\hline Categoria & $\begin{array}{l}\text { Grupo focal Município } \\
\text { interior }\end{array}$ & $\begin{array}{l}\text { Grupo focal Município } \\
\text { Capital }\end{array}$ & $\begin{array}{l}\text { Grupo focal } \\
\text { Estadual }\end{array}$ \\
\hline $\begin{array}{l}\text { Quanto à } \\
\text { importância da } \\
\text { modalidade pelo } \\
\text { repasse do FAN }\end{array}$ & $\begin{array}{l}\text { Relevância para o } \\
\text { fortalecimento da área } \rightarrow \\
\text { maior visibilidade dispor de } \\
\text { algum recurso para atuar, } \\
\text { valorização do profissional } \\
\text { da Nutrição }\end{array}$ & $\begin{array}{l}\text { Maior visibilidade para } \\
\text { area técnica e } \\
\text { potencializa a execução } \\
\text { das ações de alimentação } \\
\text { e nutrição. }\end{array}$ & $\begin{array}{l}\text { O FAN dá visibilidade à } \\
\text { PNAN. }\end{array}$ \\
\hline $\begin{array}{l}\text { Oportunidades } \\
\text { criadas pelo FAN }\end{array}$ & $\begin{array}{l}\text { Experiência de articulação } \\
\text { entre setores da secretaria e } \\
\text { inter secretarias. }\end{array}$ & $\begin{array}{l}\text { Colabora para que as } \\
\text { diretrizes da PNAN } \\
\text { sejam colocadas em } \\
\text { prática. }\end{array}$ & $\begin{array}{l}\text { Mobiliza para diálogo e ação } \\
\text { com outros setores das } \\
\text { Secretarias. }\end{array}$ \\
\hline $\begin{array}{l}\text { Limitações da } \\
\text { execução do FAN }\end{array}$ & $\begin{array}{l}\text { Número reduzido de } \\
\text { nutricionistas, excesso de } \\
\text { recursocia, humanos no } \\
\text { executivo municipal, } \\
\text { interferência de interesses } \\
\text { político-partidários. }\end{array}$ & $\begin{array}{l}\text { Burocracia, organização } \\
\text { institucional. }\end{array}$ & $\begin{array}{l}\text { Excesso de portarias, recurso } \\
\text { invisível no orçamento das } \\
\text { Secretarias, fragilidade na } \\
\text { aplicação e consequente } \\
\text { "perda de poder". }\end{array}$ \\
\hline
\end{tabular}

Fonte: Trabalho de campo. 
$\mathrm{Na}$ avaliação da dimensão processo, mais de $60 \%$ dos entrevistados referiram elaboração de plano específico para a área de alimentação e nutrição. Com relação aos aspectos referentes ao monitoramento e avaliação, o estabelecimento de metas e indicadores, mais de $50 \%$ dos gestores afirmaram que metas e indicadores são estabelecidos para acompanhamento da implementação do FAN.

No caso da dimensão do resultado, a metodologia considera a análise das ações, projetos e programas executados, e a implementação do monitoramento e avaliação. Foram também analisadas as modificações na estruturação e implementação de ações de Alimentação e Nutrição após recebimento do repasse anual do FAN. Para tanto no quadro 2 foram organizadas, com base na PNAN, o percentual das principais ações / atividades de alimentação e nutrição que foram financiadas pelo FAN em 2012, segundo os entrevistados. Foi observado que $39 \%$ dos gestores municipais não responderam à questão, dessa forma a análise neste caso se fez sem separar por esfera de atuação e todos os representantes dos estados responderam ao questionamento (22 gestores-100\%).

Quadro 2:Percentual de ações/ atividades de alimentação e nutrição que foram referidas como financiadas e executadas com recursos do repasse para estruturação e implementação das ações de Alimentação e Nutrição (FAN), segundo gestores municipais e estaduais.Brasil 2012

\begin{tabular}{|l|l|l|}
\hline Ações/Atividades realizadas & Municípios (\%) & Estado (\%) \\
\hline $\begin{array}{l}\text { Incentivo à prática do aleitamento materno e à introdução } \\
\text { adequada da alimentação complementar. }\end{array}$ & 31,5 & 40 \\
\hline $\begin{array}{l}\text { Promoção de práticas alimentares e estilos de vida saudáveis, com } \\
\text { a elaboração de materiais educativos e educação alimentar e } \\
\text { nutricional. }\end{array}$ & 71 & 45 \\
\hline $\begin{array}{l}\text { Desenvolvimento e capacitação de recursos humanos } \\
\text { Promoção de mecanismos de consolidação do Sistema de } \\
\text { Vigilância Alimentar e Nutricional (Sisvan), por meio de } \\
\text { qualificações e compra de instrumentos. }\end{array}$ & 47 & 40,8 \\
\hline $\begin{array}{l}\text { Atividades para a prevenção de deficiências de micronutrientes } \\
\text { (Ferro, vitamina A). }\end{array}$ & 2 & 9 \\
\hline $\begin{array}{l}\text { Realização/participação de eventos (congressos, seminários, } \\
\text { simpósios, oficinas) }\end{array}$ & 42,1 & 13 \\
\hline Compra de material de consumo e permanente. & 13,1 & 50 \\
\hline $\begin{array}{l}\text { Chamadas nutricionais e acompanhamento do Programa Bolsa } \\
\text { Família. }\end{array}$ & 18 & 13 \\
\hline $\begin{array}{l}\text { Reuniões técnicas para planejamento estratégico, monitoramento } \\
\text { das ações com representantes do governo federal e municipais. }\end{array}$ & Não informaram & 40 \\
\hline Diárias gastas com reuniões, congressos, cursos fora da área. & Não informaram & 18 \\
\hline Monitoramento e avaliação das ações nos municípios. & Não informaram & 13,6 \\
\hline
\end{tabular}


No quadro 2, pode-se observar que $71 \%$ dos gestores municipais referem que ações de Promoção de práticas alimentares e estilos de vida saudáveis, com a elaboração de materiais educativos e educação alimentar e nutricional são executadas com o recurso do FAN. Em contrapartida, ações relacionadas às atividades para a prevenção de deficiências de micronutrientes (Ferro, vitamina A) são executadas somente por $2 \%$ dos respondentes. É importante elucidar que estes programas fazem parte das ações prioritárias do setor saúde na Ação Brasil Carinhoso, sendo financiados com outra fonte de recurso além do FAN.

Com relação às ações referidas pelos gestores estaduais, 50\% dos gestores relatam que o recurso é gasto com a realização/participação de eventos (congressos, seminários, simpósios, oficinas). No entanto, $9 \%$ relatam que gasta com a promoção de mecanismos de consolidação do Sistema de Vigilância Alimentar e Nutricional (Sisvan), por meio de qualificações e compra de instrumentos. A qualificação e participação de recursos humanos em ações destinadas a educação em saúde contribui para a organização do processo de trabalho, no entanto, faz-se necessário o maior estimulo para a execução das ações, de maneira a torná-las mais estruturantes.

Corroborando com os dados relacionados às ações/atividades financiadas pelo FAN que foram sistematizadas no quadro acima, serão apresentados nas figuras a seguir os resultados referentes à realização e a opinião sobre a relevância de ações relacionadas ao FAN e a PNAN. Esta questão foi respondida por 93\% (57) dos gestores municipais da amostra e todos os gestores estaduais.

A figura 2 representa as responsabilidades do gestor estadual com a execução e a relevância da ação/atividade para a estruturação/implantação da PNAN na Unidade Federativa. Com relação às ações relacionadas à PNAN, os valores de maior execução foram os relacionados ao "Monitoramento das ações do programa de suplementação com vitamina A" e "Monitoramento das metas do programa de suplementação com vitamina A", seguido pela "Elaboração de material técnicos para profissionais de saúde elou população" e "Promoção da implementação de estratégia de promoção da alimentação complementar saudável para crianças até 2 anos”, com 59,1\%, 45,5\% e 40,9\%, respectivamente. Estas ações foram consideradas como muito relevante para mais de $80 \%$ dos gestores participantes da pesquisa. Em contrapartida, somente $9 \%$ dos gestores realizam a "Elaboração $e$ divulgação de publicações sobre a situação da A\&N em âmbito estadual”, mesmo considerando como muito relevante.

Às ações do estado em apoio aos municípios para implementação das ações de alimentação e nutrição também presentes na figura 2, retrataram que a "Capacitação dos 
municípios para implantação das ações de $A \& N$ " obteve o maior percentual de realização, com quase $60 \%$ das respostas, seguida por "Apoio aos municípios para o monitoramento do cumprimento das metas de A\&N do Pacto pela Saúde" e "Auxílio aos municípios na implementação da VAN (Vigilância Alimentar e Nutricional)" com 54,5\% das respostas de plena execução cada.

Sobre o recurso específico destinado a alimentação e nutrição, a análise da figura 2 permitiu observar que o item relacionado ao repasse, "Apoio aos municípios na realização de estudos de linha de base antes da implantação do FAN', apresentou o menor percentual de plena execução, segundo os respondentes (abaixo de 5\%) e também o menor número de RTAN estaduais considerando relevante. O "Apoio aos municípios na realização de pesquisas locais de avaliação do impacto das ações de A\&N financiadas pelo FAN”, 95\% dos RTAN estaduais declarou considerar muito relevante ação, no entanto, o percentual de realização foi de aproximadamente10\%. A destinação do FAN para atividades relacionadas à participação de RTAN's estaduais em eventos técnicos/científicos ou em programas de capacitação de interesse para atuação em A\&N teve execução acima de $50 \%$ e quase a totalidade dos gestores a avaliam como muito relevante. 


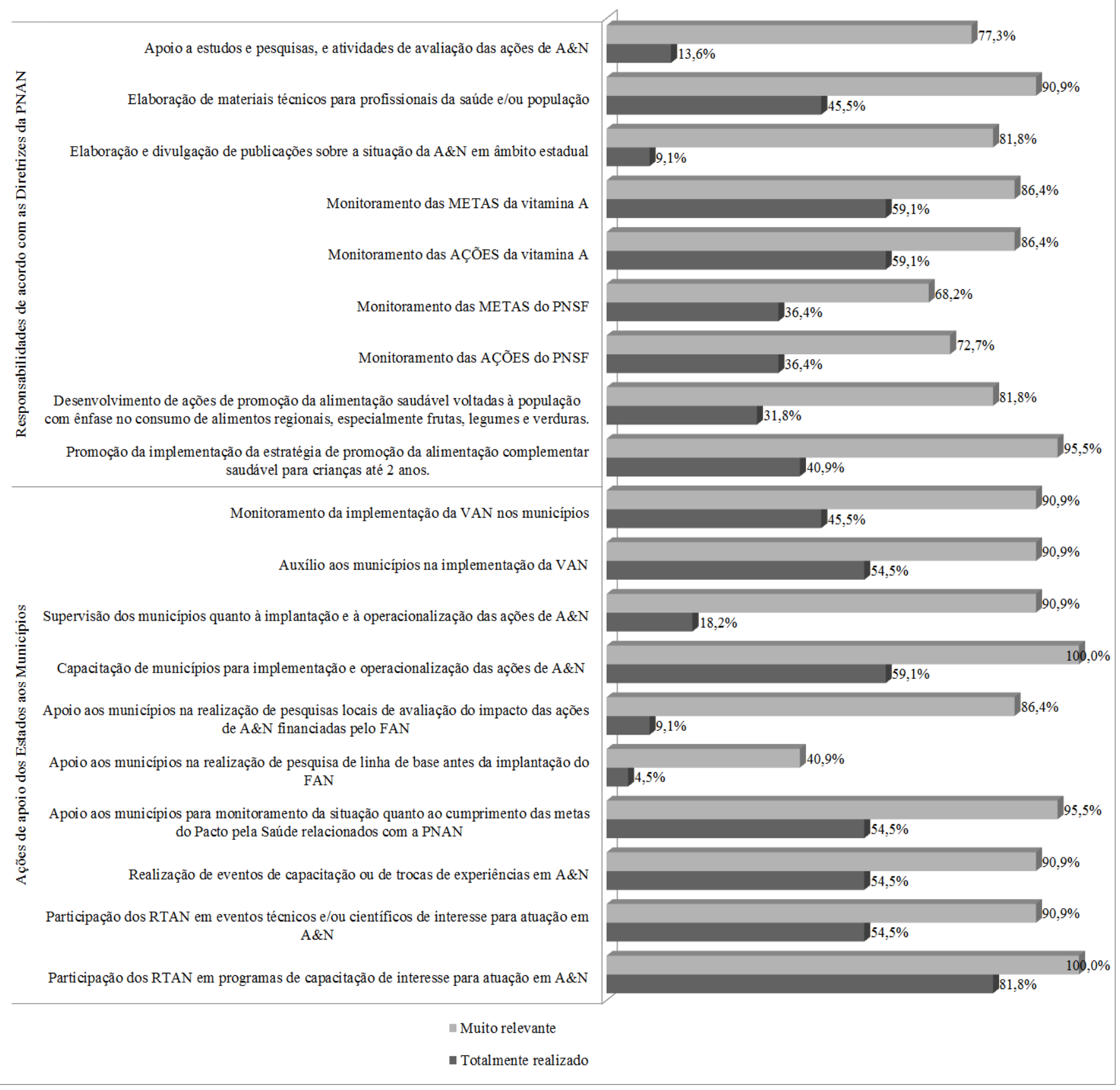

Figura 2. Percentual das ações Estaduais referentes à execução e relevância para estruturação/ implementação das ações, Brasil 2012.

A figura 3 apresenta as ações/atividades dos municípios organizadas em categorias afins. A ação com maior relato de execução com o recurso do FAN foi: "Participação dos técnicos da área em eventos técnicos ou científicos de interesse para atuação em A\&N", com 50,9\%, seguida de perto por "Elaboração de materiais técnicos para os profissionais de 
saúde elou para a população" com $42 \%$ de respondentes indicando plena execução. No que concerne a relevância, os achados mostraram que mais de $70 \%$ dos gestores consideram muito relevantes.

No que se refere à implementação das ações previstas no Pacto pela Saúde pelos gestores municípios, foi observado que o "Acompanhamento da situação alimentar $e$ nutricional dos titulares de direito do BF por meio do SISVAN" apresentou maior percentual de execução, com 42,1\% das respostas, seguida de "Acompanhamento da situação alimentar e nutricional da população por meio do SISVAN" e "Registro das informações do acompanhamento do PNSF" que, juntos, somam um valor superior a $60 \%$ de ações referidas como totalmente realizada. É importante destacar que mesmo uma baixa execução, valores inferiores a $50 \%$, em torno de $80 \%$ dos RTAN municipais consideravam estas ações muito relevantes.

Os resultados correspondentes às diretrizes da PNAN demonstraram que a maior execução relatada pelos respondentes foi a "Apoio técnico às equipes das ESF para realização das ações de A\&N" (42\%), seguida por "Apoio técnico ao Núcleo de Apoio à Saúde da Família para realização das ações de $A \& N$ " e "Apoio técnico às equipes da $A B$ do PACS para realização das ações de A\&N" (ambos aproximadamente 34\% de relatos de plena realização), e com mais de $75 \%$ dos gestores avaliando como muito relevante. A "Organização da Rede de Atenção de A\&N no território municipal" apresentou baixa execução pelos municípios, somente $3,5 \%$ realizam totalmente esta ação, entretanto, $86 \%$ dos gestores consideram muito relevante. 


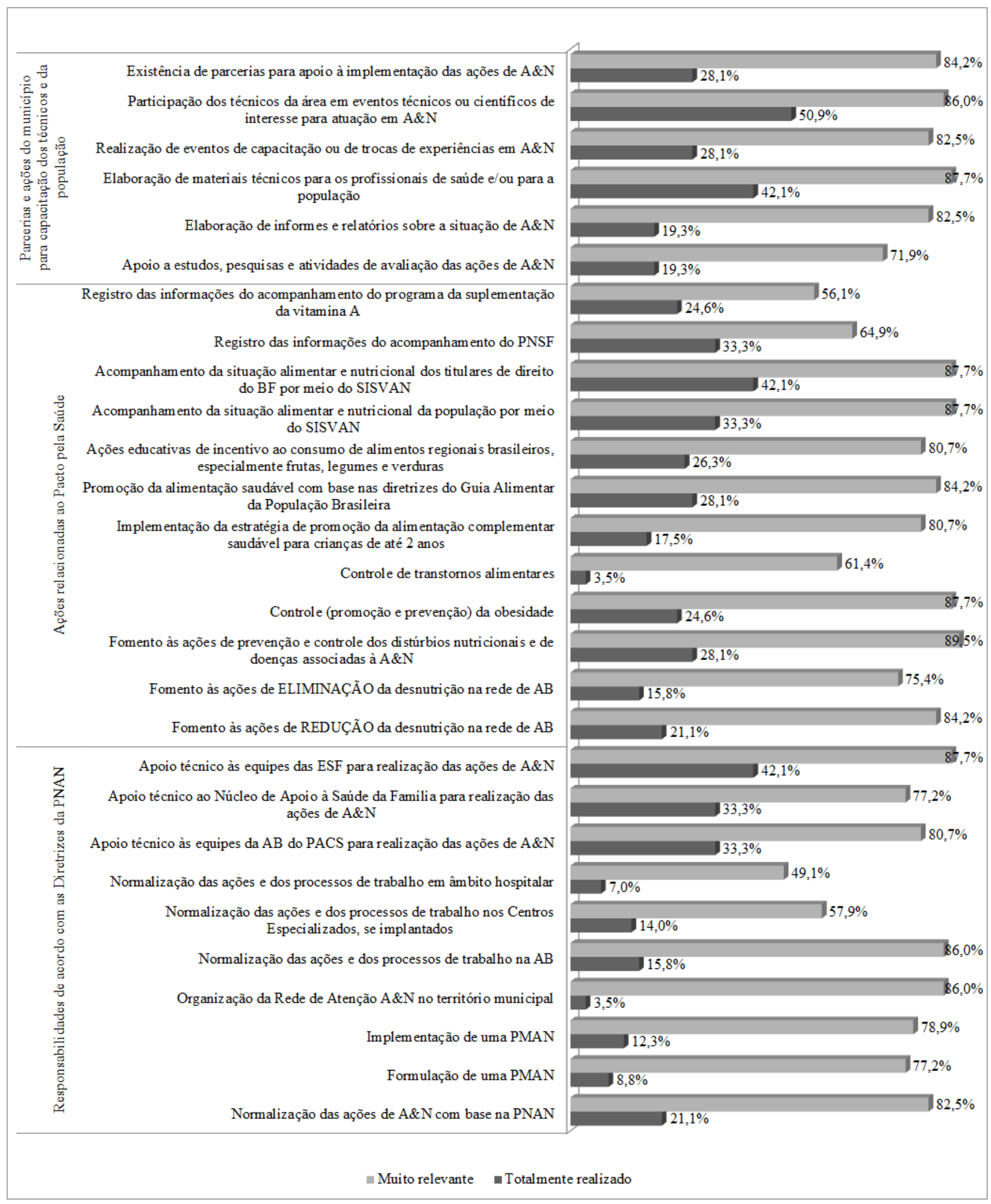

Figura 3 Percentual das ações Municipais referentes à execução e relevância para estruturação/ implementação das ações. Brasil 2012 


\section{DISCUSSÃO}

O financiamento é o principal colaborador para a implantação de programas/atividades no âmbito dos estados e municípios (SILVA, 2010). Foi observado neste estudo que as três esferas de gestão afirmaram que o recurso é repassado com regularidade e avaliam positivamente o repasse. Entretanto, principalmente os municípios apresentaram uma baixa utilização do recurso. Este achado vai de encontro com o que se preconiza o processo de descentralização que tem o objetivo, segundo Silva (2010), de favorecer que os municípios assumam uma grande parte das responsabilidades previstas no fornecimento de serviços de saúde. Assim, a própria Política de Alimentação e Nutrição publicada no final dos anos 90 e posteriormente sua versão atualizada (2011) enfatiza a importância do apoio das outras esferas governamentais para a implantação e execução das ações a nível municipal.

As políticas desenvolvidas no Brasil, as quais apresentam como objeto as dimensões relacionadas à alimentação e nutrição estão ganhando espaço na agenda das políticas públicas. Neste contexto, é possível verificar elementos que favorecem a implantação e aqueles que dificultam a sua concretização. Os resultados da análise dos grupos focais demonstraram como pontos positivos o fortalecimento da área, valorização do profissional da nutrição e maior visibilidade da PNAN. Ainda com relação às possibilidades geradas, estão às articulações entre setores da secretaria e inter secretarias, e a intersetorialidade. Corroborando com estes achados, Recine e Vasconcellos (2011) destacam que "o fortalecimento e a institucionalização da área e das ações de alimentação e nutrição no interior do SUS”, bem como o financiamento adequado para a implementação de suas diretrizes são aspectos que contribuem para recuperar os eixos da PNAN e incentivar a construção de diálogos intra e intersetoriais (RECINE E VASCONCELOS, 2011). Concernentes aos limites destacam-se a falta de profissionais nutricionistas, a rotatividade de recursos humanos, a burocracia, a forma da organização institucional, excesso de portarias, recurso invisível no orçamento das secretarias e fragilidade na aplicação.

Como citado anteriormente pelos participantes dos grupos focais, a rotatividade de recursos humanos está entre os fatores limitantes para a realização das ações. Na análise do tempo e a indicação para ocupar o cargo de responsável técnico de alimentação e nutrição, dados dos questionários, pode-se observar que a permanência maior no cargo é, principalmente, dos gestores estaduais. Estes estão há aproximadamente seis anos na gestão o que pode inferir como um resultado positivo estabelecendo como parâmetro o tempo de 
mandato de quatro anos. Entretanto, fazendo uma análise dos dois achados (grupos focais e respostas dos questionários) não se sabe se ao relatar a alta rotatividade de recursos humanos se refere a toda equipe, somente a figura do responsável técnico e outras variáveis que não foram verificadas como a reeleição, que interfere diretamente na continuidade das ações. Foi verificada a indicação formal como meio de ocupação do cargo, mas não verificou o vínculo empregatício. Aspectos relativos aos recursos humanos são destaques no âmbito da organização da gestão dos serviços de saúde no Sistema Único de Saúde (SUS). É notório que a maior permanência para a execução das atribuições de um cargo favorece a continuidade das ações, amplia a responsabilidade social e o compromisso político no aperfeiçoamento dos serviços. A rotatividade dos profissionais, seja devido ao contexto político ou a forma de contratação, é um fator que prejudica a sustentabilidade das ações (JUNQUEIRA, 2010).

$\mathrm{O}$ resultado referente a elaboração de um plano específico para $\mathrm{A} \& \mathrm{~N}$, com estabelecimento de metas e indicadores para acompanhamento da implementação do FAN comunica com a PNAN 2011 que refere que "o aperfeiçoamento dos processos de planejamento e avaliação das ações deve ser estimulado para subsidiar a pactuação e a incorporação das ações nos instrumentos de gestão" (BRASIL, 2012). Concluindo-se que a prática efetiva de planejamento, avaliação e monitoramento são imprescindíveis nas políticas públicas.

$\mathrm{Na}$ análise específica das ações/atividades de alimentação e nutrição que foram financiadas pelo FAN em 2012, as ações de promoção de práticas alimentares e estilos de vida saudáveis, com a construção de materiais educativos e educação alimentar e nutricional foram citadas como realizados pelos gestores. A realização destas atividades pelas três esferas mostra em plena concordância com a PNAN, uma vez que estas ações contribuem para o alcance do propósito da política e consequente melhora das condições de alimentação, nutrição e saúde da população brasileira (BRASIL, 2012).

As ações referentes a cooperação e apoio técnico dos Estados aos municípios vai ao encontro das diretrizes e responsabilidades definidas na PNAN, elucidando que as Secretarias Estaduais de Saúde e do Distrito Federal devem "Prestar assessoria técnica e apoio institucional aos municípios e às regionais de saúde no processo de gestão, planejamento, execução, monitoramento e avaliação de programas e ações de alimentação e nutrição" (BRASIL, 2012).

No contexto da análise outras responsabilidades do gestor estadual foram abordadas quanto à execução das ações e a relevância que os responsáveis técnicos de alimentação e nutrição atribuíam. Foi verificado que as ações mais realizadas pelos gestores estaduais são 
aquelas com maior incentivo pelo governo federal, podem-se referir destes resultados que o fato de serem programas específicos definidos pelo governo federal (Vitamina A e Promoção da Alimentação complementar saudável) com recursos destinados para este fim os RTAN's os considera muito relevantes, favorecendo a articulação e coordenação dos sistemas regionais e sua plena execução.

A “Capacitação dos municípios para implantação das ações de A\&N", "Apoio aos municípios para o monitoramento do cumprimento das metas de A\&N do Pacto pela Saúde" e "Auxílio aos municípios na implementação da VAN (Vigilância Alimentar e Nutricional)", apresentaram execução acima de $50 \%$. Este resultado pode levar ao entendimento que os gestores apresentavam uma preocupação em incentivar maior conhecimento para favorecer a implementação das ações nos municípios. Em contrapartida, ações referentes à execução do recurso apresentaram uma baixa realização, “Apoio aos municípios na realização de estudos de linha de base antes da implantação do FAN" e "Apoio aos municípios na realização de pesquisas locais de avaliação do impacto das ações de A\&N financiadas pelo FAN”, mesmo considerado muito relevante. É importante destacar que o financiamento as linhas de pesquisas e estudos em áreas afins pode ser observado desde o ano de 2004 por meio de editais, específicos por um período, lançados pelo Ministério da Saúde em conjunto com o Conselho Nacional de Desenvolvimento Científico e Tecnológico (CNPq), este processo favorece um diálogo intersetorial e mais abrangente, oportunizando um aprimoramento da nutrição no âmbito das políticas públicas brasileiras (RECINE E VASCONCELOS, 2011). Assim, a não execução plena de estudos de linha de base vai de encontro à organização das ações de nutrição nos serviços.

No que diz respeito às competências dos municípios, a execução e a relevância que os RTAN's municipais atribuíam para a implantação das ações de alimentação e nutrição verificou-se que a qualificação da força de trabalho está entre as mais executadas. Ainda com relação à qualificação de recursos humanos, os respondentes ao serem questionados sobre a participação em eventos técnicos ou científicos para atuação em A\&N apresentaram uma execução um pouco superior a 50\% e consideram muito relevante. A elaboração de materiais tanto para os profissionais quanto para a população também foi considerada muito relevante, mas com baixa execução. É importante destacar, no que tange a educação em saúde, que a qualificação dos profissionais é estratégica para a melhoria do processo de trabalho em saúde e para a organização da formação da força (BRASIL, 2012).

O Pacto pela Saúde reúne reformas institucionais do SUS pactuadas entre as três esferas de gestão (União, Estados e Municípios) e também redefine as responsabilidades de 
cada gestor de acordo com as necessidades de saúde da população. Em concordância aos princípios e diretrizes do pacto encontra-se a Política Nacional de Atenção Básica que traz no escopo do quadro de metas das ações em áreas estratégicas temas referentes aos transtornos alimentares e a eliminação da desnutrição infantil na Atenção Básica (BRASIL, 2006).

Os participantes desta pesquisa referiram executar as ações citadas anteriormente, no entanto, com percentuais menores que $20 \%$, mesmo $70 \%$ atribuindo como muito relevante. Os baixos níveis de execução relatados podem ser atribuídos ao contexto epidemiológico, as doenças relacionadas às carências nutricionais (desnutrição proteico-calórica, hipovitaminose A, pelagra, anemia ferropriva, bócio etc.), mesmo ainda existentes apresentam uma menor prevalência quando comparadas as relacionadas ao excesso nutricional (obesidade, diabetes, dislipidemias, hipertensão, certos tipos de câncer, etc.) (VASCONCELOS, 2011).

Ainda com relação às questões do Pacto pela saúde a maioria das ações apresentaram execução inferiores a $50 \%$, os maiores foram os relacionados ao SISVAN, ao Programa Nacional da Suplementação do Ferro que é um programa específico do governo federal que combinado com a suplementação da vitamina A são iniciativas de promoção da saúde da criança.

É interessante problematizar que o FAN não é o único recurso destinado para ações de alimentação e nutrição, principalmente, na Atenção Básica à saúde. O Programa Nacional do Ferro, com a descentralização da aquisição dos suplementos, recebe recurso do componente Básico da Assistência Farmacêutica para a suplementação das crianças de seis a 24 meses, gestantes e puérperas (BRASIL, 2012).

No que concerne às ações/atividades relacionadas às diretrizes da PNAN verificou-se que todas as ações de alimentação e nutrição vinculadas à Estratégia Saúde da Família, ao Núcleo de Apoio à saúde da Família e às Equipes do Programa dos Agentes Comunitários de Saúde, ou seja, à Atenção Básica à Saúde, tiveram maiores execução segundo os entrevistados. A execução das ações no âmbito da Atenção Básica conta com outros incentivos financeiros repassados pelo Ministério da Saúde, entre eles o Piso de Atenção Básica (PAB) e a Agenda de Intensificação da Atenção Nutricional à Desnutrição Infantil (ANDI), o que pode contribuir para o custeio de ações de alimentação e nutrição nos municípios.

Ratificando o exposto anteriormente sobre a execução de ações no contexto da Atenção Básica. Castro (2010) refere no seu trabalho que a priorização da Atenção Primária à saúde pelo gestor federal tem como objetivo a reorganização do sistema, com mudança no modelo de atenção com vistas a consolidar os princípios de Universalidade e Integralidade do 
SUS. Ainda no estudo, a autora cita trabalhos que enfatizam a importância dos cuidados na atenção primária a saúde e como eles são mais efetivos e alcançam maior efetividade, eficiência e equidade.

\section{CONCLUSÃO}

A Política Nacional de Alimentação e Nutrição, desde sua publicação em 1999, tem como propósito a concretização do direito humano a alimentação e nutrição adequados para melhorar a saúde da população brasileira. Recursos específicos destinados a área de alimentação e nutrição tem como objetivo contribuir para a estruturação e implementação das ações de alimentação e nutrição nas diferentes esferas de governo, atendendo a finalidade da política e a fortalecendo.

Este estudo avaliou a utilização do recurso orçamentário e as ações de alimentação e nutrição no âmbito de Secretarias Estaduais e Municipais de Saúde e a correspondência das ações/atividades com as diretrizes da PNAN, adotando a tríade estrutura-processo-resultado.

O trabalho evidenciou que a adoção de um recurso específico para a área de alimentação e nutrição contribui para uma maior visibilidade e favorece a discussão da temática dentro da organização governamental. No entanto, algumas dificuldades são encontradas para sua plena execução. Na dimensão "estrutura" pode-se observar que os gestores permanecem no cargo mais de quatro anos, no entanto, não se verificou se a maior permanência do RTAN no cargo favorece um maior tempo com uma equipe de trabalho constituída, uma vez que nos grupos focais destacaram a falta de profissionais e a rotatividade como fatores limitantes, e a mudança na organização administrativa devido o período eleitoral, prejudicando muitas vezes a continuidade das ações e impactando na utilização do recurso.

Na dimensão "processo" foi observado, como fator positivo, à regularidade do repasse e o quanto isso colabora para o planejamento, os estabelecimentos de metas e indicadores para execução das ações. Neste contexto, pode-se concluir que consideram a experiência e o conhecimento para implementação do plano, frente ao projeto estabelecido, sendo um ponto positivo.

Os "resultados" demonstraram que muitas ações com base na PNAN apresentam uma boa execução e que as diferentes esferas procuram realizar as responsabilidades descritas na política. Entretanto, cabe ressaltar que mesmo com o aumento das responsabilidades dos municípios, proporcionada pela autonomia político-administrativa deliberada na Constituição 
de 88 de assumirem papel decisório nas ações de saúde em seu território, muitos gestores não conseguiram alcançar o bom desempenho na execução.

Torna-se importante a existência do repasse visto que ele favorece o desenvolvimento de ações mais próximas das necessidades locais. Os resultados permitem avaliar positivamente a experiência estadual e municipal com o recurso específico, apesar da reconhecida necessidade de melhorar a utilização, fazendo que ele seja utilizado na sua totalidade com vistas a aumentar o número de ações de natureza estrutural. Assim, é notório que ainda há uma importante trajetória a ser empreendida para que o repasse traduza de forma plena os argumentos que justificam a sua existência.

\section{REFERÊNCIAS}

BRASIL. Ministério da Saúde. Secretaria de Atenção à Saúde. Departamento de Atenção Básica. Política nacional de alimentação e nutrição. 2. ed. rev. Brasília: Ministério da Saúde, 2003.48 p. - (Série B. Textos Básicos de Saúde).

Ministério da Saúde. Textos de opinião: temas estratégicos para a política nacional de alimentação e nutrição (PNAN) / Ação Brasileira pelaNutrição e Direitos Humanos (ABRAND H). Ministério da Saúde. Brasília: Organização Pan Americana de Saude (OPAS), 2011.196 p.

Ministério da Saúde. Portaria $n^{\circ} 1.357$, de 23 de junho de 2006. Define estrutura as ações de Alimentação e Nutrição por parte das Secretarias Estaduais e Municipais de Saúde das capitais com base na Política Nacional de Alimentação e Nutrição e normatiza a utilização do saldo restante dos recursos financeiros referentes ao Incentivo de Combate a Carências Nutricionais (ICCN) nos municípios qualificados. Diário Oficial da União, Brasília, DF, Poder Executivo, 23 de dezembro de 2006.

Ministério da Saúde. Portaria n ${ }^{\circ} 1.738$, de 19 de agosto de 2013. Estabelece incentivo de custeio para estruturação e implementação de ações de alimentação e nutrição pelas Secretarias Estaduais e Municipais de Saúde com base na Política Nacional de Alimentação e Nutrição. DOU $N^{o} 160$, página 22, 20 de agosto de 2013a.

. Ministério da Saúde. Secretaria de Atenção à Saúde. Departamento de Atenção Básica. Política nacional de atenção básica. Brasília : Ministério da Saúde, 2006. 60 p. (Série A. Normas e Manuais Técnicos) (Série Pactos pela Saúde 2006, v. 4). Disponível em: http://conselho.saude.gov.br/webpacto/text_atencao.pdf . Acesso em; 16 maio 2015.

Ministério da Saúde. Secretaria de Atenção à Saúde. Departamento de Atenção Básica. HIV/Aids, hepatites e outras DST.Brasília : Ministério da Saúde, 2006. 197 p. il. Disponível em: file:///C:/Users/Camila/Downloads/Caderno_de_atencao_basica__HIVAids_hepatites_e_outras_DSTs.pdf. Acesso em: 6 maio 2015 
- Ministério da Saúde. Secretaria de Atenção à Saúde. Departamento de Atenção Básica. Programa Nacional de Suplementação de Ferro : Ministério da Saúde. Disponível em: http://dab.saude.gov.br/portaldab/pnsf.php . Acesso em: 16 set 2015.

CAMPOS, F. C. C.; FARIA, H. P.; SANTOS, M. A. Planejamento e Avaliação de Ações em saúde. 2 ed. Belo Horizonte: Coopmed, 2010. 114p. NESCON/UFMG - Curso de Especialização em Atenção Básica em Saúde da Família. Disponível em: https://www.nescon.medicina.ufmg.br/biblioteca/imagem/0273.pdf . Acesso em: 11 maio 2015.

CARVALHO, G. O financiamento federal de ações e serviços de alimentação e nutriçãoem saúde. In: Textos de opinião: temas estratégicos para a política nacional de alimentação e nutrição (PNAN) / Ação Brasileira pelaNutrição e Direitos Humanos (ABRAND H). Ministério da Saúde. -Brasília: Organização Pan Americana de Saúde (OPAS), 2011.196 p.

CASTRO, A. L. B. de; MACHADO, C. V. A política de atenção primária à saúde no Brasil: notas sobre a regulação e o financiamento federal. Cad. Saúde Pública, Rio de Janeiro, v. 26, n. 4, p. 693-705, Apr. $2010 \quad$ Disponível em: <http://www.scielo.br/scielo.php?script=sci_arttext\&pid=S0102-

311X2010000400012\&lng=en\&nrm=iso>. Acesso em: 15 Jun 2015.

CONTANDRIOPOULOS, A.P. et al. Avaliação na área da saúde: Conceitos e Métodos. In: HARTZ, Z. M. A. (Org.).Avaliação em saúde: dos modelos conceituais à prática na análise da implantação de programas. Rio de Janeiro: FIOCRUZ, 1997.

JUNQUEIRA, T. da S. et al. As relações laborais no âmbito da municipalização da gestão em saúde e os dilemas da relação expansão/precarização do trabalho no contexto do SUS. Cad. Saúde Pública, v. 26, n. 5, p. 918-928,2010. Disponível em:<http://www.scielo.br/scielo.php?script=sci_arttext\&pid=S0102311X2010000500014\&lng=en\&nrm=iso>. Acesso em:05 Mai 2015.

RECINE, E.; VASCONCELLOS, A. B. Políticas nacionais e o campo da Alimentação e Nutrição em Saúde Coletiva: cenário atual. Ciência saúde coletiva, v. 16, n. 1, p. 73-79, 2011. Disponível em: $<\mathrm{http}: / / \mathrm{www}$.scielo.br/scielo.php?script=sci_arttext\&pid=S141381232011000100011\&lng=en\&nrm=iso>. Acesso em: 06 Mai 2015.

ROCHET, J. A institucionalidade das ações de alimentação e nutrição nas esferas de gestão do SUS. In: Textos de opinião: temas estratégicos para a política nacional de alimentação e nutrição (PNAN) / Ação Brasileira pela Nutrição e Direitos Humanos (ABRAND H). Ministério da Saúde. - Brasília: Organização Pan Americana de Saúde (OPAS), 2011. 196 p.

SANTOS, L. M. P.; PASQUIM, E. M.; SANTOS, S. M. C. dos. Programas de transferência de renda no Brasil: um estudo multidimensional da implementação do Bolsa Escola, Bolsa Alimentação e Cartão Alimentação. Ciênc. saúde coletiva, Rio de Janeiro , v. 16, n. 3, p. 1821-1834, 2011 Disponível em:<http://www.scielo.br/scielo.php?script=sci_arttext\&pid=S141381232011000300018\&lng=en\&nrm=iso>. Acesso em: 05 Mai 2015. 


\section{CONSIDERAÇÕES FINAIS}

O estudo apresentado traz importantes contribuições sobre a utilização do recurso destinado a implementação e estruturação das ações de Alimentação e Nutrição pelas Secretarias Estaduais e Municipais de Saúde com base na PNAN, uma vez que espera-se com o conhecimento das limitações e potencialidades sejam direcionadas estratégias que favoreçam o gasto consciente do recurso e direcionando esforços para o desenvolvimento de ações mais estruturantes.

A pesquisa nacional teve sua metodologia cuidadosamente delineada adotando a abordagem multidimensional da tríade estrutura-processo-resultados e método favoreceu a análise dos dados deste estudo. Ao retomar os objetivos observou-se que:

$\mathrm{Na}$ análise das portarias, conclui que muitas diretrizes presentes na PNAN estão em parte vinculadas às finalidades do fundo e muitas ações de $A \& N$ foram executadas por meio do recurso. Outro apontamento é que a regulamentação foi se adequando às novas demandas, ações e programas do Ministério da Saúde, considerando também as mudanças do contexto epidemiológico e as novas políticas de saúde. As modificações objetivaram maior efetividade do FAN, otimização do uso do recurso e especificação no conteúdo textual, superando as constantes dúvidas e as diferentes interpretações quanto à utilização do recurso. Assim, por meio da análise do marco normativo do repasse pode-se compreender que as portarias são ferramentas indutoras de boas práticas, ao tempo em que potencializa maior espaço e diálogo das ações de A\&N com as demais de interesse para o SUS e tem o intuito de facilitar o entendimento para o uso com qualidade.

A realização dos grupos focais com gestores envolvidos na execução do FAN e os dados oriundos do questionário auto aplicado, contemplou as dimensões processo e resultado. A execução propriamente dita dos resultados, evidenciam que o FAN, mesmo não sendo implementado da melhor forma possível em alguns contextos, por limites burocráticos e ou técnicos e políticos, ainda assim faz muita diferença na conformação da identidade e na construção da autonomia da área de $\mathrm{A} \& \mathrm{~N}$ no âmbito das secretarias de saúde estaduais e municipais. Observou-se a aplicação dos recursos em ações como: incentivo a prática do aleitamento materno, promoção de práticas alimentares e estilos de vida saudáveis, promoção de mecanismos de consolidação do Sistema de Vigilância Alimentar e Nutricional (Sisvan), entre outras, as quais atendem ao desejado para a finalidade da PNAN.

Há muitas ações, que estão presentes na política, que os gestores consideram extremante relevantes a execução, no entanto não alcançaram bom desempenho em 
realização. Com isso destacaram-se algumas limitações e/ou fragilidades para a execução, como: excesso burocrático que estaria impondo paralisias à utilização do recurso repassado, a descontinuidade das ações e a interferência de interesses político-partidários.

A existência do repasse é fundamental, visto que ele favorece o desenvolvimento de ações mais próximas das necessidades locais e fortalece a área de alimentação e nutrição. Os resultados permitem avaliar positivamente as experiências locais com o recurso específico, apesar da reconhecida necessidade de melhoria dos processos burocráticos para facilitar o planejamento e a execução das ações, e que ainda há uma importante trajetória a ser empreendida para que o repasse traduza de forma plena os argumentos que justificam a sua existência.

Diante do exposto, com base nos dados encontrados, recomenda-se que:

1. Continue a transferência fundo a fundo deste recurso específico.

2. Seja empreendido maior incentivo a qualificação dos gestores que trabalham direta e indiretamente com o recurso, para entendimento pleno da regulamentação vigente.

3. Criação de mecanismos de avaliação das ações e prestação de contas. 


\section{REFERÊNCIAS BIBLIOGRÁFICAS}

BAPTISTA, T. W. F. Análise das portarias ministeriais da saúde e reflexões sobre a conduta nacional da política de saúde. Cad. Saúde Pública, v. 23 p. 615-26, 2007. Disponível em: <http://www.scielo.br/pdf/csp/v23n3/20.pdf >. Acesso em: 28 jul. 2014.

BARROS, M. S. C.; TARTAGLIA, J. C. A política de alimentação e nutrição do Brasil: breve histórico, avaliação e perspectivas. Alimentação e Nutrição. Araraquara, v. 14, n. 1, p. 109121, 2003. Disponível em: <http://servbib.fcfar.unesp.br/seer/index.php/alimentos/article/viewFile/847/726>. Acesso em: 22 jun. 2015.

BRASIL. Lei n. ${ }^{\circ}$ 8.142, de 28 de dezembro de 1990. Dispõe sobre a participação da comunidade na gestão do Sistema Único de Saúde (SUS) e sobre as transferências intergovernamentais de recursos financeiros na área da saúde e dá outras providências. Diário Oficial da União, Brasília, DF, Poder Executivo, 31 dez. 1990.

. Ministério da Saúde.Programa de Combate às Carências Nutricionais - PCCN / Ministério da Saúde, Secretaria Executiva. - Brasília : Ministério da Saúde. 2001. Disponível em: http://bvsms.saude.gov.br/bvs/publicacoes/cd10_13.pdf Acesso em: 24 jun. 2015.

Ministério da Saúde. Secretaria de Atenção à Saúde. Departamento de Atenção Básica. Coordenação de Acompanhamento e Avaliação. Avaliação na Atenção Básica em Saúde:caminhos da institucionalização. Brasília, DF: Ministério da Saúde; 2005. Disponível em: http://189.28.128.100/dab/docs/publicacoes/geral/avaliacao_ab_portugues.pdf . Acesso em: 28 jun. 2015.

Ministério da Saúde. Portaria $n^{\circ} 1.357$, de 23 de junho de 2006. Define estrutura as ações de Alimentação e Nutrição por parte das Secretarias Estaduais e Municipais de Saúde das capitais com base na Política Nacional de Alimentação e Nutrição e normatiza a utilização do saldo restante dos recursos financeiros referentes ao Incentivo de Combate a Carências Nutricionais (ICCN) nos municípios qualificados. Diário Oficial da União, Brasília, DF, Poder Executivo, 24 de junho de 2006.

. Ministério da Saúde. Portaria $n^{\circ} 3.181$, de 12 de dezembro de 2007. Define recursos financeiros do Programa Alimentação Saudável para incentivar a estruturação e a implementação das ações de Alimentação e Nutrição no âmbito das Secretarias Estaduais e Municipais de Saúde, com base na Política Nacional de Alimentação e Nutrição. Diário Oficial da União, no 239, página 86, 13 de dezembro de 2007.

Ministério da Saúde. Portarianº 2.685, de 16 de novembro de 2011. Estabelece o repasse anual fundo a fundo para a estruturação e implementação das ações de Alimentação e Nutrição no âmbito das Secretarias Estaduais e Municipais de Saúde com base na Política Nacional de Alimentação e Nutrição. Diário Oficial da União, no 220, página 85, 17 de novembro de 2011.

. Conselho Nacional de Secretários de Saúde. O Financiamento da Saúde. - Brasília : CONASS, 2011. 124 p. 
Ministério da Saúde. Secretaria de Atenção à Saúde. Departamento de Atenção Básica. Política Nacional de Atenção Básica. Brasília : Ministério da Saúde, 2012. 110 p. Disponível em: http://189.28.128.100/dab/docs/publicacoes/geral/pnab.pdf Acesso em: 22 jun. 2015.

BROWNSON,R.etal. Evidence-Based Public Health. New York: Oxford University Press; 2003. Disponível em: https://books.google.com.br/books?hl=ptBR\&lr=\&id=9fxzvhVoD2cC\&oi=fnd \&pg=PR17\&dq=evaluation+of + public + health + policies +and+programs+toronto\&ots=kPCdwAxkYo\&sig=JxIVPGQzI0aoGBCkHll2q0aL9ak\#v=one page $\& q \& \mathrm{f}=$ false. Acessoem: 26 jun. 2015.

CAMPOS, F. C. C.; FARIA, H. P.; SANTOS, M. A. Planejamento e avaliação de ações em saúde. 2. ed. Belo Horizonte: Coopmed, 2010. 114p. NESCON/UFMG - Curso de Especialização em Atenção Básica em Saúde da Família. Disponível em: https://www.nescon.medicina.ufmg.br/biblioteca/imagem/0273.pdf . Acesso em: 11 maio 2015.

CARDOZO BRUM, M. La institucionalización de una cultura de la evaluaciónen la administración pública mexicana: avances y desafíospendientes. Convergencia, Toluca , v. 16, n. 49, abr. 2009. Disponível em: <http://www.scielo.org.mx/scielo.php?script=sci_arttext\&pid=S1405$14352009000100007 \& \operatorname{lng}=e s \& n r m=i s o>$. Acesso em: 27 jun. 2015.

CARVALHO, G. O financiamento federal de ações e serviços de alimentação e nutrição em saúde. In: Textos de opinião: temas estratégicos para a política nacional de alimentação e nutrição (PNAN) / Ação Brasileira pela Nutrição e Direitos Humanos (ABRAND H). Ministério da Saude. Brasilia: Organização Pan Americana de Saude (OPAS), 2011. 196 p.

CONSELHO NACIONAL DE SECRETARIAS MUNICIPAIS DE SAÚDE (CONASEMS). Propostas de critérios de rateio. Acesso em: 15 jun. 2015.

CONSELHO NACIONAL DE SECRETÁRIOS DE SAÚDE. O financiamento da saúde. Brasília: CONASS, 2007 (Coleção Para Entender a Gestão do SUS 2007, 1).

CONTANDRIOPOULOS, A.P. et al. Avaliação na área da saúde: conceitos e métodos. In: HARTZ, Z. M. A. (Org.) Avaliação em saúde: dos modelos conceituais à prática na análise da implantação de programas. Rio de Janeiro: FIOCRUZ, 1997.

COUTINHO, J. G.; GENTIL, P. C.; BERTOLIN, M. N. T. A desnutrição e obesidade no Brasil: o enfrentamento com base na agenda única da nutrição. Cadernos de Saúde Pública, v. 24, p. 332-340, 2008. Seção Ponto de Vista. Disponível em: <http://www.scielo.br/scielo.php?script=sci_arttext\&pid=S0102> Acesso em: 01 ago. 2014.

CUSTÓDIO, M. B.; YUBA, T. Y.; Cyrillo, D. C. Política de segurança alimentar e nutricional no Brasil: uma análise da alocação de recursos. Rev. Panam.Salud Publica, 2013; v.33, n.2: p. 144-150. Disponível em: http://www.scielosp.org/pdf/rpsp/v33n2/10.pdf. Acesso em: 24 jun. 2014.

FAGUNDES, H.; MOURA, A. B. Avaliação de programas e políticas públicas. Textos \& Contextos, v. 8, n. 1, p. 89-103, 2009. Disponível em: 
<http://revistaseletronicas.pucrs.br/fass/ojs/index.php/fass/article/view/5676>. Acesso em: 01 ago. 2014.

HENRIQUE, F. C. dos S. et al. Tendência do campo de avaliação de intervenções públicas de alimentação e nutrição em programas de pós-graduação no Brasil: 1980-2004. Cad. Saúde Pública, Rio de Janeiro, v. 23, n. 12, dez. 2007. Disponível em: $<$ http://www.scielo.br/scielo.php?script=sci_arttext\&pid=S0102-

311X2007001200018\&lng=en\&nrm=iso >. Acesso em : 01 ago. 2014.

INSTITUTO BRASILEIRO DE GEOGRAFIA E ESTATÍSTICA (IBGE). Pesquisa de orçamentos familiares 2008-2009: antropometria e estado nutricional de crianças, adolescentes e adultos no Brasil. Rio de Janeiro: IBGE, 2010. Disponível em: $<$ http://www.ibge.gov.br/home/estatistica/populacao/condicaodevida/pof/2008_2009_encaa/p of_20082009_encaa.pdf >. Acesso em: 28 jul. 2014.

JAIME, P. C. et al. Ações de alimentação e nutrição na atenção básica: a experiência de organização no Governo Brasileiro. Rev. Nutr., Campinas, v. 24, n. 6, dez. 2011. Disponível em:

<http://www.scielo.br/scielo.php?script=sci_arttext\&pid=S141552732011000600002\&lng=en \&nrm=iso>. Acesso em: 24 jun. 2014.

LEVCOVITZ, E.; LIMA, L. D. de; MACHADO, C. V. Política de saúde nos anos 90: relações intergovernamentais e o papel das normas operacionais básicas. Ciênc. saúde coletiva, São Paulo, v. 6, n. 2, 2001. Disponível em: $<$ http://www.scielo.br/scielo.php?script=sci_arttext\&pid=S1413$81232001000200002 \& \operatorname{lng}=$ en\&nrm=iso>. Acesso em: 28 jul. 2014.

MARQUES, R. M.; MENDES, Á. A política de incentivos do Ministério da Saúde para a atenção básica: uma ameaça à autonomia dos gestores municipais e ao princípio da integralidade? Cad. Saúde Pública, Rio de Janeiro, v. 18, supl. Jan. 2002. Disponível em: <http://www.scielosp.org/scielo.php?script=sci_arttext\&pid=S0102311X2002000700016\&lng=en\&nrm=iso>. Acesso em: 12 Jun 2015.

MENDES, Á.; LEITE, M. G.; MARQUES, R. M. Discutindo uma metodologia para a alocação equitativa de recursos federais para o Sistema Único de Saúde. Saude soc., São Paulo, v. 20, n. 3, p. 673-690, sept. 2011. Disponível em $<\mathrm{http}: / / \mathrm{www}$. scielo.br/scielo.php?script=sci_arttext\&pid=S0104$12902011000300013 \& \operatorname{lng}=$ en\&nrm=iso>. Acesso em: 12 jun 2015.

MENDES, J. M. R.; GARCIA, M. L. T.; OLIVEIRA, E. F. dos A.; FERNANDES, R. M. C. Gestão na saúde: da reforma sanitária às ameaças de desmonte do SUS. Textos Contextos, Porto Alegre, 2011; v.10, n.2. p. 331-344.

MINAYO, M. C. de S. Avaliação por triangulação de métodos: abordagem de programas sociais. Rio de Janeiro: Fiocruz, 2010.244p.

MINAYO, M. C. de S.O desafio do conhecimento: pesquisa qualitativa em saúde. 12. ed. São Paulo: Hucitec, 2010. 407p. 
NOBREGA, C. B. C. et al. Financiamento do setor saúde: uma retrospectiva recente com uma abordagem para a odontologia. Ciênc. Saúde Coletiva, Rio de Janeiro , v. 15, supl. 1, p. 1763-1772, jun. 2010.

Disponível

em:

<http://www.scielo.br/scielo.php?script=sci_arttext\&pid=S1413-

$81232010000700088 \& \operatorname{lng}=$ en \&nrm=iso>. Acesso em: 10 jun. 2015.

Rede de Nutrição do Sistema Único de Saúde (REDENUTRI). Disponível em: file://C:/Users/Camila/Downloads/nota_didatica_financiamento\%20(1).pdf . Acesso em: 12 jun. 2015.

SANTOS, L. M. P. Obesity, poverty, and food insecurity in Brazilian males and females. Cad. Saúde Pública, Rio de Janeiro, v. 29, n. 2, feb. 2013. Disponível em: $<$ http://www.scielo.br/scielo.php?script=sci_arttext\&pid=S0102-

311X2013000200010\&lng=en\&nrm=iso>. Acesso em: 01 ago. 2014.

SANTOS, S. M. C. dos; SANTOS, L. M. P. Avaliação de políticas públicas de segurança alimentar e combate à fome no período de 1995-2002: 1 - Abordagem metodológica. Cad. Saúde Pública, Rio de Janeiro , v. 23, n. 5, p. 1029-1040, maio 2007. Disponível em;; $<$ http://www.scielo.br/scielo.php?script=sci_arttext\&pid=S0102-

311X2007000500005\&lng=en\&nrm=iso>. Acesso em: 28 jul. 2014.

SAMPAIO, L. F. R. Modelo de atenção a saúde: a alimentação e nutrição nos serviços de saúde. In: Textos de opinião: temas estratégicos para a política nacional de alimentação e nutrição (PNAN) / Ação Brasileira pela Nutrição e Direitos Humanos (ABRAND H). Ministério da Saúde. - Brasília: Organização Pan Americana de Saúde (OPAS), 2011. 196 p.

TORRES, M. Modelo de calidad de la atención médica de Avedis Donabedian. INFOcalSER: investigación en calidad del servicio, información y productividad. 29 oct. 2011. Disponível em: http://infocalser.blogspot.com.br/2011/10/modelo-de-calidad-de-la-atencion-medica.html. Acesso em: 28 jun 2015.

DONABEDIAN, A. (1966). Evaluating the quality of medical care. The Milbank Memorial Fund Quarterly, Vol. 44, N 3, part 2, pp. 166-203, publicado nuevamente enjunio 2005, Vol. 83, $\quad \mathrm{N}^{\mathrm{O}} \quad 4, \quad$ pp. 691-729. .40 Disponível http://www.ncbi.nlm.nih.gov/pmc/articles/PMC2690293/. Acesso em: 28 jun 2015

UGA, M. A. et al. Descentralização e alocação de recursos no âmbito do Sistema Único de Saúde (SUS). Ciênc. saúde coletiva, Rio de Janeiro, v. 8, n. 2, 2003. Disponível em: $<$ http://www.scielo.br/scielo.php?script=sci_arttext\&pid=S1413-

$81232003000200008 \& \operatorname{lng}=$ en\&nrm=iso>. Acesso em: 28 jul. 2014.

VASCONCELOS, F. de A. G. de; BATISTA FILHO, M. História do campo da alimentação e nutrição em saúde coletiva no Brasil. Ciênc. saúde coletiva, Rio de Janeiro, v. 16, n. 1, jan. 2011. Disponível em: <http://www.scielo.br/scielo.php?script=sci_arttext\&pid=S1413$81232011000100012 \& \operatorname{lng}=$ en $\& n r m=$ iso $>$. Acesso em: 28 jul. 2014.

VAZQUEZ, D. A. Efeitos da regulação federal sobre o financiamento da saúde.Cad. Saúde Pública, Rio de Janeiro , v. 27, n. 6, p. 1201-1212, Jun 2011. Disponível em: $<$ http://www.scielo.br/scielo.php?script=sci_arttext\&pid=S0102-

311X2011000600017\&lng=en\&nrm=iso>. Acesso em: 10 Jun 2015. 


\section{APÊNDICES}

8.1. APÊNDICE 1. MATRIZ - CATEGORIAS DE ANÁLISE PARA AS DIMENSÕES ESTRUTURA, PROCESSO E RESULTADOS - QUESTÕES ORIENTADORAS PARA A COLETA DE DADOS. PESQUISA NACIONAL DE AVALIAÇÃO DO REPASSE FUNDO A FUNDO PARA INCENTIVAR AS AÇÕES DE ALIMENTAÇÃO

E NUTRIÇÃO, BRASIL 2006 A 2011.

\begin{tabular}{lll}
\hline CATEGORIAS RSTRUTURA PROCESSO RUTADOS & RESULT
\end{tabular}

Histórico do repasse Tempo de acesso ao benefício pelo Estado: anual fundo a fundo início do repasse.

no estado

Regularidade prevista para o repasse (parcelas previstas).

Valores do repasse no período em análise.

\section{Estrutura}

normativa para

gestão do programa

Existência de uma estrutura normativa para gestão do programa:

Setor e pessoa responsável - identificação, formação, tempo no cargo.

Há Responsabilidades atribuídas? Quais? Como?

Processo decisório sobre como aplicar os recursos do FAN: está previsto quem decide? Como decide? Com que informações decide?

Força de Trabalho para gestão do programa gestão e implementação do FAN.
Número de parcelas previstas e repassadas.

Regularidade efetiva no repasse? Houve atrasos?

Valores previstos/ valores repassados: houve cumprimento do previsto?

Avaliação dos gestores sobre condições previstas para o repasse.

Avaliação dos gestores sobre condições de aplicação dos recursos transferidos especifica-mente em ações de alimentação e nutrição.

O setor/pessoa identificada tem recursos técnicos, de poder, autonomia, etc. para gerir o programa? Participa do processo decisório?

Os processos decisórios e gerenciais estão ocorrendo conforme o previsto? Em caso negativo, porque?

Onde e por quem as decisões sobre o FAN estão sendo tomadas?

Houve rotatividade de pessoal na gestão do programa desde a implantação no município? Por que?

O RT responde pelo programa no estado? Quais suas atividades efetivas?

Identificação, cargo, tempo no cargo, formação, responsabilidades decisórias e gerenciais.
Houve rotatividade do RT no estado? Porque?

Tem exercido responsabilidades gerenciais e decisórias dentro do previsto? Em caso negativo, porque?
A existência de alterações nas parcelas gerou algum resultado sobre o plano previsto para aplicação dos recursos? E sobre as ações previstas? Isto teve resultados sobre a implementação das ações da PNAN? Quais?

A existência de problemas quanto a estrutura normativa do programa gerou algum resultado sobre o plano previsto para aplicação dos recursos? E sobre as ações previstas? Isto teve resultados sobre a implementação das ações da PNAN? Quais?

A condição de formação e de trabalho do RT tem gerado algum efeito sobre a implementação das ações do FAN no estado? Em caso positivo, quais?

Porque? 
Planejamento da Em que local/ instância está prevista a elaboração e

aplicação

financeira dos

recursos do FAN aprovação do plano de aplicação?

Que critérios foram previstos para a aplicação dos recursos do FAN?

Existe algum mecanismo/sistema de acompanhamento da aplicação dos recursos? Em caso positivo, qual? Periodicidade? Quem faz? O que é acompanhado?

Existe algum mecanismo/sistema de avaliação do uso dos recursos do FAN? Em caso positivo, qual? O que é avaliado? Como? Há indicadores? Periodicidade? Quem responde pela avaliação? A quem os resultados da avaliação devem ser referenciados?

Em caso de acompanhamento e avaliação, estes resultados são divulgados? Para quem? Como? Periodicidade?

A proposta Existência de plano de ação ou programa ou projeto que estadual do FAN definas os problemas estabeleça os objetivos, metas, responsabilidades, áreas de abrangência; população alvo; diretrizes da PNAN contempladas; estratégias, periodicidade, acompanhamento e avaliação; prazo de vigência; articulação com o PES? Com resultados da Conferência estadual de saúde?

Descentralização: o plano estadual do FAN alcança municípios? Como? Quantos? Porque? Com que tipo de ações? Quais os critérios de seleção de municípios? Há acompanhamento e avaliação? Como?

Responsabilidade na elaboração: quem? Onde? De que forma? Com que critérios foi elaborado? Há uma instância de consulta/aprovação? Qual?

Responsabilidade na implementação: quem? Como?
Responsabilidade efetiva na elaboração e aprovação do plano: onde e como foi elaborado?

Quem participou do planejamento?

Os critérios previstos para aplicação do FAN foram adotados? Em caso negativo, porque? Que critérios foram adotados? Por que estes?

Os mecanismos de acompanhamento estão sendo utilizados? Em caso negativo, porque?

Em caso positivo: com que periodicidade? O que está sendo acompanhado? Quem faz?

A avaliação está sendo realizada? Em caso negativo, porque?

Em caso positivo: o que foi avaliado? Quem avaliou?

Os resultados foram divulgados? Como? Para quem?

Plano de ação é conhecido por gestores e outros atores sociais envolvidos com a implementação de ações da PNAN?

O plano vem sendo executado na forma planejada? Em caso negativo, porque?

Descentralização: os municípios previstos foram alcançados? Em caso negativo, porque?

No caso dos municípios atendidos: como foram selecionados? As ações previstas foram/estão sendo realizadas? Como a aplicação dos recursos esta sendo monitorada? E avaliada?
A forma de planejamento da aplicação do FAN teve repercussão sobre a efetiva aplicação dos recursos nas ações de A\&N? Em caso positivo, como?

A aplicação do FAN teve efeito sobre a integração com as ações dos NASF?

Em caso de monitoramento, os resultados geraram algum efeito sobre as ações do FAN? Em caso positivo, quais?

Em caso de avaliação, os resultados geraram algum efeito sobre as ações do FAN? Em caso positivo, quais?

O plano de ação com uso dos recursos do FAN tem alcançados os objetivos e metas previstos? Em caso negativo, por que? Em caso positivo, o que favorece isto?

As diretrizes da PNAN relacionadas com o plano estão sendo cumpridas? Em caso negativo, por que? Em caso positivo, o que viabiliza isto?

Descentralização: percentual de alcance dos municípios; ações da PNAN fomentadas nos municípios; população alcançada: caracterização, dimensionamento.

Fonte: Pesquisa Nacional 
8.2. APÊNDICE 2. QUESTIONÁRIOS AUTOAPLICÁVÉIS PARA RESPONSÁVEIS TÉCNICOS DE ALIMENTAÇÃO E NUTRIÇÃO - NÍVEL ESTADUAL E MUNICIPAL

NÍVEL ESTADUAL

\section{AVALIAÇÃO DO REPASSE ANUAL FUNDO A FUNDO PARA \\ ESTRUTURAÇÃO E \\ IMPLEMENTAÇÃO DAS AÇÕES DE ALIMENTAÇÃO E NUTRIÇÃO}

Unidade da Federação.

Sigla $(\ldots \ldots \ldots . . .$.

Identificação:(suas informações pessoais não serão divulgadas)

Nome completo. Instituição:

Cargo Tempo no cargo: $\operatorname{anos}() \quad \operatorname{meses}(\quad)$

E-mail

Tel ( )

Cel ( )

1. Há quanto tempo o/a Sr./Sra atua como gerente da área técnica de Alimentação e Nutrição (A\&N) no estado?

\begin{tabular}{|c|l|l|}
\hline 1 & $(\quad)$ & Menos de 6 meses \\
\hline 2 & $(\quad)$ & Entre 6-12 meses \\
\hline 3 & $(\quad)$ & Mais de 12 meses: especificar: $(\quad)$ anos \\
\hline
\end{tabular}

2. O Sr./Sra. foi formalmente indicado para ocupar este cargo? Sim ( ) Não ( )

3. Ao exercer esta função, quais são suas responsabilidades junto ao Fundo de Alimentação e Nutrição (FAN)?

\begin{tabular}{|l|l|l|l|}
\hline 1 & $(\quad)$ & Predominantemente técnicas & Especificar: \\
\hline 2 & $(\quad)$ & Predominantemente administrativas & Especificar: \\
\hline 3 & $(\quad)$ & Técnicas e administrativas & Especificar: \\
\hline 4 & $(\quad)$ & Outras & Especificar: \\
\hline
\end{tabular}

4. Qual sua opinião sobre esta modalidade de repasse para apoio às ações de alimentação e nutrição no estado?

Muito boa ( ) $\quad$ Boa ( ) $\quad$ Regular ( ) $\quad \operatorname{Rim}($ ) $\quad$ Muito ruim ( )

Porque?

5. O repasse do FAN acontece de forma regular? Sim $(\quad) \quad$ Não $(\quad$ )

6. Com que regularidade? Semestral ( ) Anual ( ) A cada 2 anos ( )

Outra.

7. Qual é o percentual (aproximado) do orçamento do FAN executado em 2012? ( ) \%

8. Como avalia esta execução?

Muito boa ( ) Boa ( ) Regular ( ) Rim ( ) Muito ruim ( )

Porque?

9. Em caso de saldo entre o recebido e o executado, o que é feito com estes recursos?

Fica em caixa e acumula para o ano seguinte ( ) É utilizado em outro tipo de ação de saúde

( )Outro destino qual?..... 
10. Em sua opinião há repercussão do repasse fundo da fundo específico para a estruturação e implementação das ações de alimentação e nutrição no estado?

( ) SIM 11.De que forma?

( ) NÃO 12.Por que?

13. O estado tem uma política/ plano/ programa/ projeto estadual de alimentação e nutrição? Sim ( ) Não ( )

14. Em caso positivo, qual o período de vigência? De ( ) até ( )

15. Como foi elaborado(a)?

16. Quem participou?

17. Em caso negativo, o componente A\&N está contemplado no Plano Estadual de Saúde? Sim ( ) Não ( )

18. Quais ações/ atividades de alimentação e nutrição foram financiadas pelo FAN no estado em 2012 ?

19. Como e por quem foram definidas as ações que seriam apoiadas pelo FAN em 2012 ?

20. Foram estabelecidas metas e indicadores para acompanhamento e avaliação da aplicação dos recursos do FAN no estado? Sim ( ) Não ( )

21. O Conselho Estadual de Saúde participou de alguma forma da implementação do FAN no estado? $\operatorname{Sim}($ ) Não ( )

22. Em caso positivo, como?

23. Foram adquiridos equipamentos como balanças, antropômetros e material de informática para a A\&N com recursos do FAN recebidos desde a primeira Portaria em 2007? Sim ( ) Não ( ) Não sabe ( )

Caso afirmativo especificar quantidade:
24. Balanças: $\mathrm{n}^{\mathrm{o}}(\quad$ )
25. Antropômetros: $\mathrm{n}^{\mathrm{o}}(\quad)$
26. Computadores: $n^{\circ}(\quad)$
27. Impressoras: $\mathrm{n}^{\mathrm{o}}(\quad)$

28. Outros equipamentos: especificar:

Não sabe informar a quantidade ( ) 
ATENÇÃO: no quadro a seguir estão listadas sentenças sobre o FAN. Por favor, leia-as com atenção.

No primeiro conjunto de colunas intitulado: "Implantação da ação/ atividade no estado considerando a aplicação de recursos do FAN", por favor responda SE VOCÊ CONCORDA QUE A AÇÃO/ ATIVIDADE DE FATO FOI REALIZADA. No segundo conjunto de colunas intitulado "Relevância da ação/atividade para a estruturação/ implantação da PNAN no estado" por favor emita sua OPINIÃO SOBRE A RELEVÂNCIA DE CADA AÇÃO/ ATIVIDADE DESCRITA na sentença.Na coluna da direita há espaço aberto para registrar suas observações.

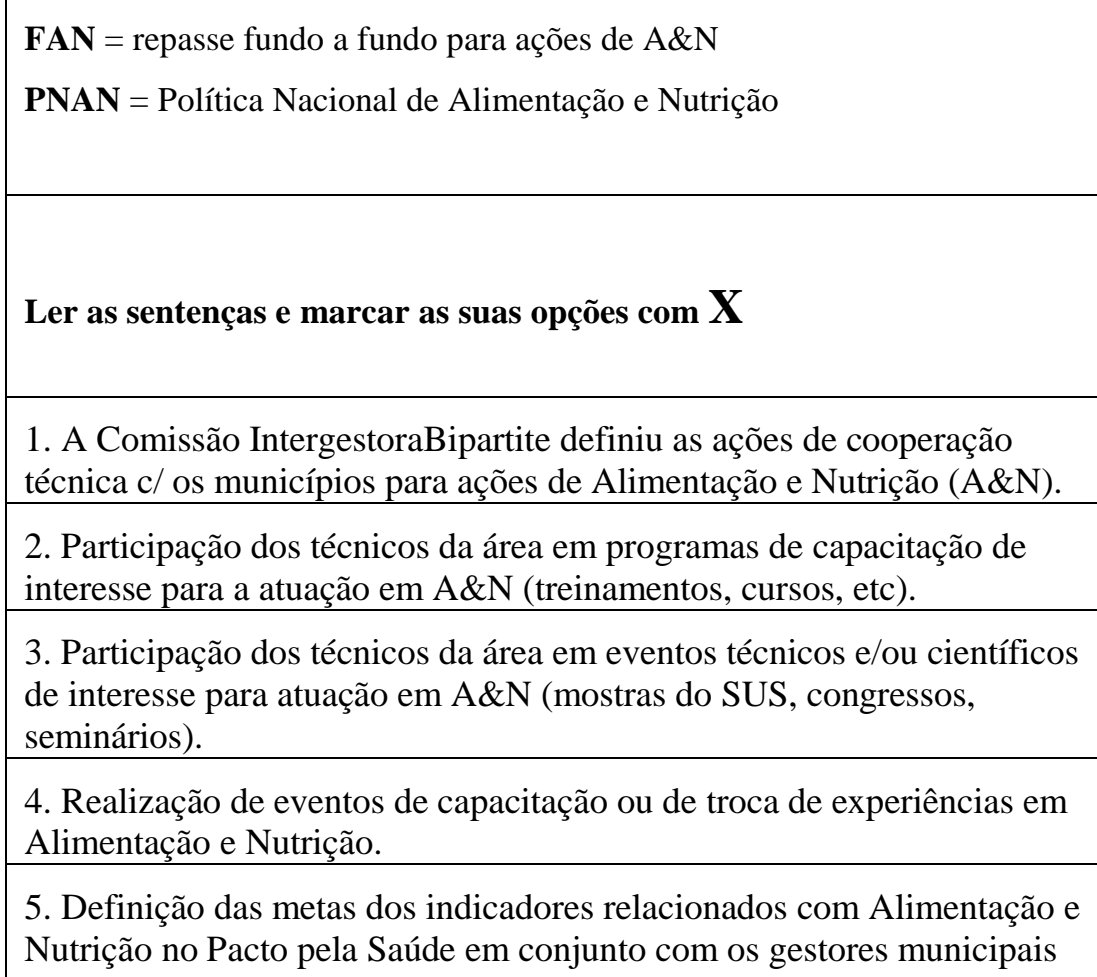

no âmbito da Comissão IntergestoresBipartite.

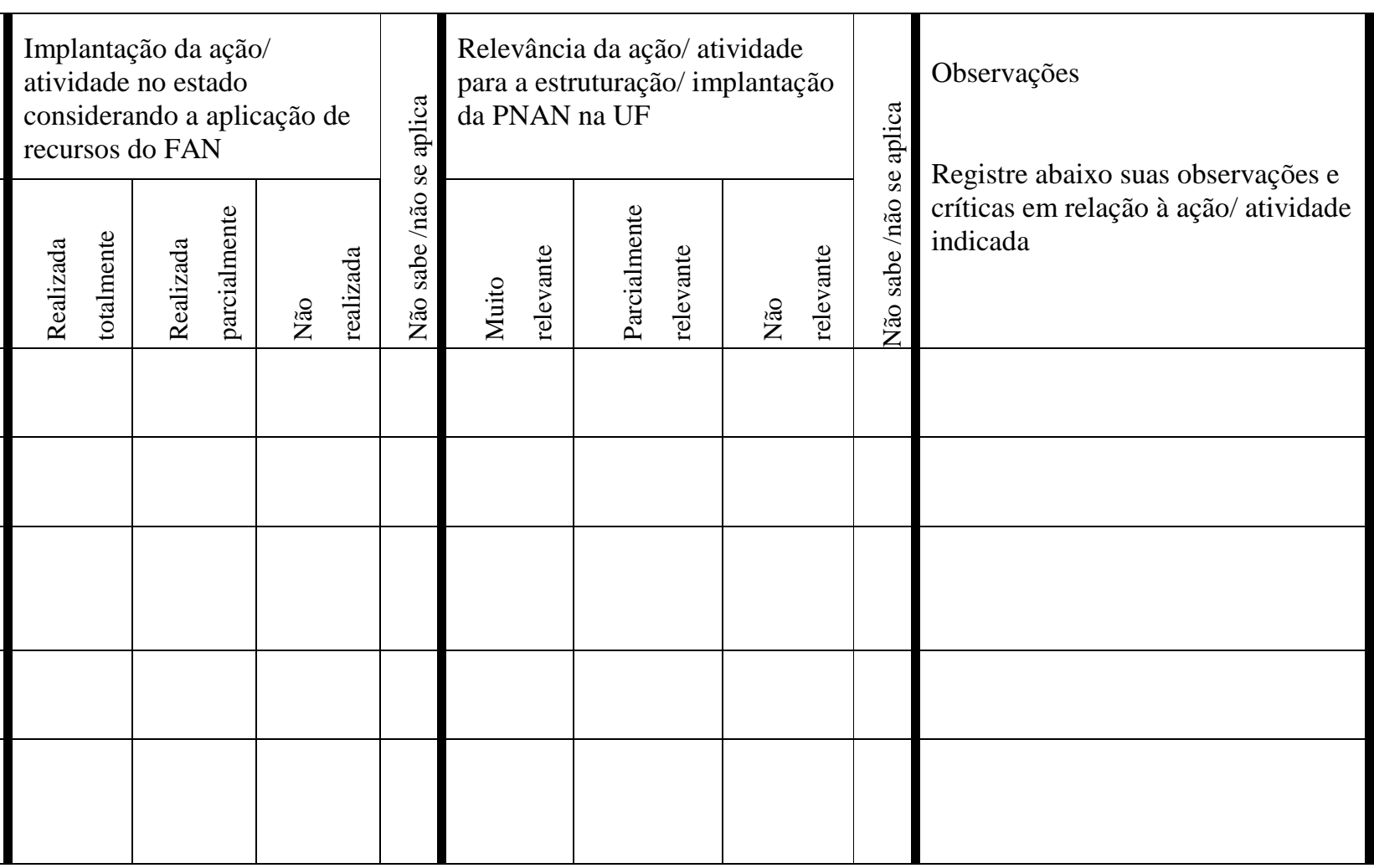


FAN = repasse fundo a fundo para ações de A\&N

PNAN = Política Nacional de Alimentação e Nutrição

Ler as sentenças e marcar as suas opções com $\mathrm{X}$

6. Apoio aos municípios para o monitoramento da sua situação quanto ao cumprimento das metas do Pacto pela Saúde relacionadas com a política nacional de A\&N.

7. Apoio aos municípios na realização de pesquisa de linha de base antes da implantação do FAN.

8. Apoio aos municípios na realização de pesquisas locais de avaliação do impacto das ações de Alimentação e Nutrição financiadas pelo FAN.

9. Capacitação de municípios para implantação e operacionalização das ações de Alimentação e Nutrição.

10. Supervisão dos municípios quanto à implantação e à operacionalização das ações de Alimentação e Nutrição.

11. Auxílio aos municípios na implementação da vigilância alimentar e nutricional.

12. Monitoramento da implementação da vigilância alimentar e nutricional nos municípios.

13. Promoção da implementação da estratégia de Promoção da

Alimentação Complementar saudável para crianças de até 2 anos de

idade.
Implantação da ação/

atividade no estado

considerando a aplicação de

recursos do FAN

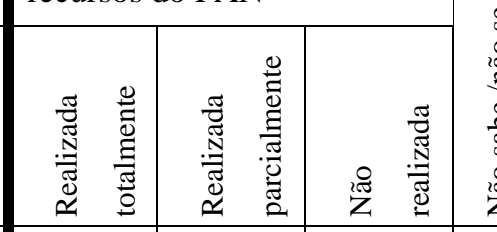

$\simeq$
Relevância da ação/ atividade para a estruturação/ implantação da PNAN na UF

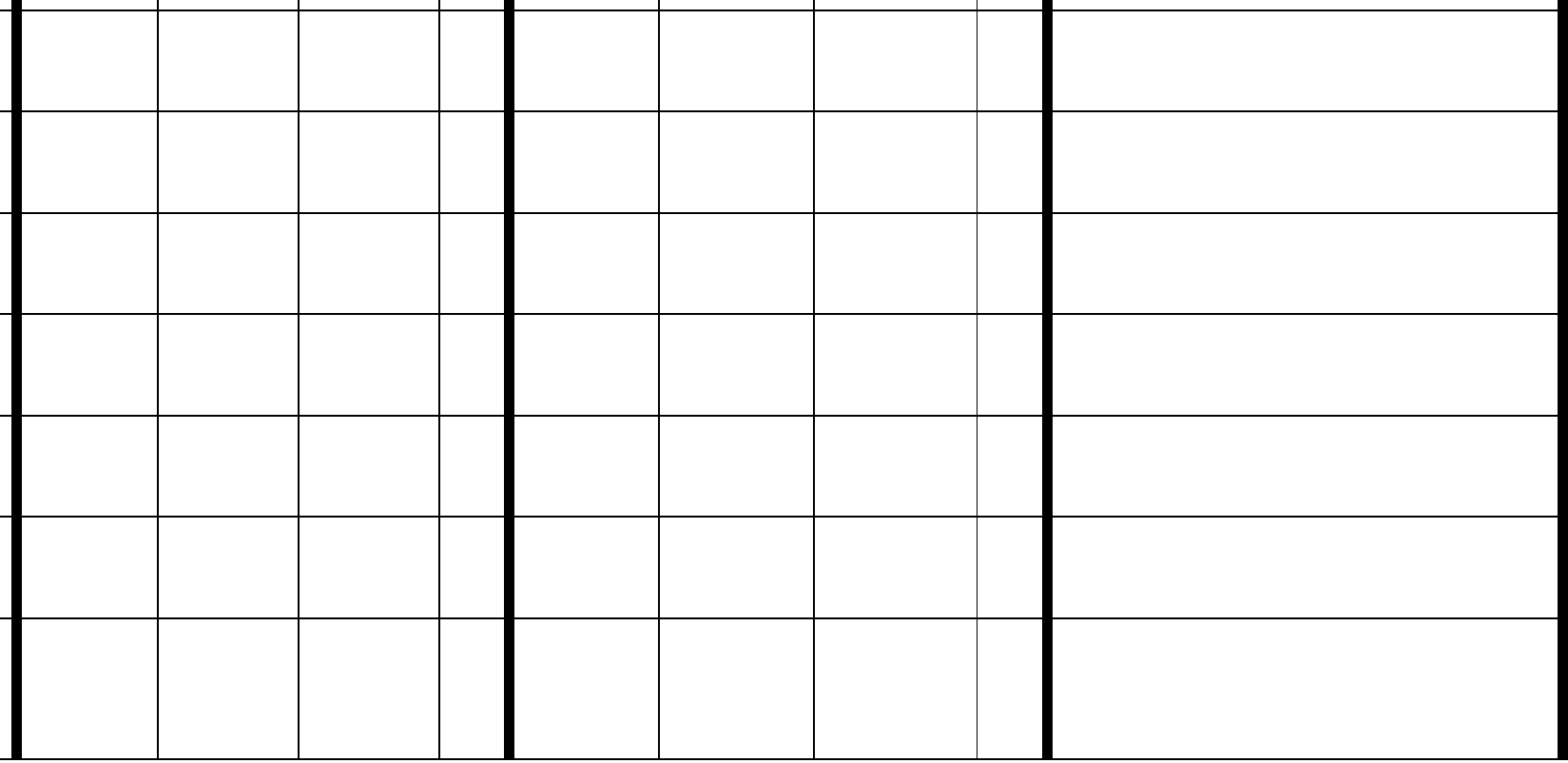


FAN = repasse fundo a fundo para ações de A\&N

PNAN = Política Nacional de Alimentação e Nutrição

Ler as sentenças e marcar as suas opções com $\mathrm{X}$

14. Desenvolvimento de ações de promoção da alimentação saudável voltadas à população, com ênfase no consumo de alimentos regionais, especialmente frutas, legumes e verduras.

15. Monitoramento das ações do programa nacional de suplementação de ferro.

16. Monitoramento das metas do programa nacional de suplementação de ferro.

17. Monitoramento das ações do programa nacional de suplementação com vitamina $\mathrm{A}$.

18. Monitoramento das metas do programa nacional de suplementação com vitamina A.

19. Elaboração e divulgação de publicações sobre a situação da alimentação e nutrição em âmbito estadual.

20. Elaboração de materiais técnicos para os profissionais de saúde e/ou para a população (manuais, vídeos, folhetos, informativos, cartazes,etc.).

21. Apoio a estudos e pesquisas e atividades de avaliação das ações de Alimentação e Nutrição.

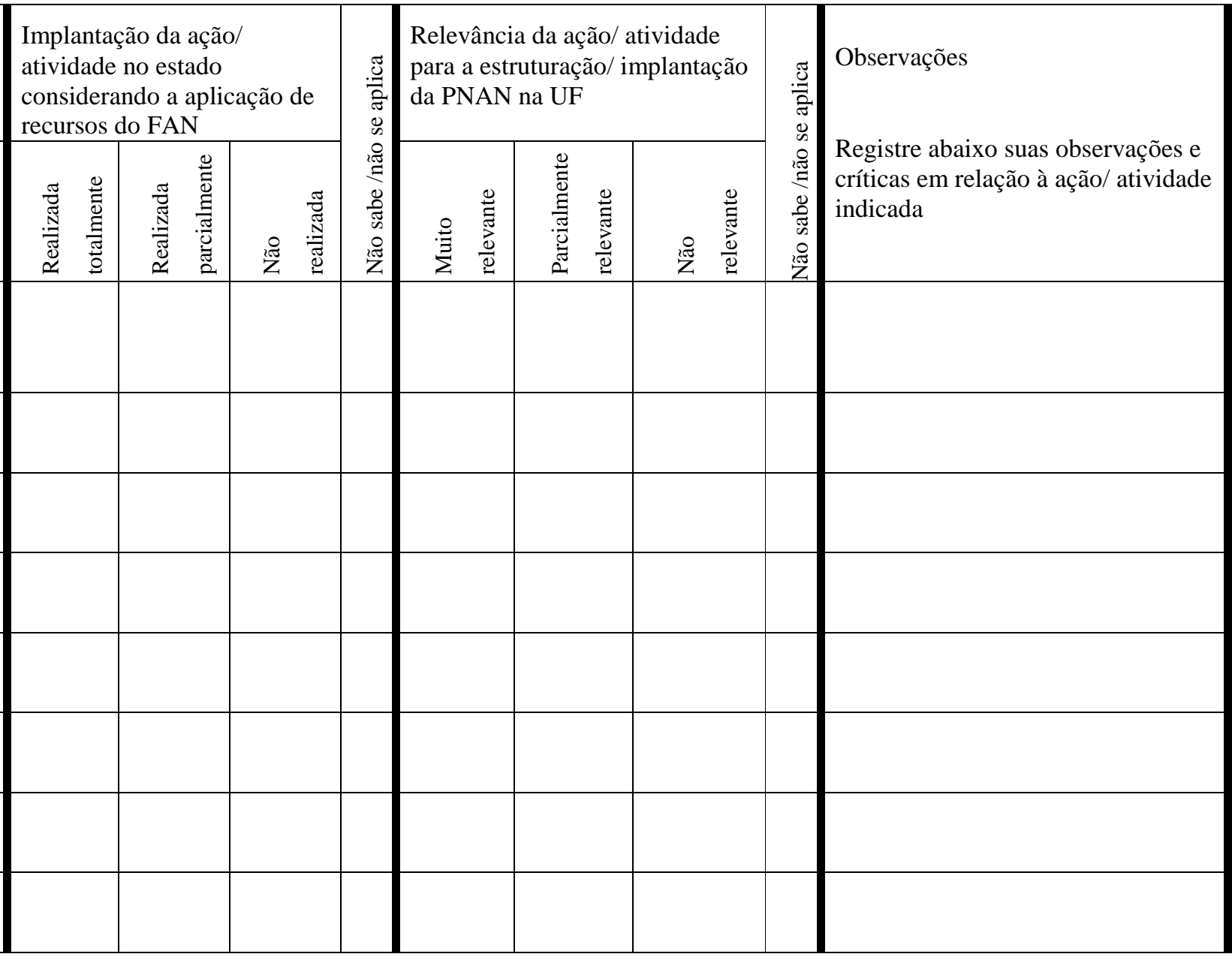




\section{AVALIAÇÃO DO REPASSE ANUAL FUNDO A FUNDO PARA ESTRUTURAÇÃO E IMPLEMENTAÇÃO DAS AÇÕES DE ALIMENTAÇÃO E NUTRIÇÃO}

Município

Sigla $(\ldots \ldots \ldots . . .$.

Identificação:(suas informações pessoais não serão divulgadas)

Nome completo.

Instituição:

Cargo. ..Tempo no cargo: anos ( ) meses( )

E-mail:

Tel ( )

..Cel ( )

1. Há quanto tempo o/a Sr./Sra atua como gerente da área técnica de Alimentação e Nutrição (A\&N) no município?

\begin{tabular}{|l|l|l|}
\hline 1 & $(\quad)$ & Menos de 6 meses \\
\hline 2 & $(\quad)$ & Entre 6-12 meses \\
\hline 3 & $(\quad)$ & Mais de 12 meses: especificar: $(\quad)$ anos \\
\hline
\end{tabular}

2. O Sr./Sra. foi formalmente indicado para ocupar este cargo? $\operatorname{Sim}(\quad) \quad$ Não $(\quad$ )

3. Ao exercer esta função, quais são suas responsabilidades junto ao Fundo de Alimentação e Nutrição (FAN)?

\begin{tabular}{|l|l|l|l|}
\hline 1 & $(\mathbf{l})$ & Predominantemente técnicas & Especificar: \\
\hline 2 & $(\quad)$ & Predominantemente administrativas & Especificar: \\
\hline 3 & $(\quad)$ & Técnicas e administrativas & Especificar: \\
\hline 4 & $(\quad)$ & Outras & Especificar: \\
\hline
\end{tabular}

4. Qual sua opinião sobre esta modalidade de repasse para apoio às ações de alimentação e nutrição no município?

Muito boa ( ) Boa ( ) Regular ( ) Rim ( ) Muito ruim ( )

Porque?

5. O repasse do FAN acontece de forma regular? Sim ( ) Não ( )

6. Com que regularidade? Semestral ( ) Anual ( ) A cada 2 anos ( )

Outra.

7. Qual é o percentual (aproximado) do orçamento do FAN executado em 2012? ( ) \%

8. Como avalia esta execução?

Muito boa ( ) Boa ( ) Regular ( ) Rim ( ) Muito ruim ( )

Porque?

9. Em caso de saldo entre o recebido e o executado, o que é feito com estes recursos?

Fica em caixa e acumula para o ano seguinte ( ) É utilizado em outro tipo de ação de saúde ( )

Outro destino - qual?.

10. Em sua opinião há repercussão do repasse fundo da fundo específico para a estruturação e implementação das ações de alimentação e nutrição no município?

( ) SIM 11.De que forma?

( ) NÃO 12.Por que?

13. O município tem uma política/ plano/ programa/ projeto municipal de alimentação e nutrição? Sim ( ) Não ( ) 
14. Em caso positivo, qual o período de vigência? De ( ) até ( ）

15. Como foi elaborado(a)?

16. Quem participou?

17. Em caso negativo, o componente A\&N está contemplado no Plano Municipal de Saúde? Sim ( ) Não ( )

18. Quais ações/ atividades de alimentação e nutrição foram financiadas pelo FAN no município em 2012 ?

19. Como e por quem foram definidas as ações que seriam apoiadas pelo FAN em 2012 ?

20. Foram estabelecidas metas e indicadores para acompanhamento e avaliação da aplicação dos recursos do FAN no estado? $\operatorname{Sim}($ ) Não ( )

21. O Conselho Municipal de Saúde participou de alguma forma da implementação do FAN no estado?

$\operatorname{Sim}($ ) Não ( )

22. Em caso positivo, como?

23. Foram adquiridos equipamentos como balanças, antropômetros e material de informática para a A\&N com recursos do FAN recebidos desde a primeira Portaria em 2007? Sim ( ) Não ( ) Não sabe ( )

Caso afirmativo especificar quantidade:
24. Balanças: $n^{\circ}(\quad)$
25. Antropômetros: $n^{\circ}(\quad)$

26. Computadores: $n^{\circ}($

27. Impressoras: $\mathrm{n}^{\mathrm{o}}(\quad)$

28. Outros equipamentos: especificar:

Não sabe informar a quantidade ( ) 
ATENÇÃO: no quadro a seguir estão listadas sentenças sobre o FAN. Por favor, leia-as com atenção.

No primeiro conjunto de colunas intitulado: "Implantação da ação/ atividade no município considerando a aplicação de recursos do FAN", por favor responda SE VOCÊ CONCORDA QUE A AÇÃO/ ATIVIDADE DE FATO FOI REALIZADA.

No segundo conjunto de colunas intitulado "Relevância da ação/atividade para a estruturação/ implantação da PNAN no município" por favor emita sua OPINIÃO SOBRE A RELEVÂNCIA DE CADA AÇÃO/ ATIVIDADE DESCRITA na sentença. Na coluna da direita há espaço aberto para registrar suas observações.

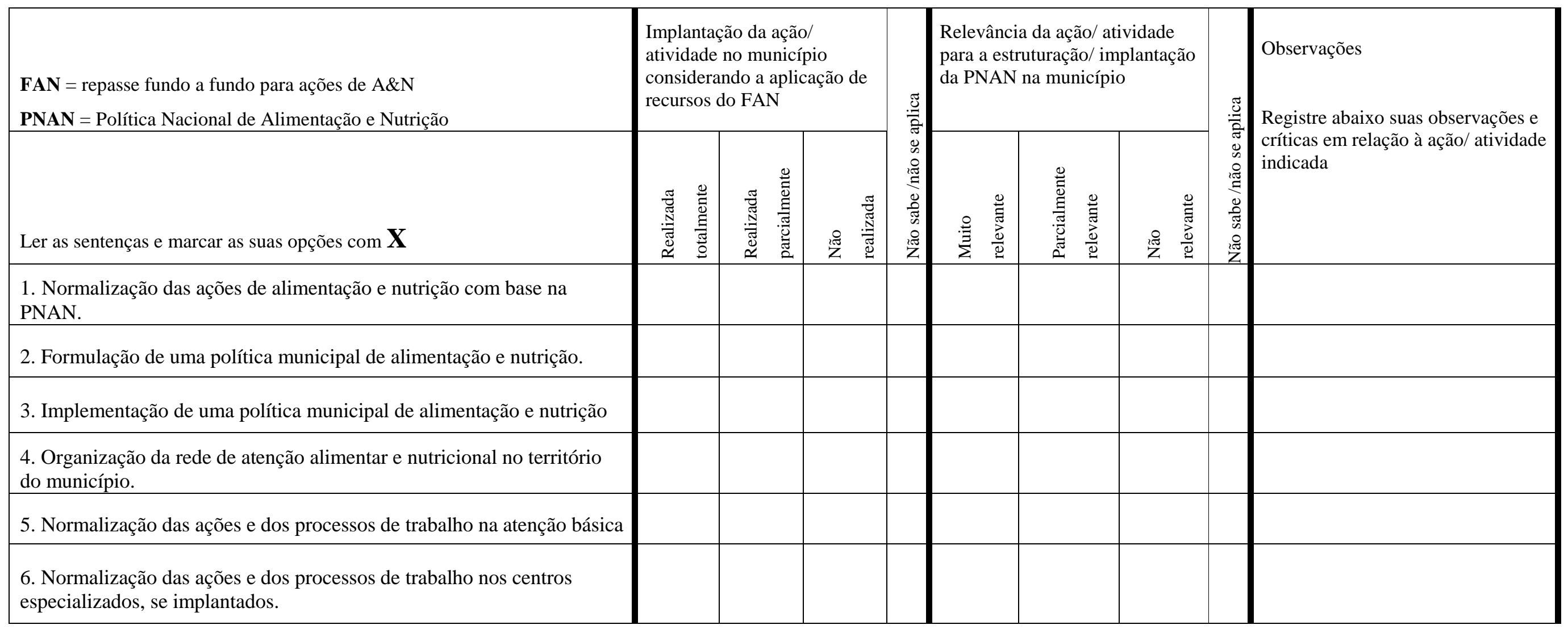




\begin{tabular}{|c|c|c|c|c|c|c|c|c|c|}
\hline \multirow{2}{*}{$\begin{array}{l}\text { FAN = repasse fundo a fundo para ações de A\&N } \\
\text { PNAN = Política Nacional de Alimentação e Nutrição } \\
\text { Ler as sentenças e marcar as suas opções com } \mathbf{X}\end{array}$} & \multicolumn{3}{|c|}{$\begin{array}{l}\text { Implantação da ação/ } \\
\text { atividade no estado } \\
\text { considerando a aplicação de } \\
\text { recursos do FAN }\end{array}$} & \multirow{2}{*}{ 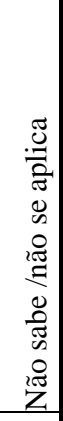 } & \multicolumn{3}{|c|}{$\begin{array}{l}\text { Relevância da ação/ atividade } \\
\text { para a estruturação/ implantação } \\
\text { da PNAN na UF }\end{array}$} & \multirow{2}{*}{ 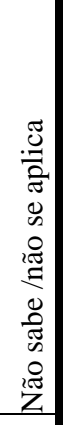 } & \multirow{2}{*}{$\begin{array}{l}\text { Observações } \\
\text { Registre abaixo suas observações e } \\
\text { críticas em relação à ação/ atividade } \\
\text { indicada }\end{array}$} \\
\hline & 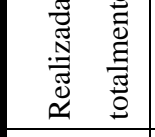 & 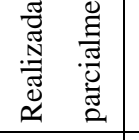 & 宽 & & 总 & 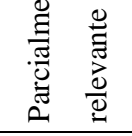 & 疍 & & \\
\hline \multicolumn{10}{|c|}{$\begin{array}{l}\text { 7Normalização das ações e dos processos de trabalho em âmbito } \\
\text { hospitalar. }\end{array}$} \\
\hline \multicolumn{10}{|c|}{$\begin{array}{l}\text { 8. Apoio técnico às equipes da atenção básica do PACS para realização } \\
\text { das acões de alimentacão e nutricão. }\end{array}$} \\
\hline \multicolumn{10}{|c|}{$\begin{array}{l}\text { 9. Apoio técnico ao núcleo de apoio à saúde da família para realização } \\
\text { das ações de alimentação e nutrição. }\end{array}$} \\
\hline \multicolumn{10}{|c|}{$\begin{array}{l}10 \text { Apoio técnico às equipes da estratégia saúde da família para } \\
\text { realização das ações de alimentação e nutrição. }\end{array}$} \\
\hline \multicolumn{10}{|c|}{$\begin{array}{l}\text { 11. .Fomento às ações de redução da desnutrição na rede de Atenção } \\
\text { Básica. }\end{array}$} \\
\hline \multicolumn{10}{|c|}{$\begin{array}{l}\text { 12.Fomento às ações de eliminação da desnutrição na rede de Atenção } \\
\text { Básica. }\end{array}$} \\
\hline \multicolumn{10}{|c|}{$\begin{array}{l}\text { 13. Fomento às ações de prevenção e controle dos distúrbios nutricionais } \\
\text { e de doenças associadas à A\&N }\end{array}$} \\
\hline \multicolumn{10}{|l|}{ 14. Controle (Promoção e Prevenção) da obesidade } \\
\hline 15Controle de transtornos alimentares. & & & & & & & & & \\
\hline
\end{tabular}


FAN = repasse fundo a fundo para ações de A\&N

PNAN = Política Nacional de Alimentação e Nutrição

Ler as sentenças e marcar as suas opções com $\mathbf{X}$

16. Implementação da estratégia de Promoção da alimentação complementar saudável para crianças de até 2 anos de idade

17. Promoção da alimentação saudável com base nas diretrizes do guia alimentar da população brasileira.

18. .Ações educativas de incentivo ao consumo de alimentos regionais brasileiros, especialmente frutas, legumes e verduras.

19. Acompanhamento da situação alimentar e nutricional da população por meio do SISVAN.

20. Acompanhamento da situação alimentar e nutricional dos titulares de direito do programa bolsa família por meio do SISVAN.

21. Registro das informações do acompanhamento do Programa de Suplementação de Ferro.

22.Registro das informações do acompanhamento do programa de suplementação de vitamina A

23.Implantação de ações do pacto pela saúde, pactuadas na CIB , e relacionadas com a PNAN

24.Cumprimento das ações do pacto pela saúde, pactuadas na CIB , e relacionadas com a PNAN.

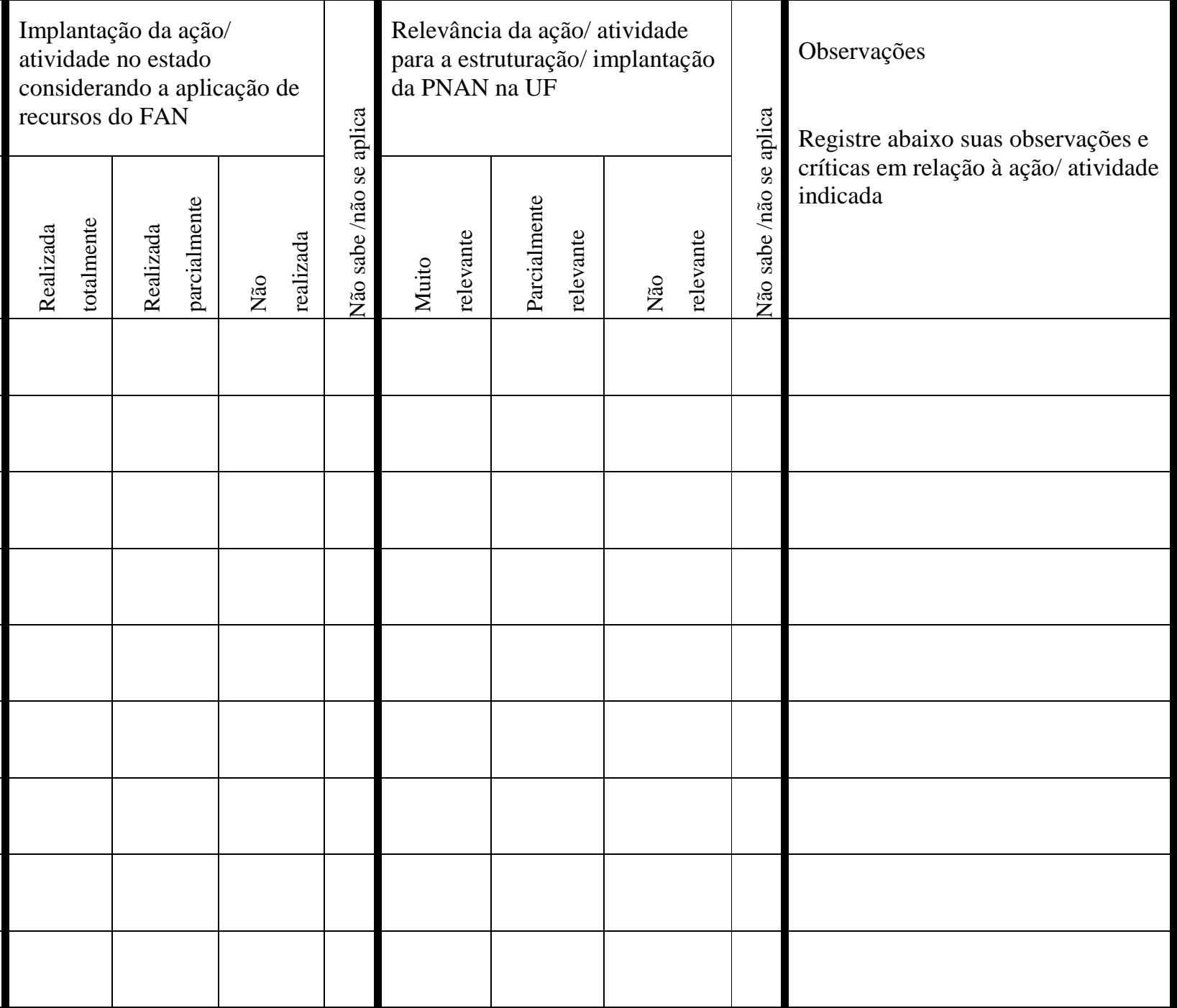


25.Apoio a estudos e pesquisas e atividades de avaliação das ações de alimentação e nutrição.

26.Elaboração de informes e relatórios sobre a situação de alimentação e nutrição do município.

27.Elaboração de materiais técnicos para os profissionais de Saúde e/ou para a população (manuais, vídeos, informativos, folhetos, cartazes, etc.).

28. Realização de eventos de capacitação ou de troca de experiências em alimentação e nutrição.

29.Participação dos técnicos da área em eventos técnicos e ou científicos de interesse para atuação em A\&N (mostras do SUS, congressos, seminários, etc.).

30.Existência de parcerias para apoio a implementação das ações de alimentação e nutrição.

\begin{tabular}{|l|l|l|l|l|l|l|l|l|}
\hline & & & & & & & & \\
\hline & & & & & & & & \\
\hline & & & & & & & & \\
\hline
\end{tabular}


8.3 APÊNDICE 3 - ROTEIROS DOS GRUPOS FOCAIS: MUNICÍPIOS DO INTERIOR, CAPITAL E ESTADO.

\section{Roteiro de Grupo Focal - Gestor do município da}

\section{Capital e/ou Distrito Federal}

1. Qual a sua experiência na gestão do FAN no município da capital (ou DF)?

2. Como você avalia os resultados da aplicação destes recursos nas ações de alimentação e nutrição no município da capital (ou DF)?

\section{Roteiro de Grupo Focal - Gestor Estadual}

1. Qual a sua experiência na gestão do FAN no seu estado?

2. Como você avalia os resultados da aplicação destes recursos nas ações de alimentação e nutrição no seu estado? 


\section{ANEXOS}

9.1 ANEXO 1. TERMO DE CONSENTIMENTO LIVRE E ESCLARECIDO - TCLE

O (a) Senhor(a) está sendo convidado(a) a participar do projeto: Avaliação do repasse anual fundo a fundo para estruturação e implementação das ações de Alimentação e Nutrição. O objetivo desta pesquisa é desenvolver metodologia e projeto piloto de avaliação do repasse anual fundo a fundo para estruturação e implementação das ações de Alimentação e Nutrição no âmbito de Unidades da Federação e nas suas capitais.

$\mathrm{O}$ (a) senhor(a) receberá todos os esclarecimentos necessários antes e no decorrer da pesquisa e lhe asseguramos que seu nome não aparecerá sendo mantido o mais rigoroso sigilo através da omissão total de quaisquer informações que permitam identificá-lo(a). A sua participação será por meio de um questionário estruturado que o(a) senhor(a) deverá responder na data combinada com um tempo estimado de 30 minutos para sua realização. Informamos que o(a) Senhor(a) pode se recusar a responder (ou participar de qualquer procedimento) qualquer questão que lhe traga constrangimento, podendo desistir de participar da pesquisa em qualquer momento sem nenhum prejuízo para o(a) senhor(a). Sua participação é voluntária, isto é, não há pagamento por sua colaboração.

Os resultados da pesquisa serão divulgados nas Instituições Universidade de Brasília, Universidade Federal da Bahia, Fundação Oswaldo Cruz (Fiocruz) e Ministério da Saúde podendo ser publicados posteriormente. Os dados e materiais utilizados na pesquisa ficarão sobre a guarda do pesquisador. Se o(a) Senhor(a) tiver qualquer dúvida em relação à pesquisa, por favor telefone para: $\operatorname{Dr}(a)$. Leonor Maria Pacheco Santos na Universidade de Brasília, telefone: (61) 3107 - 1951, no horário: 08:00h às 22:00h. Alternativamente pelo celular 9161-2440. Este projeto foi Aprovado pelo Comitê de Ética em Pesquisa da Faculdade de Ciências da Saúde da Universidade de Brasília. As dúvidas com relação à assinatura do TCLE ou os direitos do sujeito da pesquisa podem ser obtidos através do telefone: (61) 3107-1947.

Este documento foi elaborado em duas vias, uma ficará com o pesquisador responsável e a outra com o sujeito da pesquisa.

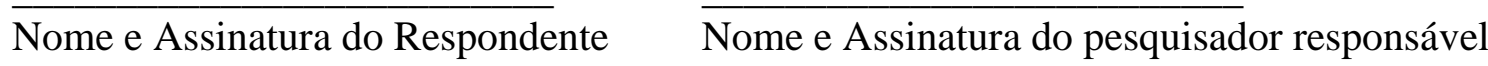
Brasília, de de 